\title{
Separating Information About Cash Flows From Information About Risk in Losses
}

\author{
by \\ Bin Li \\ Business Administration \\ Duke University
}

Date:

Approved:

Katherine Schipper, Supervisor

Qi Chen

Frank Ecker

John Graham

Mohan Venkatachalam

Dissertation submitted in partial fulfillment of the requirements for the degree of Doctor of Philosophy in Business Administration in the Graduate School of Duke University 


\title{
$\underline{\text { ABSTRACT }}$ \\ Separating Information About Cash Flows From Information About Risk in Losses
}

\author{
by \\ Bin Li \\ Business Administration \\ Duke University
}

Date:

Approved:

Katherine Schipper, Supervisor

Qi Chen

Frank Ecker

John Graham

Mohan Venkatachalam

An abstract of a dissertation submitted in partial fulfillment of the requirements for the degree of Doctor of Philosophy in Business Administration in the Graduate School of

Duke University 
Copyright by

Bin Li

2012 


\section{Abstract}

This paper reconsiders the information content of losses, specifically, the extent to which losses contain distinct and offsetting information about future cash flows and about risk. Based on theory that suggests exit value is the lower bound of firm value, I posit that shareholders who decide to abandon the firm, including a portion thereof, will receive the exit value of disposed resources, thereby resolving uncertainty about payoffs, i.e., cash flow uncertainty. Under this view, a higher likelihood of abandonment, proxied by losses, should be associated with both lower payoffs (the exit value of the disposed net assets) and lower risk (because uncertainty about the payoff is partially resolved). Using Vuolteenaho's (2002) method to decompose realized returns into expected returns, cash flow news and discount rate (risk) news, I predict and find that losses provide adverse news about cash flows (the valuation numerator) and favorable news about the discount rate (the valuation denominator). Because the effects of the two types of news are mutually offsetting, the relation between earnings and returns appears weaker for firm-year loss observations than for firm-years with positive income. These results suggest that losses are valuation relevant, in the sense of providing information that is correlated with the information in returns. 


\section{Dedication}

I dedicate this dissertation to my family, especially to my parents for instilling the importance of hard work and higher education. 


\section{Contents}

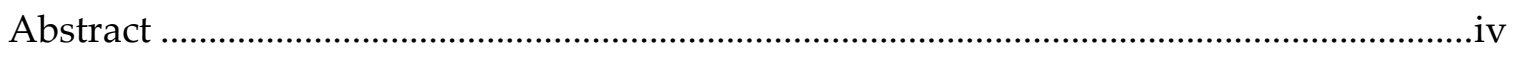

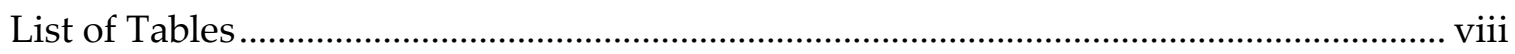

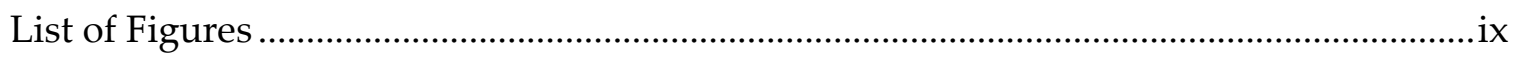

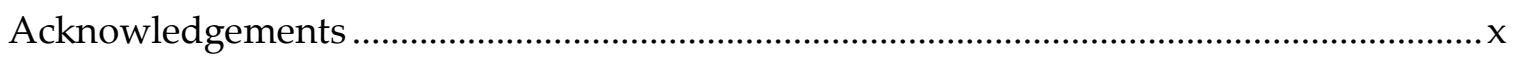

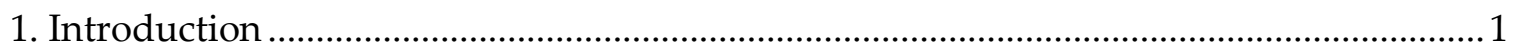

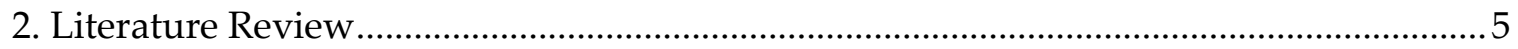

2.1 Losses and realized returns (return components) .................................................

2.2 Abandonment option, future payoffs and risk .................................................. 6

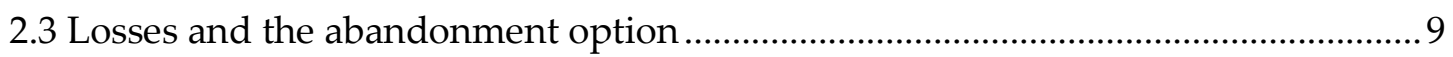

3. Valuation Framework with Losses and the Abandonment Option ..............................14

3.1 The Burgstahler and Dichev (1997) model............................................................ 15

3.2 Future payoffs and risk of the abandonment option............................................ 17

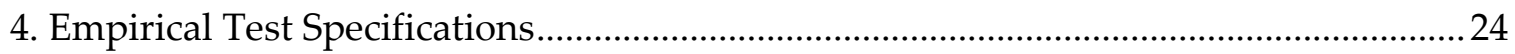

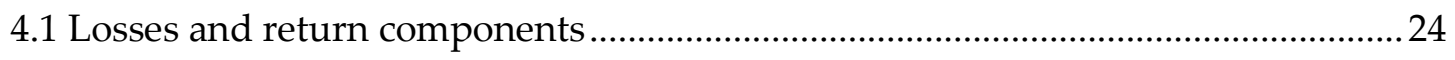

4.2 Decomposing stock returns into cash flow news and discount rate news.............28

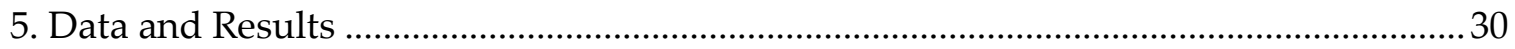

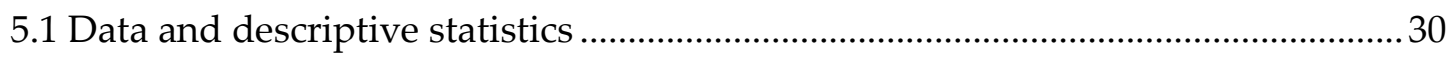

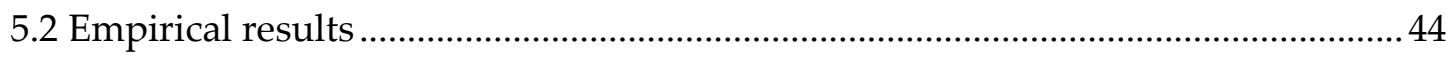

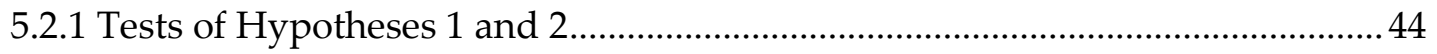

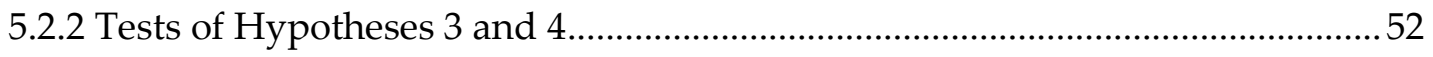




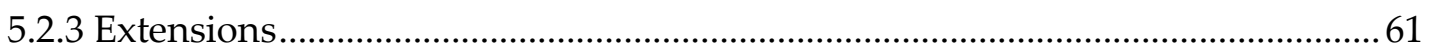

5.2.3.1 Firm risk and the return-earnings relation of losses ...................................61

5.2.3.2 Losses, asset sales, and the news components...............................................6 66

5.2.3.3 Earnings quality and the informativeness of losses................................... 72

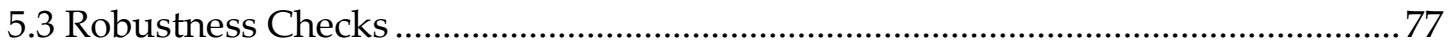

5.3.1 Alternative explanations for the muted return-earnings relation for losses.....77

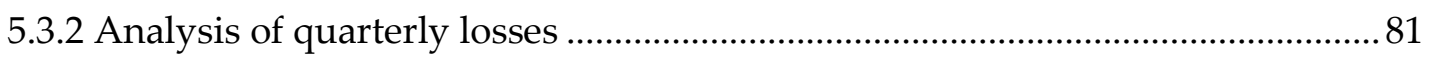

5.3.3 Alternative proxies for the news components ............................................... 82

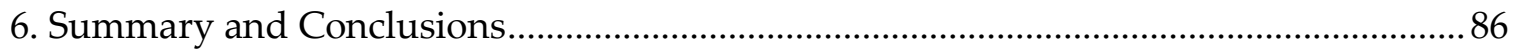

Appendix A. Proofs of the propositions in the valuation model ....................................... 88

Appendix B. Estimation of the VAR model …............................................................... 93

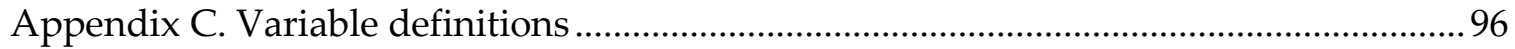

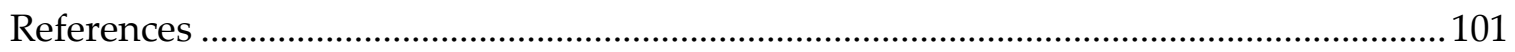

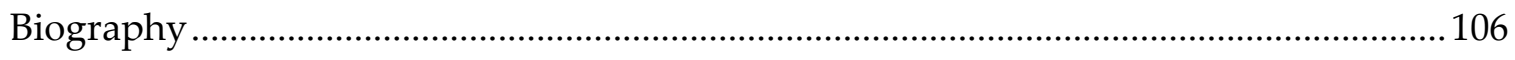




\section{List of Tables}

Table 1: Sample selection and description of loss incidence..............................................34

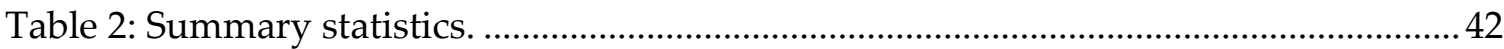

Table 3: The relations between realized returns and news components and earnings

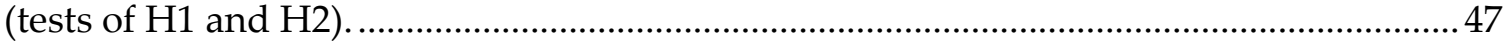

Table 4: The effects of earnings attributes and firm characteristics on the relations between the news components and earnings (tests of $\mathrm{H} 3$ and $\mathrm{H} 4$ ) ...................................59

Table 5: The effect of firm risk on the return-earnings relation of losses...........................64

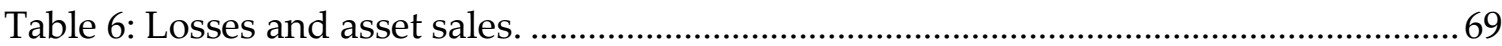

Table 7: The effects of earnings quality on the informativeness of losses..........................76

Table 8: Subsamples of loss firm-years according to the signs of the news components. 79

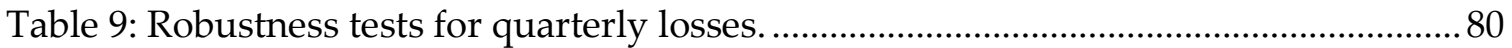

Table 10: Results using alternative proxies for the return components............................ 84 


\section{List of Figures}

Figure 1: Distribution of operating cash flows and the abandonment option. .................17

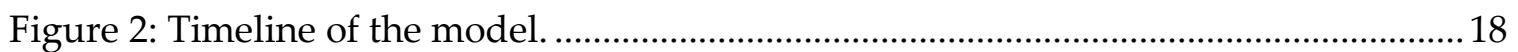

Figure 3: Distribution of earnings-to-price ratios for the period $1962-2010(n=127,656)$. 36

Figure 4: Frequency of reported losses for the period $1962-2010(n=26,885) \ldots \ldots \ldots \ldots \ldots . . . .37$ 


\section{Acknowledgements}

I am indebted to my dissertation committee, Katherine Schipper (chair), Qi Chen, Frank Ecker, John Graham, and Mohan Venkatachalam, for their continuous support and guidance. I thank the other faculty members and my fellow doctoral students at Duke University's Fuqua School of Business for their insightful comments and helpful suggestions. 


\section{Introduction}

This paper reconsiders the information content of losses, specifically, the extent to which losses contain distinct and offsetting information about cash flows and about risk (that is, expected return). Using Vuolteenaho's (2002) method to decompose realized returns into expected returns, cash flow news and discount rate news, I predict and find that both profits and losses contain information about both cash flows and risk. In the case of losses the two types of information offset each other, resulting in a weaker association between losses and stock returns than between profits and stock returns. This weaker association has been attributed by, for example, Hayn (1995) to the transitory nature of losses that in turn occurs because shareholders can abandon all or part of the firm (that is, exercise the abandonment option) instead of continuing to absorb losses.

My research extends the reasoning in Hayn (1995) and other research that links the transitory nature of losses with the abandonment option. My analysis is based on the twin ideas that shareholders always have the option to abandon (that is, dispose of) all or part of the firm they own ${ }^{1}$ and, when the abandonment option is exercised, the uncertainty about future cash flows associated with the abandoned/disposed net assets is resolved. A higher likelihood of abandonment, proxied by losses, should be associated

\footnotetext{
${ }^{1}$ The abandonment option does not require the liquidation of the firm since management can opt to dispose of unprofitable investments within the firm and retain operations that are profitable (e.g., Berger, Ofek, and Swary, 1996; Watts, 2003). Following Berger et al. (1996), I use "abandonment" to refer to the disposal of either a material part of a firm or the entire firm.
} 
with both lower future payoffs (the value of the abandoned net assets) and lower risk (because uncertainty about the payoffs is resolved). Losses provide adverse information about cash flows, the numerator of the valuation expression, and favorable (risk reducing) information about expected return, the denominator of the valuation expression. The adverse numerator information about cash flows is offset by the favorable denominator information about expected return, resulting in a muted valuation response to losses, compared to profits. This prediction is supported by both prior literature and the valuation model in my paper.

Using a broad sample of 127,656 firm-year observations over 1962 to 2010, I find that losses are common (21\% of firm-years in my sample are losses) and the association between stock returns and earnings for the loss sample (firm-years with negative earnings) is weaker than that for the profit sample (firm-years with positive earnings). Using Vuolteenaho's (2002) method to decompose realized stock returns into expected returns, cash flow news and discount rate (risk) news, I find that, for the loss sample, the correlations between the two news components and earnings both exceed .39 in magnitude, but are of opposite sign; for the profit sample, correlations between the news components and earnings are .26 and .06 for cash flow news and discount rate news, respectively. These results indicate that, for the loss sample, the cash flow news in stock returns is positively related to earnings (i.e., cash flow news is value-decreasing, because earnings are negative for the loss sample) and the discount rate news is negatively related to earnings (i.e., the discount rate news is value-increasing); for the profit 
sample, both the cash flow news and the discount rate news in stock returns are positively related to earnings. The results of conventional valuation regressions of stock returns or the news components (cash flow news and discount rate news) on earnings support the inference drawn from correlation analyses.

Prior research documents that the likelihood of exercising the abandonment option is affected by both earnings attributes, including reported losses, and firm characteristics (e.g., Berger et al., 1996; Joos and Plesko, 2005; Darrough and Ye, 2007), so the informativeness of losses should vary across firms through variation in earnings attributes and firm characteristics. In particular, I find that losses convey less adverse cash flow news and less favorable discount rate news for firms with more transitory losses, more nonrecurring charges, larger R\&D expenditures, larger cash holdings, more external financing, more specialized assets, fewer industry competitors, and better earnings quality. Furthermore, I show that the muted return-earnings relation for losses is attributable to both the favorable discount rate news and the high risk (expected returns) of loss firms. ${ }^{2}$ Finally, I provide support for the "abandonment option" assumption in prior literature by showing that loss firms are more likely to sell their operating assets than profit firms.

Taken together, the results suggest that losses are valuation relevant, in the sense of providing information that is correlated with the information in returns. However,

\footnotetext{
${ }^{2}$ I use "loss firms" and "profit firms" to refer to firm-year observations with negative earnings and positive earnings, respectively.
} 
the information provided by losses about cash flows is, in effect, of the opposite sign compared to the information provided by losses about risk (discount rates). Separately analyzing the valuation relevance of the two types of earnings information provides evidence that losses contain decision-useful information despite the weak overall association between losses and realized returns.

The rest of this paper describes how the valuation effects of the abandonment option, combined with losses, yield hypotheses about the relation between losses and both cash flow news and discount rate news. Sections 2 and 3 present the literature review and a valuation model that links losses with the abandonment option. Section 4 formulates empirical predictions. Section 5 describes the data and empirical results; section 6 concludes. 


\section{Literature Review}

\subsection{Losses and realized returns (return components)}

Prior research has documented that earnings appear to explain a small fraction of the total variation in stock returns (for a summary of this evidence see Lev, 1989) and that this phenomenon is at least partially attributable to the weak association between losses and realized returns (e.g., Hayn, 1995). In particular, Hayn (1995) finds that, compared to profits, losses are associated with smaller earnings response coefficients (hereafter ERC) and lower explanatory power for stock returns $\left(\mathrm{R}^{2}\right)$. Assuming that shareholders always have an abandonment option, Hayn concludes that losses are not expected to perpetuate (they are not persistent because they will not be sustained indefinitely) and thus they are less informative than profits. This view is also supported by Subramanyam and Wild (1996).

Prior research shows that realized returns can be decomposed into three components: expected returns, cash flow news, and discount rate news (e.g., Campbell, 1991; Vuolteenaho, 2002). The correlation between earnings and realized returns may therefore arise from the association of earnings with expected returns, with cash flow news, with discount rate news, or with all three. Hecht and Vuolteenaho (2006) use Campbell's (1991) return decomposition framework to investigate the relative importance of these three components in regressions of return components on cash flow proxies, including earnings. In particular, Hecht and Vuolteenaho (2006) observe that earnings are positively associated with cash flow news and negatively associated with 
discount rate news for all firms in the cross-section, dampening the correlation between earnings and realized returns. ${ }^{1}$ Therefore, the ERC and $\mathrm{R}^{2}$ from a regression of returns on earnings may understate the information content of earnings, in the sense of providing information to equity investors.

\subsection{Abandonment option, future payoffs and risk}

Real option valuation models assume that investors are active, i.e., they can modify a firm in the sense of making, abandoning, expanding, or contracting investments. Viewing firm risk as an increasing function of the risk embedded in the firm's investments, investors could manage risk through adjusting investments, for example, exercising the abandonment option. ${ }^{2}$

In the context of real option valuation, previous research analyzes how the existence of an abandonment option affects firm values (or project values), including future payoffs and risk (e.g., Robichek and Van Horne, 1967; Galai and Masulis, 1976; Cheung, 1990). Under the view that investors have an option to abandon a firm (or a project) at its exit value, the market value of equity (the project value) is jointly determined by the present value of operating cash flows (operation value) and exit value (e.g., Berger, Ofek, and Swary, 1996; Burgstahler and Dichev, 1997; Barth, Beaver, and

\footnotetext{
${ }^{1}$ Hecht and Vuolteenaho (2006) study the correlations between return components and earnings for all firms in the cross-section. They do not separate reported losses from reported profits, and they do not offer explanations for the correlations they report. This paper provides an explanation for their findings.

2 By contrast, discounted cash flow (DCF) or net present value (NPV) models the most likely or representative outcomes, and the flexibility available to investors is ignored.
} 
Landsman, 1998). ${ }^{3}$ Robichek and Van Horne (1967) include the abandonment option as a contingency in the forecast of future cash flows for estimating the value and risk of an investment project, and argue that it is optimal for investors to abandon the project if current exit value exceeds operation value. Cheung (1990) and Burgstahler and Dichev (1997) find that a firm (an asset) can be valued as its exit value plus a call option on the operating cash flows. When operation value is low relative to exit value, investors will opt out of the operation value in favor of the exit value (e.g., Hite, Owers, and Rogers, 1987; Berger, Ofek, and Swary, 1996). Thus, for a firm, the exit value from exercising the abandonment option is the lower bound of firm value.

The abandonment option also affects firm risk, which is the value-weighted sum of the risks of a firm's individual investments (e.g., Ball, Kothari, and Watts, 1993; Riedl and Serafeim, 2011). Firm risk varies with the firm's investment or divestment decisions. The decision to dispose of operating assets reduces firm risk, because the proceeds from asset disposal have a shorter time horizon and lower uncertainty than the cash flow from operations. As a firm becomes more likely to dispose of its operating assets, "the [abandonment] option moves farther into the money" (Berger et al., 1996, page 261). Lang, Poulsen, and Stulz (1995) find that firms with poor profitability tend to sell their

\footnotetext{
${ }^{3}$ Similar to Burgstahler and Dichev (1997), I define operation value as capitalized future operating cash flows when the firm recursively applies its current business technology to its resources, and exit value as the fair value of the firm's assets to be disposed of or the value from exercising the abandonment option.
} 
operating assets and pay out the proceeds to shareholders. ${ }^{4}$ That is, compared with profit firms, loss firms are more likely to exercise the abandonment option and distribute the proceeds from asset disposal to shareholders. When this happens, the uncertainty about future payoffs is partially resolved (that is, risk decreases). Furthermore, firms can manage risk through the exercise of real options, including the abandonment option, embedded in their production and investment decisions. For example, firms can use proceeds from exercising the abandonment option to diversify investments and reduce the risk of their undiversifiable human capital (e.g., Amihud and Lev, 1981), or to increase debt capacity and reduce default risk (e.g., MacKay, 2003). Finally, Kim and Schatzberg (1987) show that the announcement of asset dispositions reduces systematic risk (market beta). They attribute this phenomenon to two reasons: (i) Where formerly the firms sold the output of their production, they now are selling the means of production; (ii) Once the proceeds of abandonment (exit value) are known, general market movements will have little effect on the abandoning firms' stock prices. ${ }^{5}$ In sum, previous research suggests that the existence of the abandonment option limits both the

\footnotetext{
${ }^{4}$ Managers have choices about what to do with the proceeds of asset disposal, including distributing the proceeds to investors and reinvesting the proceeds. The focus in my paper is the analysis of losses, so I do not document the frequencies of these two uses of proceeds from asset disposal.

${ }^{5}$ Compared with the cash flows from selling the output of production (operation value), the cash flows from selling the means of production (exit value) have a short time horizon and lower uncertainty. Using measures of operation value and exit value following Berger et al. (1996), I document that the standard deviation of exit value is about $1 / 10$ of the standard deviation of operation value for the entire sample, and the change in exit value associated with reporting a loss is about 1/15 of the change in operation value (untabulated results). These findings provide evidence for the argument in Kim and Schatzberg (1987).
} 
downside firm value and risk, so the likelihood of abandonment is inversely related to both shareholders' future payoffs and risk.

\subsection{Losses and the abandonment option}

The likelihood of abandonment is higher for loss firms (that is, for firm-years in which earnings are negative) than for profitable firms (e.g., Hayn, 1995; Collins, Pincus, and Xie, 1999), so the valuation effects of the abandonment option are more pertinent for loss firms (Plummer and Tse, 1999). ${ }^{6}$ Losses are linked to the likelihood of exercising the abandonment option because profitability is a key determinant of shareholders' abandonment decisions (e.g., Jain, 1985; Schary, 1991). As an indication of managerial and/or organizational inefficiency, poor financial performance acts as a heuristic trigger for shareholders to abandon or contract investments (e.g., Ghosh, Owers, and Rogers, 1991; Lang et al., 1995; Pinnuck and Lillis, 2007). ${ }^{7}$ When shareholders conclude that the value from continuing operations (operation value) is low relative to the value from abandoning operations (exit value) after observing losses, they will become more likely to abandon some or all operations and receive the exit value. As the firm's likelihood of

\footnotetext{
${ }^{6}$ The abandonment option is not the only real option available to investors of loss firms. More broadly, investors could restructure a firm by changing its control, operations, and financial policies. John, Lang, and Netter (1992) show that most firms choose to sell assets or divest after reporting losses, suggesting that the abandonment option is often exercised by loss firms.

${ }^{7}$ I assume no agency problem between investors and managers. My paper focuses on the analysis of losses, not how firms deal with the proceeds from asset disposal. In the absence of agency problem, investors are indifferent about the uses of the proceeds from abandoning assets. Even if investors form expectations about the uses of the proceeds of asset disposals, the expected value of reinvestment would still be lower than the operation value as long as managers act in investors' interests; otherwise, the firm would have already switched to the alternative investment. In addition, managers will act in investors' interests in deciding whether and when to exercise the abandonment option.
} 
abandonment increases, shareholders place more (valuation) weight on the exit value and less (valuation) weight on the operation value (Barth et al., 1998).

Shareholders lower their estimates of both future payoffs and risk after observing losses, because loss firms have higher likelihood of abandonment, and abandonment is inversely related to both future payoffs and risk. That is, firms that report losses experience simultaneous downward revisions to cash flow expectations (adverse/negative cash flow news) and to discount rates (positive discount rate news, or a negative-that is, risk reducing-discount rate shock). This reasoning supports my first hypothesis (H1) that loss firms will have downward revisions to both expected cash flows and discount rate; the former reduces share price and the latter increases share price.

Because losses imply downward revisions to both the valuation numerator and the valuation denominator, these two revisions (partially) offset each other, dampening the relation between earnings and returns for loss firms. In other words, the information provided by losses about future cash flows is, in effect, of the opposite sign compared to the information provided by losses about risk (discount rate), so these two types of information provided by losses offset each other in realized returns as a summary outcome measure. This reasoning supports my second hypothesis $(\mathrm{H} 2)$ that losses induce downward revisions to both the numerator and the denominator in a valuation 
expression, thereby weakening the return-earnings relation for loss firms relative to the valuation expression for profit firms. ${ }^{8}$

The extent to which a reported loss revises investors' estimates of the valuation numerator and denominator depends on both earnings attributes and firm characteristics. The persistence of losses is the most important earnings attribute that investors assess when confronted with losses (Joos and Plesko, 2005), because the abandonment option assumption suggests that investors of loss firms will dispose of operating assets if they expect the losses to continue (Hayn, 1995; Berger et al., 1996). Joos and Plesko (2005) show that whether a loss firm returns to profit (loss reversal) is determined by the financial profile, the incidence and frequency of past losses, and the dividend policy. In particular, they find that losses exhibit higher probability of reversal if they are reported by firms with higher previous profitability, a shorter loss sequence, larger size, and higher likelihood of dividend payment. Joos and Plesko (2005) develop a loss-reversal model and use the predicted probability of loss reversal as their (inverse) proxy for the likelihood of exercising the abandonment option.

Nonrecurring charges, such as asset write-offs and write-downs, are another earnings attribute associated with the frequency and magnitude of reported losses (e.g., Givoly and Hayn, 2000; Klein and Marquardt, 2006). Some nonrecurring charges are

\footnotetext{
${ }^{8}$ This reasoning is similar to the argument in Patatoukas and Yan (2010). They argue that market-wide aggregate earnings induce a positive cash flow effect and a negative discount rate effect. At the market level, the discount rate effect offsets the stock price reaction to cash flow news in aggregate earnings and so the aggregate earnings-return relation is weak or even negative.
} 
completely transitory, while others are expected to reverse in the future and induce a negative autocorrelation in earnings. Nonrecurring charges such as asset write-offs, inventory write-downs, and restructuring charges can increase future earnings by reducing future expenses (Darrough and Ye, 2007). Therefore, losses that are more transitory or that contain more nonrecurring charges would increase the likelihood of abandonment less than other losses. This reasoning supports my third hypothesis $(\mathrm{H} 3)$ that loss firms with more transitory losses or more nonrecurring charges experience smaller downward revisions to both the valuation numerator and denominator than other loss firms.

Firm characteristics, such as business model, financial sustainability, asset specialization, and industry membership, also affect the informativeness of losses by influencing the extent to which reported losses affect the likelihood of abandonment. Darrough and Ye (2007) document that loss firms with larger R\&D expenditures, larger cash holdings, and more external financing are more sustainable and further away from exercising the abandonment option. ${ }^{9}$ Berger et al. (1996) show that the likelihood of exercising the abandonment option varies with the asset structure, i.e., more specialized assets are more difficult to dispose of, and thus, firms with specialized assets have lower likelihood of abandonment. In addition, investors' decision to exercise the abandonment option is influenced by the loss firm's industry characteristics, especially the number of

\footnotetext{
${ }^{9}$ I do not consider sales growth, because the results in Darrough and Ye (2007, p. 85) do not support their "Sales Growth Hypothesis".
} 
firms in the industry. Industries with more firms are more likely to have a competitive used-asset market where firms can dispose of their operating assets. In addition, firms in such industries may face more intense competition and therefore have to react to losses quickly. This reasoning supports my fourth hypothesis (H4) that loss firms with larger R\&D expenditures, larger cash holdings, more external financing, more specialized assets, and fewer industry competitors have smaller downward revisions to both the valuation numerator and denominator. 


\section{Valuation Framework with Losses and the Abandonment Option}

Burgstahler and Dichev's (1997) model of firm value expresses the market value of equity as a function of the operation value (capitalized future payoffs from recursively applying the firm's current business technology to existing resources) and the exit value (the value from exercising the abandonment option or fair value of the operating assets to be disposed of). The relative weights on the two components of value reflect the probability that shareholders will exercise the abandonment option, i.e., the likelihood of abandonment (Burgstahler and Dichev, 1997; Barth et al., 1998). Specifically, shareholders will opt out of operation value in favor of exit value when the exit value exceeds the operation value.

In this section, I show how the framework proposed by Burgstahler and Dichev (1997) can be used to support the predictions that losses provide adverse news about future cash flows (the valuation numerator) and favorable news about risk (the valuation denominator). The main intuition is that earnings, as a measure of how the firm's resources are currently used, is an indicator of future cash flows (operation value), so negative earnings (losses) imply both a reduction in the operation value and an increase in the likelihood of abandonment. As the likelihood of abandonment is inversely related to both future payoffs and risk, loss firms will experience simultaneous downward revisions to both future cash flows (reflecting payoffs) and discount rate 
(reflecting risk). These two revisions offset each other, dampening the relation between earnings and stock returns (i.e., change in market value of equity) for loss firms.

\subsection{The Burgstahler and Dichev (1997) model}

Burgstahler and Dichev (1997) develop a one-period model in which investors are assumed to be risk-neutral. Under this assumption, investors consider the expected payoffs, but not the riskiness of the payoffs (i.e., the discount rate is not considered). Key variables in their model are defined as follows:

$$
P_{1}=\text { market value of equity at date } 1 \text {, }
$$

$\tilde{\theta}=$ investors' beliefs about future operating cash flows that will occur from using the firm's current business technology at date 1 ( $\tilde{\theta}$ is a random variable, and $\tilde{\theta} \sim N\left(\bar{\theta}, 1 / h_{\theta}\right)$, where $N(\cdot)$ denotes the normal distribution with mean $\bar{\theta}$ and precision $\left.h_{\theta}\right)$,

$c=$ multiplier for cash flows $(c>0)$ at date $1(c \tilde{\theta}$ represents investors' updated beliefs about the firm's operation value at date 1$)^{1}$,

$a=$ the firm's exit value at date 1 ( $a$ is a constant, and $a \geq 0$ ).

At date 1 , the market value of equity $\left(P_{1}\right)$ reflects the option to choose either the operation value $(c \tilde{\theta})$ or the exit value $(a)$, whichever is larger, at some point in the future. In expression (1), $E(\cdot)$ denotes shareholders' expectation.

\footnotetext{
${ }^{1}$ The multiplier $(c)$ can be interpreted as a capitalization factor that discounts all future cash flows to date 1.
} 


$$
P_{1}=E[\max (c \theta, a)]=\iint_{\theta, a} \max (c \theta, a) f(\theta, a) d \theta d a
$$

I assume that exit value $(a)$ is constant to capture the idea that the exit value has lower uncertainty than operation value. ${ }^{2}$ Because investors have to forecast a longer series of operating cash flows to estimate operation value than to estimate exit value (Bonini, 1977), their uncertainty about operation value is higher than that about exit value. As operation value decreases, investors become more likely to exercise the abandonment option and receive the constant exit value, and thus their uncertainty about future payoffs is partially resolved.

Expanding equation (1) for a fixed exit value, the market value of equity at date 1 is given by equation $(2)(f(\cdot)$ denotes the probability density function of $\tilde{\theta})$ :

$$
P_{1}=\int_{-\infty}^{a / c} a f(\theta) d \theta+\int_{a / c}^{\infty} c \theta f(\theta) d \theta
$$

As noted by Burgstahler and Dichev (1997), the exercise point of abandonment option is in the future, so both the expected operation value and exit value should be discounted to the present. Burgstahler and Dichev (1997) omit the discount factor to simplify the expression.

\footnotetext{
${ }^{2}$ Burgstahler and Dichev (1997) consider two cases: (1) exit value is a constant and operation value is a random variable, (2) exit value is a random value and operation value is a constant. I only consider the first case in this paper, because my (untabulated) results show that, using the measures of operation value and exit value in Berger et al. (1996), (i) the standard deviation of exit value is about 1/10 of the standard deviation of operation value, (ii) the change in exit value is about $1 / 15$ of that in operation value when firms report losses.
} 
Figure 1 shows that investors decide whether to abandon the firm based on the distribution of the operating cash flows and the exit value. The threshold of integration $(a / c)$ is the point of investor indifference, where the operation value (capitalized future cash flows) equals the exit value. For $\theta>a / c$, investors choose to continue operating the firm using the current technology; for $\theta<a / c$, they choose to exercise the abandonment option.

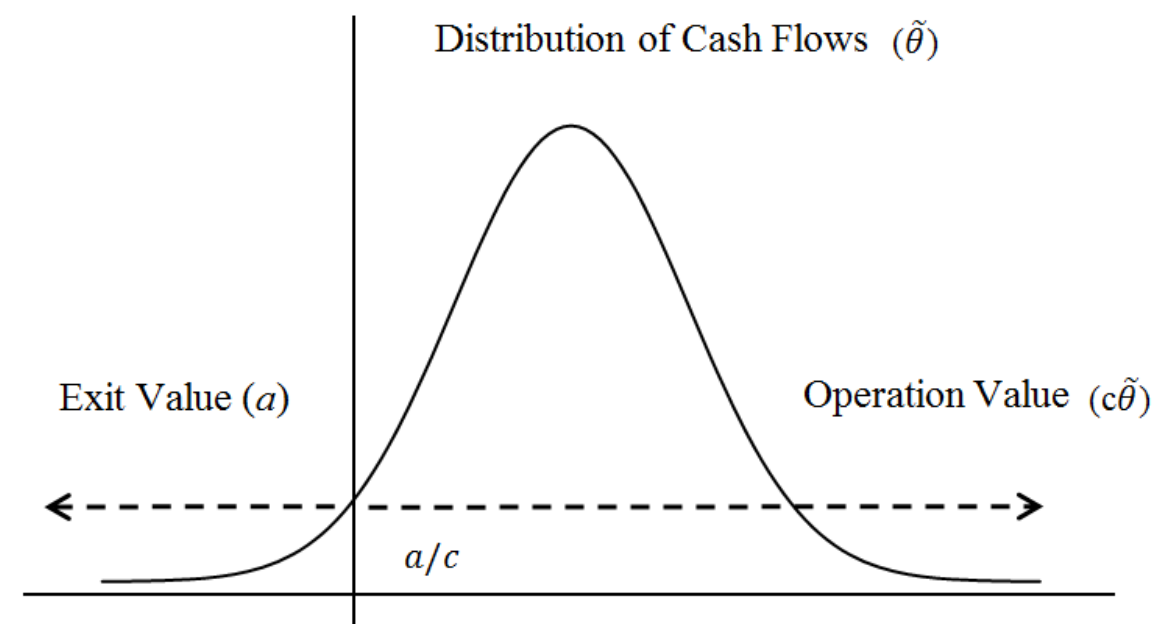

Figure 1: Distribution of operating cash flows and the abandonment option.

\subsection{Future payoffs and risk of the abandonment option}

I expand Burgstahler and Dichev's (1997) model in several ways. First, I assume investors are risk-averse, i.e., they consider both the expected payoff and the riskiness of the payoff. Thus, the discount factor in equation (2) can no longer be omitted. Second, the discount rate (risk) is an increasing function of the uncertainty about future payoffs, 
which cannot be entirely diversified (Robichek and Van Horne, 1967; Bonini, 1977).

Third, I expand their model to three periods, because the discount rate can no longer be assumed constant over time based on the two assumptions above. The abandonment option changes the riskiness of future payoffs, so its existence affects the discount rate. Finally, I assume that investors observe accounting earnings as a noisy signal about future operating cash flows. ${ }^{3}$

\begin{tabular}{lll} 
Date 0 & \multicolumn{1}{c}{ Date 1} & Date 2 \\
$\begin{array}{l}\text { Risk-averse investors acquire } \\
\text { a firm that generates operating }\end{array}$ & $\begin{array}{l}\text { The investors observe earnings }(e) \\
\text { and update their beliefs about the }\end{array}$ & $\begin{array}{l}\text { If investors exercise the } \\
\text { abandonment option, they receive }\end{array}$ \\
$\begin{array}{ll}\text { cash flows }(\tilde{\theta}) \text { after date } 1 . & \text { operating cash flows accordingly } \\
\text { the exit value }(a) \text {; otherwise, they }\end{array}$ & $\begin{array}{l}\text { keep the current operations and } \\
\text { obtain operation value }(\tilde{v} \tilde{v}) .\end{array}$ \\
& $\begin{array}{ll}\text { to abandon the firm at date } 2 . \\
\text { The firm is priced at } \mathrm{P}_{1} .\end{array}$ & The firm is priced at $\mathrm{P}_{2}$.
\end{tabular}

Figure 2: Timeline of the model.

Figure 2 presents the timeline of this model. At date 0, risk-averse investors acquire a firm at the price $P_{0}$ that generates operating cash flows after date 1 . Their $e x-$ ante beliefs about the cash flow process follow the distribution $\tilde{\theta} \sim N\left(\bar{\theta}, 1 / h_{\theta}\right)$, where $N(\cdot)$ denotes the normal distribution and $\bar{\theta}$ and $h_{\theta}$ are the mean and precision of $\tilde{\theta}$,

\footnotetext{
${ }^{3}$ My model is an extension of the Burgstahler and Dichev (1997) model that assumes a single-asset firm, so abandonment is modeled as a liquidation of the entire firm. This is a simplification of the real world. A firm with multiple assets or business lines could be viewed as a parent firm that has multiple single-asset subsidiaries. When the parent firm reports a loss that is attributable to some loss-making subsidiaries, investors will choose to abandon those unprofitable subsidiaries, and the parent firm's overall likelihood of abandonment will increase. Therefore, a partial asset sale in a firm with multiple assets also meets the model's definition of abandonment.
} 
respectively. At date 1 , investors observe accounting earnings $(e)$ that is a noisy signal of future operating cash flows $\left(\tilde{e}=\tilde{\theta}+\tilde{\varepsilon}\right.$, where $\tilde{\varepsilon} \sim N\left(0,1 / h_{\varepsilon}\right), h_{\varepsilon}$ is the precision of $\tilde{\varepsilon}$, and $\tilde{\theta}$ and $\tilde{\varepsilon}$ are independent). They use earnings to update their prior beliefs about operating cash flows, and their ex-post beliefs about the cash flows become $\tilde{v}=\tilde{\theta} \mid e\left(\tilde{v} \sim N\left(\mu, \sigma^{2}\right)\right.$, where $\mu$ and $\sigma^{2}$ are the mean and variance of investors' updated beliefs about the operating cash flows $(\tilde{v})$, respectively. 4 Then, investors decide whether to exercise the abandonment option at date 2. They receive the exit value $(a)$ from exercising the abandonment option at date 2; otherwise, they receive the operation value $(c v)$. The investors will opt out of the operation value $(c v)$ in favor of the exit value $(a)$ when the exit value exceeds the operation value. The market price of the firm at date 1 is $P_{1}$. At date 2, the investors' decision about whether to exercise the abandonment option is realized, and they receive either the operation value $(c v)$ or the exit value $(a)$. The market price of the firm at date 2 is $P_{2}{ }^{5}$

I focus on the firm's market value at date $1\left(P_{1}\right)$, when the investors own the firm but cannot observe the realization of future cash flows, and thus, face uncertainty about whether to exercise the abandonment option. At date 1, they set the market value of equity $\left(P_{1}\right)$ equal to the expected payoff at date $2\left(E\left(P_{2}\right)\right)$ deflated by the discount rate

\footnotetext{
${ }^{4}$ Following the Bayesian updating rule, we know that $\mu=\left(h_{\theta} \bar{\theta}+h_{\varepsilon} e\right) /\left(h_{\theta}+h_{\varepsilon}\right)$ and $\sigma^{2}=1 /\left(h_{\theta}+h_{\varepsilon}\right)$.

${ }^{5}$ Abel et al. (1996) consider both an abandonment option and an expansion option. They assume investors of extremely profitable firms are likely to expand their investments, investors of extremely unprofitable firms are likely to divest their investments, and other investors keep their current investments. Both Burgstahler and Dichev (1997) and my paper ignore the expansion option, because our interest is to investigate how the abandonment option affects equity value. My model targets loss firms, where the abandonment option plays a more important role than the expansion option.
} 
$(E(R)) . E\left(P_{2}\right)$ and $E(R)$ can be viewed as the numerator and denominator in a valuation function, respectively. Assuming that investors are risk-neutral, Burgstahler and Dichev's (1997) model omits the discount rate $(E(R))$ in the valuation expression $\left(P_{1}=E\left(P_{2}\right)\right)$, so the investors maximize the valuation numerator $E\left(P_{2}\right)$ in their model (Burgstahler and Dichev, 1997, footnote 5).

Under the assumption that the discount rate is increasing in the uncertainty associated with future payoffs, I further assume that the firm's discount rate has the following functional form to simplify the expression: $E(R)=\gamma \operatorname{Var}\left(P_{2}\right)>1$, where $\gamma$ is a constant $(\gamma>0)$ and $\gamma$ captures investor risk-aversion. ${ }^{6}$ The market value of equity at date 0 incorporates both the expected payoff and the discount rate as follows:

$$
P_{1}=\frac{E\left(P_{2}\right)}{E(R)}=\frac{E\left(P_{2}\right)}{\gamma \operatorname{Var}\left(P_{2}\right)}
$$

Following equation (2), the expected payoff $\left(E\left(P_{2}\right)\right)$ is given by:

$$
\begin{aligned}
& E\left(P_{2}\right)=\int_{-\infty}^{a / c} a f(v) d v+\int_{a / c}^{\infty} c v f(v) d v=a \Phi(x)+c[\mu+ \\
& \sigma \lambda(x)][1-\Phi(x)]
\end{aligned}
$$

where $f(\cdot)$ denotes the probability density function of $\tilde{v}, \Phi(\cdot)(\phi(\cdot))$ is the cumulative distribution function (probability distribution function) of the standard normal distribution, $x=-\frac{c \mu-a}{c \sigma}=\left[(a / c-\bar{\theta}) h_{\theta}+(a / c-e) h_{\varepsilon}\right] /\left(h_{\theta}+h_{\varepsilon}\right)^{3 / 2}$, and $[\mu+\sigma \lambda(x)]$ is

\footnotetext{
${ }^{6}$ If the abandonment option is not exercised at date 2, the discount rate of cash flows is determined by its variance, i.e., $\gamma \operatorname{Var}(\tilde{v})=\gamma /\left(h_{\theta}+h_{\varepsilon}\right) \neq \gamma \operatorname{Var}\left(P_{1}\right)$, where $\gamma /\left(h_{\theta}+h_{\varepsilon}\right)>1$. Obviously, the discount rate at date 1 is different from that at date 0 , when the abandonment option still exists. The multiplier for operation cash flows equals $c=\gamma /\left(\gamma-h_{\theta}-h_{\varepsilon}\right)$, where $\gamma>h_{\theta}+h_{\varepsilon}$. As $\gamma, h_{\theta}$, and $h_{\varepsilon}$ are all fixed, the multiplier (c) is a constant. I continue using $c$ as the multiplier for cash flows to simplify the expression.
} 
the mean of $\tilde{v}$ left-truncated at $x$. In this expression, $x$ measures the gap between operation value and exit value. The appendix shows the derivation of $E\left(P_{2}\right)$.

The variance of $P_{2}\left(\operatorname{Var}\left(P_{2}\right)\right)$ is given by:

$$
\operatorname{Var}\left(P_{2}\right)=c^{2} \sigma^{2}[1-\Phi(x)]\{1+[x-\lambda(x)][\phi(x)+x \Phi(x)]\}
$$

The appendix shows the derivation of $\operatorname{Var}\left(P_{2}\right)$.

The discount rate $(E(R))$ is an increasing function of $P_{2}$ 's variance:

$$
\begin{aligned}
& E(R)=\gamma \operatorname{Var}\left(P_{2}\right) \\
& \quad=\gamma c^{2} \sigma^{2}[1-\Phi(x)]\{1+[x-\lambda(x)][\phi(x)+x \Phi(x)]\}
\end{aligned}
$$

Substituting $E\left(P_{2}\right)$ and $E(R)$ into equation (3) yields:

$$
\begin{gathered}
P_{1}=\frac{E\left(P_{2}\right)}{E(R)}=\frac{\Phi(x)}{E(R)} \cdot a+\frac{1-\Phi(x)}{E(R)} \cdot c[\mu+\sigma \lambda(x)]=\rho_{1} a+\rho_{2} c[\mu+ \\
\sigma \lambda(x)]
\end{gathered}
$$

where $[\mu+\sigma \lambda(x)]$ is the mean of $\tilde{v}$ left-truncated at $x, \lambda(x)=\phi(x) /[1-\Phi(x)]$, $E(R)=\gamma c^{2} \sigma^{2}[1-\Phi(x)]\{1+[x-\lambda(x)][\phi(x)+x \Phi(x)]\}, \rho_{1}=\frac{\Phi(x)}{E(R)}, \rho_{2}=[1-\Phi(x)] / E(R)$ , and $\rho_{1} / \rho_{2}=\Phi(x) /[1-\Phi(x)]$.

From equation (6), firm value at date $1\left(P_{1}\right)$ is a function of both the exit value $(a)$ and the operation value $(c[\mu+\sigma \lambda(x)]$ is the mean of $c \tilde{v}$ left-truncated at $x)$. The likelihood of abandonment $(\Phi(x))$ is a decreasing function of the gap between operation value and exit value $(x=-(c \mu-a) / c \sigma$, so $x$ is an inverse measure of the gap between $c \mu$ and $a)$. The expected operation value $\left(c \mu=c\left(h_{\theta} \bar{\theta}+h_{\varepsilon} e\right) /\left(h_{\theta}+h_{\varepsilon}\right)\right)$ monotonically increases in accounting earnings $(e)$. Given a fixed exit value $(a)$, the gap between operation value and exit value $(-x)$ increases in accounting earnings $(e)$, so the 
likelihood of abandonment $(\Phi(x))$ decreases in accounting earnings $(e)$. The relative weights on the two components of firm value reflect the likelihood of abandonment $\left(\rho_{1} / \rho_{2}=\Phi(x) /[1-\Phi(x)]\right)$, consistent with prior literature (e.g., Barth et al., 1998).

I incorporate firm value at date $0\left(P_{0}\right)$ into equation (6). The return between date 1 and date $0\left(R_{1}\right)$ is given by:

$$
\begin{gathered}
R_{1} \equiv \frac{P_{1}-P_{0}}{P_{0}}=\frac{E\left(P_{2}\right)}{E(R) \cdot P_{0}}-1=\rho_{1} a / P_{0}+\rho_{1} c[\mu+\sigma \lambda(x)] / P_{0}-1 \\
=\frac{a \cdot \Phi(x)+c[\mu+\sigma \lambda(x)] \cdot[1-\Phi(x)]}{E(R) \cdot P_{0}}-1
\end{gathered}
$$

Similar to equation (6), the valuation weights on the exit value and operation value in equation (7) are also related to the likelihood of abandonment. As the firm's likelihood of abandonment increases, investors will place more valuation weight on the exit value and less valuation weight on the operation value. The main hypotheses of my paper are articulated in the following two propositions.

In equations (6) and (7), $E\left(P_{2}\right)$ and $E(R)$ can be viewed as the valuation numerator and valuation denominator, respectively. Taking the first order derivatives of $E\left(P_{2}\right)$ (Eq. (4), the valuation numerator) and $E(R)$ (Eq. (5), the valuation denominator) with respect to $e$ separately, I find that $E\left(P_{2}\right)$ and $E(R)$ are both increasing in earnings $\left(\partial E\left(P_{2}\right) / \partial e>0\right.$ and $\left.\partial E(R) / \partial e>0\right)$.

Proposition 1: A reported loss induces simultaneous downward revisions to both the cash flow expectation (the valuation numerator) and the discount rate (the valuation denominator). 
Proposition 1 supports my first hypothesis (H1) that losses provide adverse cash flow news and favorable discount rate news; the former increases stock price and the latter decreases stock price. These two types of news offset each other in forming returns, dampening the relation between losses and returns. Proposition 2 extends Proposition 1 to posit an explanation for the weak association between losses and stock returns $(\mathrm{H} 2)$.

Proposition 2: Since losses provide adverse news about investors' cash flow expectation (the valuation numerator) and favorable news about discount rate (the valuation denominator), the association between losses and stock return is dampened. 


\section{Empirical Test Specifications}

\subsection{Losses and return components}

I use the Vuolteenaho (2002) return decomposition method ${ }^{1}$ to separate realized return into expected return, cash flow news $(N c f)$, and discount rate news $(N r)$ as shown in equation (8). ${ }^{2}$ I use the following sign and labeling conventions: positive (negative) cash flow news $(N c f)$ means a favorable (unfavorable) revision to the valuation numerator, where a favorable revision is an increase in cash flow expectations; positive (negative) discount rate news $(\mathrm{Nr})$ means a favorable (unfavorable) revision to the valuation denominator, where a favorable revision is a decrease in the discount rate.

$$
R_{t} \equiv E_{t-1}\left(R_{t}\right)+N c f_{t}+N r_{t}
$$

where $R_{t}=$ realized stock return in year $t^{3} ; N c f_{t}=$ cash flow news in year $t ; N r_{t}=$ discount rate news in year $t$; and $E_{t-1}\left(R_{t}\right)=$ expected return at the end of year $t-1$.

\footnotetext{
${ }^{1}$ The Vuolteenaho (2002) method has been used in both finance and accounting research (e.g., Hecht and Vuolteenaho, 2006; Callen and Segal, 2004). An alternative decomposition method, proposed by Easton and Monahan (2005), requires consensus analyst forecast data. This requirement reduces the sample size of loss observations by $90 \%$ (see table 10). In addition, the Vuolteenaho (2002) method guarantees that stock returns equal the sum of cash flow news, discount rate news, and expected return (Eq. (8)), but the news components in Easton and Monahan (2005) do not have this additive relation and are not comparable in magnitude. The regression coefficients and $R^{2} \mathrm{~s}$ in equation (10) are additive and comparable because they are based on the return components from Vuolteenaho (2002), rather than those from Easton and Monahan (2005). Section 5 discusses this issue.

${ }^{2}$ Cash flow news $(N c f) /$ discount rate news $(N r)$ represents all news about cash flows/risk in a fiscal year. The term "news components" refers to both "cash flow news" (Ncf) and "discount rate news" (Nr), and the term "return components" refers to "cash flow news", "discount rate news", and "expected returns".

${ }^{3}$ Empirically, Vuolteenaho (2002) uses the natural logarithm of one plus the realized return $(\log R)$ as the measure of realized return (Ret). $\log R$ is approximately equal to Ret. In the estimation of the news components, the natural logarithm of one plus the risk-free rate $(\log (1+R f))$ is excluded from $\log R$.
} 
Using this return decomposition, I decompose a regression of realized returns on earnings into three component regressions, corresponding to expected returns, cash flow news, and discount rate news, respectively (Hecht and Vuolteenaho, 2006). Prior research regresses realized returns $\left(R_{t}\right)$ on the earnings-to-price ratio $\left(X_{t} / P_{t-1}\right)$ to estimate the information content of earnings (Eq. (9)).

$$
R_{t}=\alpha_{0}+\beta_{0} X_{t} / P_{t-1}+\varepsilon_{0 t}
$$

Following Hecht and Vuolteenaho (2006), I replace the realized return with the expected return and news components (as given in Eq. (8)) as the dependent variables in three component regressions, given in equations (10a), (10b), and (10c). ${ }^{4}$

$$
\begin{aligned}
& N c f_{t}=\alpha_{1}+\beta_{1} X_{t} / P_{t-1}+\varepsilon_{1 t} \\
& N r_{t}=\alpha_{2}+\beta_{2} X_{t} / P_{t-1}+\varepsilon_{2 t} \\
& E_{t-1}\left(R_{t}\right)=\alpha_{3}+\beta_{3} X_{t} / P_{t-1}+\varepsilon_{3 t}
\end{aligned}
$$

where $R_{t}=$ realized stock return in year $t ; N c f_{t}=$ cash flow news of year $t ; N r_{t}=$ discount rate news of year $t$; and $E_{t-1}\left(R_{t}\right)=$ expected return at the end of year $t-1$. $X_{t}=$ earnings-per-share (EPS) of year $t$; and $P_{t-1}=$ the share price at the end of fiscal year $t-1 . X_{t} / P_{t-1}=$ earnings scaled by lagged price (earnings-to-price ratio). $\beta_{0}$ is the earnings response coefficient (ERC). $R^{2} R, R^{2}{ } c f, R^{2}{ }_{N r}$, and $R^{2} E(R)$ denote the corresponding

\footnotetext{
${ }^{4}$ I use component regressions, instead of reverse regressions of earnings on the return components, for the following reasons. The correlation between the news components is high (-.627) for the loss sample, so reverse regressions would face a multicolinearity problem. In addition, the return components from estimating the Vuolteenaho (2002) model would contain more measurement errors than earnings, so I put the return components on the left-hand side. Finally, the Vuolteenaho (2002) model generates additive and comparable return components, so the coefficients from the components regressions have the same properties.
} 
$R^{2}$ S from equations (9), (10a), (10b), and (10c), respectively. $\beta_{0}\left(R^{2} R\right)$ represents the overall association between stock returns and earnings, $\beta_{1}\left(R^{2} N_{c f}\right)$ represents earnings' informativeness with regard to cash flow news, $\beta_{2}\left(R^{2}{ }_{N r}\right)$ represents earnings' informativeness with regard to discount rate news, and $\beta_{3}\left(R^{2} E(R)\right)$ represents the association between expected return and earnings.

Since the explanatory variable in each of the three component regressions is the same as in the regression (9), we can think of regression (9) as the sum of the three component regressions (Hecht and Vuolteenaho, 2006).

$$
R_{t}=\alpha_{0}+\left(\beta_{1}+\beta_{2}+\beta_{3}\right) X_{t} / P_{t-1}+\left(\varepsilon_{1 t}+\varepsilon_{2 t}+\varepsilon_{3 t}\right)
$$

From regressions (10) and (11), it is clear that earnings $\left(X_{t} / P_{t-1}\right)$ can explain stock returns $\left(R_{t}\right)$ for various reasons, i.e., earnings can explain expected return, cash flow news, or discount rate news - or any combination of the three.

As previously discussed, the first hypothesis (H1) predicts that losses are positively related to cash flow news $(N c f)$ and negatively related to discount rate news $(\mathrm{Nr})$.

H1. For loss observations, $\beta_{1}>0$ and $\beta_{2}<0$ in equations $(10 a, b)$.

The second hypothesis $(\mathrm{H} 2)$ predicts that the return-earnings relation for losses is dampened because the valuation effects of cash flow news and discount rate news offset each other.

H2. For loss observations, $R_{R}^{2}<\max \left\{R_{N c f}^{2}, R_{N r}^{2}\right\}$ in equations $(10 a, b)$. 
The third and fourth hypotheses (H3 and $\mathrm{H} 4)$ suggest that the information content of losses varies with earnings attributes and firm characteristics, including the persistence of losses, nonrecurring charges, R\&D expenditures, cash holdings, external financing, specialized assets, and number of firms in the industry (industry size). The extent to which reported losses could revise the likelihood of abandonment is an increasing function of all these variables, except for industry size. In order to test the last two hypotheses, I introduce each of those variables into equations $(10 a, b)$ as both a main effect and an interaction with losses (negative earnings).

$$
\begin{aligned}
& N c f_{t}=\alpha_{1}+\beta_{1} X_{t} / P_{t-1}+\gamma_{1}\left(X_{t} / P_{t-1} \cdot L_{i}\right)+\delta_{1} L_{i}+\varepsilon_{1 t} \\
& N r_{t}=\alpha_{2}+\beta_{2} X_{t} / P_{t-1}+\gamma_{2}\left(X_{t} / P_{t-1} \cdot L_{i}\right)+\delta_{2} L_{i}+\varepsilon_{2 t},
\end{aligned}
$$

where $N c f_{t}=$ cash flow news of year $t ; N r_{t}=$ discount rate news of year $t ; X_{t} / P_{t-1}=$ negative earnings scaled by lagged price; $L_{i}=$ a measure of earnings attributes or firm characteristics; and $\left(X_{t} / P_{t-1} \cdot L_{i}\right)=$ the interaction between $X_{t} / P_{t-1}$ and $L_{i}$.

The third hypothesis (H3) predicts that losses that are more transitory or contain more nonrecurring charges convey less adverse cash flow news and less favorable discount rate news than other losses.

H3. $\gamma_{1}<0$ and $\gamma_{2}>0$ in equation $(12 a, b)$ for loss observations, where higher values of $L_{i}$ indicate more transitory losses or more nonrecurring charges.

The fourth hypothesis $(\mathrm{H} 4)$ predicts that losses reported by firms with more R\&D expenditures, more cash holdings, more external financing, more specialized assets, or 
fewer firms in the industry convey less adverse cash flow news and less favorable discount rate news.

H4. $\gamma_{1}<0$ and $\gamma_{2}>0$ in equation $(12 a, b)$ for loss observations, where higher values of $L_{i}$ indicate more RED expenditures, more cash holdings, more external financing, more specialized assets, or fewer firms in the industry.

\subsection{Decomposing stock returns into cash flow news and discount rate news}

This section describes the Vuolteenaho (2002) return decomposition approach.

The appendix explains the details of the estimation. Based on the clean surplus relation, Vuolteenaho (2002) shows that a firm's unexpected return can be expressed as:

$$
r_{t}-E_{t-1}\left(r_{t}\right)=\Delta E_{t} \sum_{j=0}^{\infty} \rho^{j}\left(\text { roe }_{t+j}-i_{t+j}\right)-\Delta E_{t} \sum_{j=0}^{\infty} \rho^{j} r_{t+j}
$$

where $\Delta=$ the first difference operator, $E_{t}=$ the expectation operator and $\Delta E_{t}=E_{t}(\cdot)-$ $E_{t-1}(\cdot), r_{t}=\log$ stock return (cum dividend) in excess of the risk-free rate in period $t$, $\rho=$ a constant error approximation term ${ }^{5}$, roe $_{t}=\log \left(1+X_{t} / B V_{t-1}\right)=$ natural logarithm of return on equity in period $t, B V_{t}=$ book value of equity at time $t, X_{t}=$ earnings in period $t$, and $i_{t}=$ natural logarithm of one plus the risk-free rate in period $t$.

\footnotetext{
${ }^{5} \rho$ is often empirically estimated to take on a value of 0.967 as in Vuolteenaho (2002). Following Easton and Monahan (2005), I estimate $\rho$ for five portfolios based on the price-to-dividend ratio, as a robustness check. Consistent with prior literature, the value of $\rho$ appears to have little impact on my results for values between 0.92 and 1.00 .
} 
Equation (13) shows that unexpected return $\left(r_{t}-E_{t-1}\left(r_{t}\right)\right)$ depends on both the revision to cash flow expectations (the change in expected ROE) ${ }^{6}$ and the revision to the discount rate (the change in expected return). Defining these revisions as cash flow news $(N c f)$ and discount rate news $(N r)^{7}$, equation (13) can be expressed as:

$$
r_{t}-E_{t-1}\left(r_{t}\right)=N c f_{t}+N r_{t}
$$

where $N c f_{t}=\Delta E_{t} \sum_{j=0}^{\infty} \rho^{j}\left(\right.$ roe $\left._{t+j}-i_{t+j}\right)=$ cash flow news, and $N r_{t}=-\Delta E_{t} \sum_{j=0}^{\infty} \rho^{j} r_{t+j}=$ discount rate news.

Equation (14) shows that unexpected returns increase with favorable cash flow news and favorable discount rate news. Favorable (that is, positive) cash flow news conveys positive information about future cash flows, and favorable news about the discount rate (that is, a decrease) conveys favorable information about expected (required) returns.

\footnotetext{
${ }^{6} \mathrm{ROE}$ is used as the proxy for the basic cash-flow fundamental in the return decomposition literature (e.g., Vuolteenaho, 2002; Callen and Segal, 2004; Easton and Monahan, 2005; Sadka, 2007). Change in ROE is considered as a better measure of cash-flow fundamentals than dividend growth (e.g., Vuolteenaho, 2002; Sadka, 2007).

${ }^{7}$ In contrast to previous research (e.g., Vuolteenaho, 2002; Callen and Segal, 2004), I add a negative sign before $\Delta E_{t} \sum_{j=0}^{\infty} \rho^{j} r_{t+j}$ so that more positive discount rate news represents lower risk in the future. Following Chen and Zhao (2009), I directly estimate both cash flow news (Ncf) and discount rate news ( $N r$ ) to reduce the measurement error in the news components, rather than calculating the discount rate news component first and then backing out the cash flow news from unexpected returns.
} 


\section{Data and Results}

\subsection{Data and descriptive statistics}

I obtain stock return data from the CRSP database and annual financial data from the Compustat database. I obtain analyst forecast data from I/B/E/S and asset sales data from the SDC Platinum M\&A database. Panel A of Table 1 describes the sample selection process. The initial sample consists of all firm-year observations available on the Compustat fundamental annual file during fiscal years 1959-2010 (264,957 firmyears). I exclude firm-years without annual stock return data on the CRSP monthly file and firm-years without earnings data (earnings-to-price ratio) on the Compustat fundamental annual file. I also exclude observations for which data required to calculate the news components of returns are missing: current and one-year lagged earnings, book value, market value, and stock returns. ${ }^{1}$ The final sample contains 127,656 firmyear observations over 1962 - 2010, representing 13,146 distinct firms. Some analyses impose additional data requirements that further reduce the sample size.

My earnings measure is income before extraordinary items for year $t$ (Compustat: $I B$ ) deflated by the market value of equity at the end of year $t-1$

${ }^{1}$ Following previous literature (e.g., Callen and Segal, 2004), I remove the top and bottom $1 \%$ of each of the variables used in the return decomposition to mitigate the impact of outliers. I also exclude firms in the financial and utilities industries (SIC 6000-6999 and 4900-4999). 
(Compustat: $\left.P R C C \_F \times C S H O\right) .{ }^{2}$ Losses are defined as firm-years with negative earnings $(I B<0)$. Stock returns (CRSP: RET) are assigned to each firm's fiscal year so as to match the time period of its reported financial data. ${ }^{3}$ To ensure the return period captures the market response to year $t^{\prime}$ s earnings and not to the earnings for year $t-1$, I calculate annual return over the 12-month period ending at the month of the earnings announcement (press release) for year $t .{ }^{4}$ The return components, i.e., cash flow news and discount rate news, are estimated using the Vuolteenaho (2002) return decomposition method.

To estimate the measures of earnings attributes and firm characteristics, I use the approaches in Joos and Plesko (2005), Darrough and Ye (2007), and Berger et al. (1996). Following these papers, I employ the predicted probability of loss reversal to measure the persistence of losses (Joos and Plesko, 2005); nonrecurring charges, R\&D expenditures, cash holdings, and external financing to calibrate the sustainability of loss firms (Darrough and Ye, 2007); and the portion of specialized assets to gauge asset

\footnotetext{
2 I use current earnings as my main proxy for operation value, because "( $i$ ) current earnings reflect, by definition, the results of applying the firm's current technology; (ii) it is difficult to improve on current earnings as a predictor of future earnings" (Burgstahler and Dichev, 1997, page 193).

${ }^{3}$ Following previous research on losses (e.g., Hayn, 1995; Li, 2011), I use realized return (Ret) as the main measure of stock return, rather than the natural logarithm of one plus the realized return $(\log R)$ according to the Vuolteenaho (2002) return decomposition method. $\log R$ is approximately equal to Ret.

${ }^{4}$ If the earnings announcement date is not available on the Compustat quarterly file, I calculate the return over the 12-month period commencing with the fourth month after the end of the firm's fiscal year $t-1$. If a stock is delisted during the return window, the CRSP delisting return is included in the buy-and-hold return. I require delisted firms to have at least 9 months of return data; other firms are required to have 12 months of return data. My results are robust to the exclusion of delisted firm-years. Details of the computation of annual stock returns are provided in the appendix.
} 
structure (Berger et al., 1996). In addition, I use the number of firms in the industry to proxy for a used asset market and/or the intensity of competition in the industry. Details of estimation of these variables are provided in both the next section and the appendix.

Control variables in this test are motivated by previous studies (e.g., Fama and French, 1992; Lang et al., 1995; Burstahler and Dichev, 1997; Barth et al., 1998; Dichev, 1998; Hecht and Vuolteenaho, 2006). Taking book value of equity (BV) and earnings $(X)$ as proxies for exit value and operation value, respectively ${ }^{5}$, we can view the market value of equity $(P)$ as an increasing function of both $B V$ and $X$, i.e., $P_{t}=\rho_{1} B V_{t-1}+\rho_{2} X_{t}$ (e.g., Burgstahler and Dichev, 1997; Barth et al., 1998; also see Eq. (6)). Deflating $P_{t}$ by lagged market value $P_{t-1}$ and rewriting the equation yields:

$$
R_{t} \equiv\left(P_{t}-P_{t-1}\right) / P_{t-1}=\rho_{1} B V_{t-1} / P_{t-1}+\rho_{2} X_{t} / P_{t-1}-1
$$

where $R_{t}=$ the realized stock return $($ Ret $)$ in period $t, X_{t} / P_{t-1}=$ the earnings-to-price ratio $(X / P)$ in period $t$, and $B V_{t-1} / P_{t-1}=$ the book-to-market ratio $(B / M)$ for period $t-1$.

As an empirical specification of equation (7), equation (15) is an increasing function of both lagged book-to-market ratio $(B / M)$ and earnings-to-price ratio $(X / P)$. Thus, it is important to control for the lagged book-to-market ratio $(B / M)$ in the regression of realized returns $($ Ret $)$ on the earnings-to-price ratio $(X / P)$. The coefficient on lagged book-to-market ratio $(B / M)$ should be positive. According to Hecht and

\footnotetext{
${ }^{5}$ An alternative proxy for operation value in Berger et al. (1996) requires consensus analyst forecasts of twoyear earnings and five-year earnings growth, and therefore reduces the size of the loss sample by about $70 \%$. My results are robust to the proxies for operation value and exit value following Berger et al. (1996).
} 
Vuolteenaho (2006), both current and one-year lagged earnings (i.e., earnings-to-price ratio) are important in explaining variation in the return components. Also, the regression coefficients on current earnings will reflect the association between the news in realized returns and the unexpected portion of current earnings, conditional on lagged earnings.

Fama and French (1992) document that, apart from the book-to-market ratio, firm size also captures the cross-sectional variation in realized returns, so I include both oneyear lagged firm size (Size) and the lagged book-to-market ratio $(B / M)$ in the regressions of return/return components on earnings. As discussed in the literature review, firm size (i.e., the natural logarithm of market value of equity) is a function of both operation value and exit value under the view that investors always have the abandonment option (e.g., Berger et al., 1996; Burgstahler and Dichev, 1997; Barth et al., 1998). Thus, lagged operation value and lagged exit value are both controlled for by adding lagged firm size (Size) as a control variable in the regressions. Furthermore, since firms with poor profitability and high leverage have more voluntary asset sales (e.g., Lang et al., 1995) and higher probability of bankruptcy (e.g., Dichev, 1997), I employ the one-year lagged leverage ratio (Lev) and the Altman (1968) Z score (Zscore) as controls for capital structure and the probability of bankruptcy, respectively. In sum, my main control variables include one-year lagged earnings-to-price ratio $(\operatorname{lag} X / P)$, one-year lagged firm size (lagSize), one-year lagged book-to-market ratio (lagB/M), one-year lagged leverage 
ratio (lagLev), and current Altman Z score (Zscore). ${ }^{6}$ All variables are defined in the appendix.

\section{Table 1: Sample selection and description of loss incidence.}

\section{Panel A: Sample Selection}

Sample selection

Number of firm years

All Compustat firm fiscal years 1959 - 2010

264,957

Excluding firm fiscal years:

With incomplete earnings data (earnings scaled by one-year lagged stock price)

With incomplete stock return data

With insufficient data to calculate news components following Vuolteenaho (2002)

78,489

Final sample:

Loss sample

Profit sample

Panel B: Distribution of firms (at least 8 years of data) by the number of years with losses

\begin{tabular}{lrr}
\hline Number of loss years & Number of firms & \% of firms \\
\hline All firms & 5,917 & $100.0 \%$ \\
0 & 1,638 & $27.7 \%$ \\
1 & 868 & $14.7 \%$ \\
2 & 748 & $12.6 \%$ \\
3 & 638 & $10.8 \%$ \\
4 & 535 & $9.0 \%$ \\
5 & 420 & $7.1 \%$ \\
6 & 320 & $5.4 \%$ \\
8 & 219 & $3.7 \%$ \\
9 & 188 & $3.2 \%$ \\
10 or more & 116 & $2.0 \%$ \\
\hline
\end{tabular}

${ }^{6}$ In robustness checks, I control for the change in earnings-to-price ratio (Easton and Harris, 1991), alternative measures of operation value and exit value and their volatilities following Berger et al. (1996), change in beta, firm fixed effects, industry fixed effects, and year fixed effects. My results are robust to all these controls. I also test the sensitivity of my results to various earnings measures, including ROA, ROE, and EPS. In addition, untabulated results show that the associations between the return components and earnings exist within each firm size or age quintile. 
Table 1. Sample selection and description of loss incidence.

Panel C: Probability of losses by portfolios ordered by firm size (market value of equity)

\begin{tabular}{lrrr}
\hline Portfolio & Number of firm years & Number of loss years & $\%$ of loss years \\
\hline All portfolios & 127,656 & 26,885 & $21.1 \%$ \\
1 (smallest firms) & 12,766 & 5,562 & $43.6 \%$ \\
2 & 12,768 & 3,833 & $30.0 \%$ \\
3 & 12,763 & 3,447 & $27.0 \%$ \\
4 & 12,766 & 3,049 & $23.9 \%$ \\
5 & 12,765 & 2,719 & $21.3 \%$ \\
6 & 12,766 & 2,420 & $19.0 \%$ \\
7 & 12,766 & 2,022 & $15.8 \%$ \\
8 & 12,765 & 1,610 & $12.6 \%$ \\
9 & 12,766 & 1,256 & $9.8 \%$ \\
10 (largest firms) & 12,765 & 967 & $7.6 \%$ \\
\hline
\end{tabular}

Table 1 presents the sample selection process and the sample composition by loss history and firm size. The sample is comprised of 127,656 firm-year observations between 1962 and 2010 with sufficient financial and trading data from the Compustat and CRSP databases. Panel A reports the sample selection process. Panel B reports the distribution of individual firms by the number of losses in the firm's history. Panel C reports the number of losses by firm-size portfolios.

Losses are common, appearing in $21.1 \%$ of all firm-years in my sample. Figure 3 plots the (pooled) distribution of the earnings-to-price ratio for the sample, including the proportion of the earnings-to-price ratio that falls below zero. Figure 4 depicts the annual frequency of losses; the percentage of losses varies from $1.78 \%$ in the early $1960 \mathrm{~s}$ to $34.6 \%$ in 2001. Consistent with Hayn (1995) and Klein and Marquardt (2006), loss frequency increased during the 1980s and remained high in the later years of the sample. ${ }^{7}$ Panel B of Table 1 indicates that $72.3 \%$ of sample firms with more than eight

\footnotetext{
${ }^{7}$ Klein and Marquardt (2006) discuss the accounting and non-accounting factors behind the change in the frequency of losses over the past 50 years. In particular, they report that the annual frequency of losses is significantly related to accounting conservatism, Compustat coverage of small firms, real firm performance, and business cycle factors. The non-accounting factors tend to play the dominant role in explaining the accounting losses over their sample period. The non-accounting factors appear to have little effect on the informativeness of losses in conveying cash flow news and discount rate news. The accounting factors, such
} 
years of data incur at least one loss during the sample period. Panel C of Table 1 reveals a monotonic relation between firm size and the probability of a loss. The probability of incurring a loss in a given year is about $8 \%$ for the largest firms (portfolio 10) and about $44 \%$ for the smallest firms (portfolio 1). The results relating loss frequency to firm size suggest that if the likelihood of abandonment increases in the presence of losses, and loss incidence varies by firm size, small firms should have higher likelihood of abandonment than large firms. In other words, because small firms report losses more often, their investors are more likely to exercise the abandonment option, consistent with previous literature (e.g., Joos and Plesko, 2005; Li, 2011).

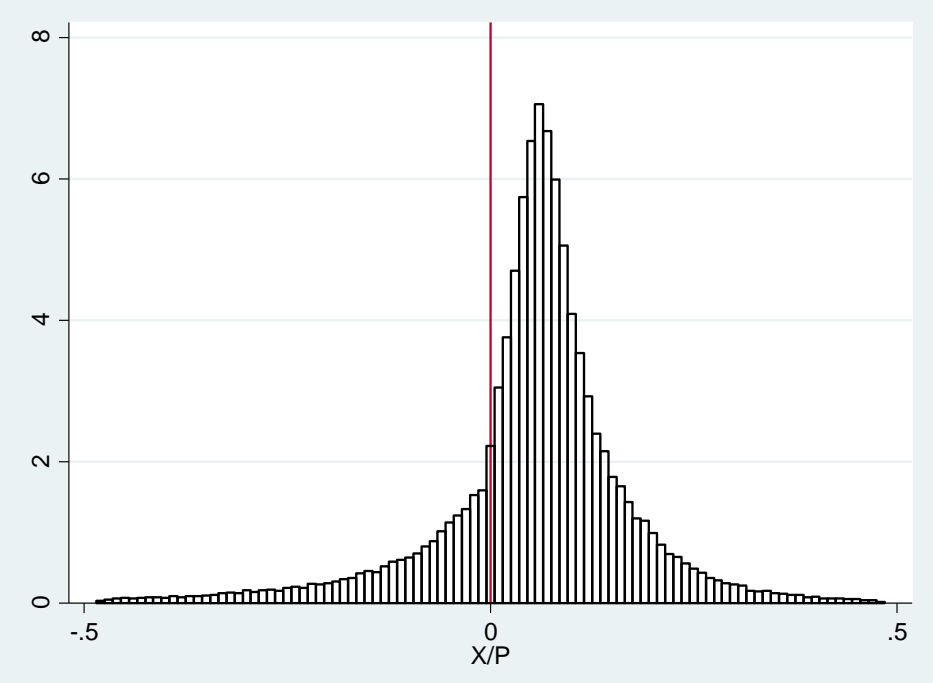

Figure 3: Distribution of earnings-to-price ratios for the period $1962-2010(n=127,656)$.

as conservatism, change the likelihood of exercising the abandonment and affect the informativeness of losses. I discuss how conservatism influence the informativeness of losses in section 5.2.3. 


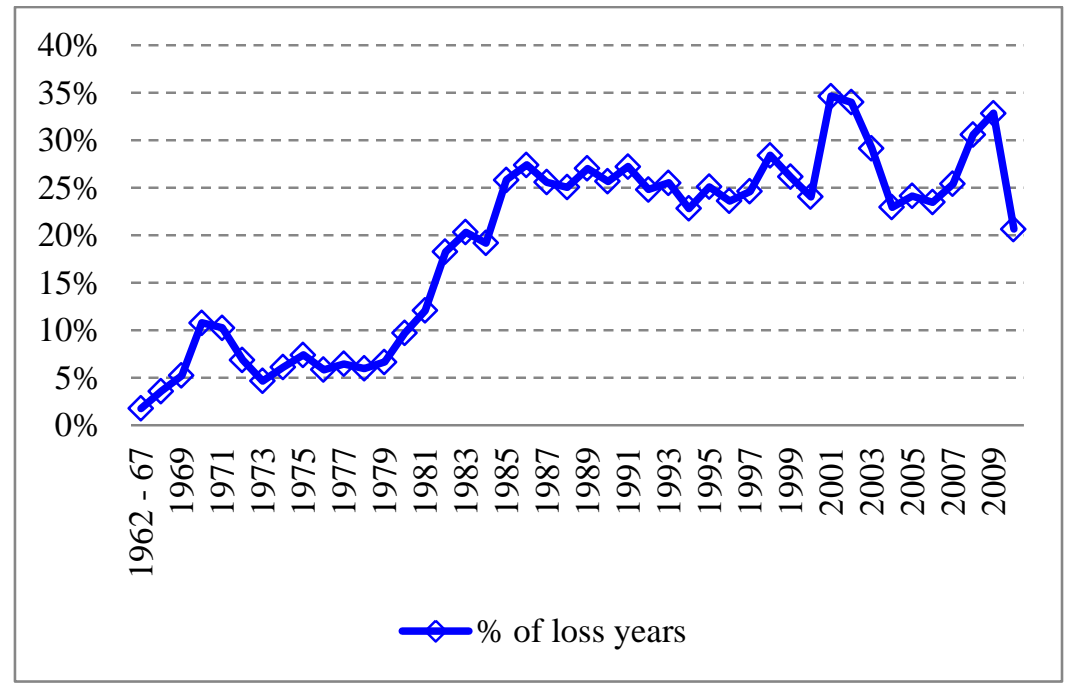

Figure 4: Frequency of reported losses for the period $1962-2010(n=26,885)$.

Table 2 presents summary statistics for the main variables. The loss sample includes firm-years with negative earnings, and the profit sample includes firm-years with non-negative earnings. The number of observations varies depending on data availability. Panel A provides descriptive statistics for the profit and loss samples separately. Profit observations have higher annual returns and a more positive earnings change than loss observations: the mean (median) values of annual return (Ret) and $(\triangle X P)$ for the profit sample are significantly (at the .001 level or better) larger than those for the loss sample. Most loss observations have a negative earnings change $(\triangle X P)$, while most profit observations have a positive earnings change. Compared to profit observations, loss firms experience adverse (negative) cash flow news (Ncf) and favorable (positive) discount rate news $(\mathrm{Nr})$. This result is consistent with the prediction 
that losses are associated with downward revisions to both the valuation numerator and the valuation denominator. The profit sample shows favorable (positive) cash flow news and adverse (negative) discount rate news. ${ }^{8}$ On average, the magnitudes of the news components for the profit sample are smaller than their counterparts for the loss sample, implying that losses are more informative than profits when the news components are separately considered. Loss observations have significantly (at the .001 level or better) higher mean (1.241 versus 1.082) and median (1.171 versus 1.034) beta (Beta) than profit observations, indicating that loss firms have higher systematic risk than profit firms. In addition, loss observations are smaller than profit observations, with higher book-tomarket ratios $(B / M)$, higher leverage ratios (Lev), and lower Altman Z scores (Zscore) (significant at the .001 level or better).

Panel B of Table 2 reports current and one-year lagged firm characteristics of loss observations. Panel B shows that loss observations have smaller firm sizes (Size), lower betas (Beta), and higher book-to-market ratios $(B / M)$ than in the prior period (the differences are significant at the .001 level or better). In addition, firms have lower Altman Z score (Zscore) and higher leverage (Lev) after reporting losses (significant at the .001 level or better). According to Kim and Schatzberg (1997), the announcement of abandonment intention reduces the systematic risk (market beta) of abandoning firms.

\footnotetext{
8 The correlation between the discount rate news $(\mathrm{Nr} r)$ and positive earnings is positive (.055), indicating that profit firms with higher earnings experience larger risk reductions.
} 
As loss firms are more likely to sell operating assets, reporting losses should lower the firms' systematic risk by increasing the likelihood of abandonment. In this case, loss firms have lower systematic risk after reporting a loss, although they have more debt and higher financial distress after reporting losses. ${ }^{9}$

Panel C of Table 2 reports correlation coefficients between the main variables, separately for the profit sample (upper right) and loss sample (lower left). The main focus is the correlation between returns/return components and earnings. For the profit sample, the correlation coefficient between annual returns (Ret) and earnings (X/P) is .346; for the loss sample, the coefficient is .002. Consistent with Hayn (1995) and Joos and Plesko (2005), this result reveals that the returns-earnings relation is weaker for losses than for profits. Panel $\mathrm{C}$ also shows that the correlation coefficients between the news components (Ncf and $N r$ ) and earnings (X/P) are .392 and -.399 for the loss sample, and .263 and .055 for the profit sample. This result is consistent with the predictions and results in Panel A, suggesting that loss firms have adverse (that is, negative) cash flow news $(N c f)$ and favorable (risk decreasing) discount rate news $(N r)$, while profit firms have favorable cash flow news and little discount rate news. Losses are more correlated

\footnotetext{
${ }^{9}$ Higher Altman (1968) Z scores or higher book-to-market ratios do not necessarily mean higher firm risk. Dichev (1998) finds that the Altman (1968) Z score is negatively related to expected return, proxied by future realized returns. Higher book-to-market ratios $(B / M)$ have two implications: $(i)$ viewing $B / M$ as a proxy for growth opportunity, firms have fewer growth opportunities after reporting losses, because growth opportunities disappear after exercising the abandonment option and losses firms have higher likelihood of abandonment; (ii) investors will put more valuation weight on the exit value after observing losses, so the market value of equity will be closer to book value of equity, and thus the book-to-market ratio will decrease (see Eq. (15)).
} 
with the two news components ( $N c f$ and $N r$ ) considered separately than with stock returns (Ret), while the return-earnings relation for profit firms is mostly attributable to the correlation between earnings and cash flow news. ${ }^{10}$

Consistent with theory (e.g., Campbell, 1991; Vuolteenaho, 2002), the correlations between realized return (Ret) and the news components ( $N c f$ and $N r)$ are positive and significant for both the loss and profit samples. The correlations between cash flow news (Ncf) and discount rate news $(\mathrm{Nr})$ are -.627 and -.011 for the profit and loss samples, respectively. ${ }^{11}$ These results imply that, for the loss sample, the valuation numerator and denominator change in the same direction; for the profit sample, the association between the news components is weak. Consistent with Ball, Kothari, and Watts (1993), there is a significant negative correlation between earnings change $(\triangle X / P)$ and discount rate news (Nr) (-.260 and -.095 for the loss and profit samples), indicating that risk increases in accounting earnings. In addition, the correlation between earnings change $(\triangle X / P)$ and cash flows news (Ncf) is positive (.430 and .537 for the loss and profit samples). Taken together, the results show that, similar to loss firms, firms with negative earnings changes would also experience adverse cash flow news and favorable discount rate news. Compared with losses (negative earnings), decreases in earnings are less related

\footnotetext{
${ }^{10}$ My (untabulated) results show discount rate news and earnings are negatively correlated for the entire sample (coeff. $=-.318$ ), consistent with Hecht and Vuolteenaho (2006).

11 The correlation between $N c f$ and $N r$ is negative for the full sample using either the Vuolteenaho (2002) method or the Easton and Monahan (2005) method, consistent with previous literature (e.g., Easton and Monahan, 2005; Vuolteenaho, 2002; Hecht and Vuolteenaho, 2006).
} 
to the abandonment option, because negative earnings changes do not necessarily imply a firm's operating assets are unprofitable. In fact, a current earnings decline says nothing about the level of earnings. Finally, correlations between beta $($ Beta) and earnings $(X / P)$ are reliably positive for the loss sample and reliably negative for the profit sample. This evidence suggests that firms with larger losses have lower systematic risk, because they have an increased likelihood of abandonment. 
Table 2: Summary statistics.

Panel A: Descriptive statistics of all firm-year observations

\begin{tabular}{|c|c|c|c|c|c|c|c|c|c|}
\hline Variable & Sample & $N$ & Mean & $\begin{array}{l}\text { Diff. in } \\
\text { Mean }\end{array}$ & $\begin{array}{l}\text { Std. } \\
\text { Dev. }\end{array}$ & Q1 & Median & $\begin{array}{l}\text { Diff. in } \\
\text { Median }\end{array}$ & Q3 \\
\hline \multirow[t]{2}{*}{ Ret } & Loss & 26,885 & -0.060 & -0.255 & 0.558 & -0.439 & -0.182 & -0.297 & 0.144 \\
\hline & Profit & 100,771 & 0.195 & & 0.493 & -0.113 & 0.115 & & 0.393 \\
\hline \multirow[t]{2}{*}{ Ncf } & Loss & 26,885 & -0.441 & -0.559 & 0.720 & -0.668 & -0.293 & -0.379 & -0.063 \\
\hline & Profit & 100,771 & 0.118 & & 0.272 & -0.020 & 0.086 & & 0.212 \\
\hline \multirow[t]{2}{*}{$\mathrm{Nr}$} & Loss & 26,885 & 0.104 & 0.132 & 0.325 & -0.095 & 0.058 & 0.078 & 0.253 \\
\hline & Profit & 100,771 & -0.028 & & 0.166 & -0.115 & -0.020 & & 0.068 \\
\hline \multirow[t]{2}{*}{$\mathrm{X} / \mathrm{P}$} & Loss & 26,885 & -0.170 & -0.269 & 0.222 & -0.211 & -0.092 & -0.169 & -0.037 \\
\hline & Profit & 100,771 & 0.099 & & 0.080 & 0.047 & 0.077 & & 0.125 \\
\hline \multirow[t]{2}{*}{$\Delta \mathrm{X} / \mathrm{P}$} & Loss & 26,882 & -0.074 & -0.108 & 0.264 & -0.166 & -0.064 & -0.076 & 0.005 \\
\hline & Profit & 100,771 & 0.034 & & 0.124 & -0.006 & 0.012 & & 0.039 \\
\hline \multirow[t]{2}{*}{ Beta } & Loss & 26,825 & 1.241 & 0.159 & 0.820 & 0.692 & 1.171 & 0.137 & 1.706 \\
\hline & Profit & 100,638 & 1.082 & & 0.626 & 0.661 & 1.034 & & 1.439 \\
\hline \multirow[t]{2}{*}{ Size } & Loss & 26,885 & 3.821 & -1.364 & 2.080 & 2.321 & 3.645 & -1.436 & 5.169 \\
\hline & Profit & 100,771 & 5.185 & & 2.228 & 3.517 & 5.081 & & 6.720 \\
\hline \multirow[t]{2}{*}{$\mathrm{B} / \mathrm{M}$} & Loss & 26,885 & 0.993 & 0.146 & 0.771 & 0.424 & 0.778 & 0.086 & 1.332 \\
\hline & Profit & 100,771 & 0.847 & & 0.604 & 0.419 & 0.692 & & 1.097 \\
\hline \multirow[t]{2}{*}{ Lev } & Loss & 26,826 & 0.248 & 0.018 & 0.212 & 0.039 & 0.225 & 0.002 & 0.404 \\
\hline & Profit & 100,640 & 0.230 & & 0.169 & 0.084 & 0.223 & & 0.348 \\
\hline \multirow[t]{2}{*}{ Zscore } & Loss & 26,037 & 2.843 & -2.089 & 4.557 & 0.298 & 2.168 & -1.997 & 4.465 \\
\hline & Profit & 95,224 & 4.932 & & 3.628 & 2.563 & 4.165 & & 6.419 \\
\hline
\end{tabular}


Table 2: Summary statistics.

Panel B: Change in firm characteristics of loss observations

\begin{tabular}{lcccccccc}
\hline Variable & $N$ & Mean & $\begin{array}{c}\text { Diff. in } \\
\text { Mean }\end{array}$ & $\begin{array}{c}\text { Std. } \\
\text { Dev. }\end{array}$ & Q1 & Median & $\begin{array}{c}\text { Diff. in } \\
\text { Median }\end{array}$ & Q3 \\
\hline X/P & 26,458 & $\mathbf{- 0 . 1 7 1}$ & $\mathbf{- 0 . 1 2 2}$ & 0.222 & -0.212 & $\mathbf{- 0 . 0 9 2}$ & $\mathbf{- 0 . 0 7 6}$ & -0.037 \\
lagX/P & 26,458 & $\mathbf{- 0 . 0 4 9}$ & & 0.154 & -0.101 & $\mathbf{- 0 . 0 1 6}$ & & 0.038 \\
& & & & & & & & \\
Beta & 24,152 & $\mathbf{1 . 2 3 2}$ & $\mathbf{- 0 . 0 3 7}$ & 0.796 & 0.696 & $\mathbf{1 . 1 6 6}$ & $\mathbf{- 0 . 0 2 6}$ & 1.684 \\
lagBeta & 24,152 & $\mathbf{1 . 2 6 9}$ & & 0.822 & 0.716 & $\mathbf{1 . 1 9 2}$ & & 1.734 \\
& & & & & & & & \\
B/M & 26,885 & $\mathbf{0 . 9 9 3}$ & $\mathbf{0 . 0 4 6}$ & 0.771 & 0.424 & $\mathbf{0 . 7 7 8}$ & $\mathbf{0 . 0 2 7}$ & 1.332 \\
lagB/M & 26,885 & $\mathbf{0 . 9 4 7}$ & & 0.721 & 0.419 & $\mathbf{0 . 7 5 1}$ & & 1.261 \\
& & & & & & & & \\
Zscore & 25,959 & $\mathbf{2 . 8 4 6}$ & $\mathbf{- 1 . 5 2 0}$ & 4.559 & 0.299 & $\mathbf{2 . 1 7 4}$ & $\mathbf{- 1 . 1 0 9}$ & 4.469 \\
lagZscore & 25,959 & $\mathbf{4 . 3 6 6}$ & & 5.109 & 1.270 & $\mathbf{3 . 2 8 3}$ & & 6.005 \\
& & & & & & & & \\
Lev & 26,809 & $\mathbf{0 . 2 4 8}$ & $\mathbf{0 . 0 2 8}$ & 0.212 & 0.039 & $\mathbf{0 . 2 2 5}$ & $\mathbf{0 . 0 3 1}$ & 0.404 \\
lagLev & 26,809 & $\mathbf{0 . 2 2 0}$ & & 0.195 & 0.026 & $\mathbf{0 . 1 9 4}$ & & 0.366 \\
\hline
\end{tabular}

Panel C: Correlation coefficients (left corner: the loss sample; right corner: the profit sample)

\begin{tabular}{lcccccc}
\hline Variable & Ret & $\mathrm{Ncf}$ & $\mathrm{Nr}$ & $\mathrm{X} / \mathrm{P}$ & $\Delta \mathrm{X} / \mathrm{P}$ & Beta \\
\hline \multirow{2}{*}{ Ret } & & 0.508 & 0.522 & 0.346 & 0.254 & 0.021 \\
& & $(0.000)$ & $(0.000)$ & $(0.000)$ & $(0.000)$ & $(0.000)$ \\
& & & & & & \\
$\mathrm{Ncf}$ & 0.279 & & -0.011 & 0.263 & 0.537 & 0.038 \\
& $(0.000)$ & & $(0.001)$ & $(0.000)$ & $(0.000)$ & $(0.000)$ \\
& & & & & & \\
$\mathrm{Nr}$ & 0.279 & -0.627 & & 0.055 & -0.095 & -0.036 \\
& $(0.000)$ & $(0.000)$ & & $(0.000)$ & $(0.000)$ & $(0.000)$ \\
& & & & & & \\
$\mathrm{X} / \mathrm{P}$ & 0.002 & 0.392 & -0.399 & & 0.379 & -0.012 \\
& $(0.699)$ & $(0.000)$ & $(0.000)$ & & $(0.000)$ & $(0.000)$ \\
& & & & & & \\
$\Delta \mathrm{X} / \mathrm{P}$ & 0.158 & 0.430 & -0.260 & 0.336 & & 0.038 \\
& $(0.000)$ & $(0.000)$ & $(0.000)$ & $(0.000)$ & & $(0.000)$ \\
& & & & & & \\
Beta & 0.038 & -0.007 & 0.006 & 0.037 & 0.077 & \\
& $(0.000)$ & $(0.281)$ & $(0.322)$ & $(0.000)$ & $(0.000)$ & \\
\hline
\end{tabular}

Table 2 presents summary statistics for the variables used in the analyses. Panel A reports descriptive statistics for the loss and profit samples. Panel B reports changes in firm characteristics of loss observations before and after reporting losses. Panel C reports Pearson correlation coefficients between the variables for 
the loss and profit observations, respectively. All variables are defined in the appendix. In the first two panels, numbers in bold font represent variables that are significantly different from zero at the .001 level. In Panel C, p-values are presented in parentheses. All variables are winsorized at the bottom and top $1 \%$ extremes.

\subsection{Empirical results}

Discussion of the results is divided into three sections. Section 5.2.1 discusses the tests of Hypotheses 1 and 2; Section 5.2.2 provides results on Hypotheses 3 and 4 . Section 5.2.3 presents several extensions. All standard errors of regression coefficients are estimated using the two-dimensional clustering approach at the firm and year levels (Petersen, 2009).

\subsubsection{Tests of Hypotheses 1 and 2}

The first hypothesis (H1) is that negative earnings are positively/negatively associated with cash flow news $(N c f) /$ discount rate news $(N r)$. The second hypothesis $(\mathrm{H} 2)$ predicts that the overall return-earnings relation for loss firms is dampened by the offsetting news components. Hayn (1995) uses a regression of realized stock returns on negative earnings to study the relation between returns and losses (Eq. (9)). When the discount rate news mutes the effect of cash flow news on realized returns, this method does not capture the two separate components of the information content of losses. Following Hecht and Vuolteenaho (2006), I regress each of the news components in realized returns on losses to study how losses convey cash flow news and discount rate news (Eq. (10a, b)). Since the Vuolteenaho (2002) return decomposition method yields 
return components that are additive and comparable, the coefficients from each component regression also have the same properties (Eq. (10)). Equation (10c) will be discussed separately in Section 5.2.3.

The first panel of Table 3 presents the results from pooled regressions for the loss sample, the profit sample, and the entire sample, respectively. ${ }^{12}$ I focus on the coefficients on the earnings variable $(X / P)$ in regressions where the dependent variable is realized returns (Ret) or the news components considered separately, i.e., $\beta_{0}, \beta_{1}$, and $\beta_{2}$ in equations (9) and (10). Based on the prediction that losses and profits have different implications for cash flow news $(N c f)$ and discount rate news $(N r)$, I separately estimate the regressions for the loss sample (results in the first three columns of Panel A) and the profit sample (results in the second three columns of Panel A). The earnings response coefficients (ERC) are similar to those reported in previous research (e.g., Hayn, 1995): the ERC $\left(\beta_{0}\right)$ for loss firms is 0.006 (t-stat. $\left.=0.14\right)$, and the ERC $\left(\beta_{0}\right)$ for profit firms is 2.128 $(\mathrm{t}$-stat. $=11.95)$ in Panel A. There are similar differences in the adjusted $\mathrm{R}^{2}$ of the returnearnings regressions $\left(R^{2}\right)$. $R^{2} R^{\prime}$ s for the loss sample and the profit sample are $0.0 \%$ and

\footnotetext{
12 I also consider firm-specific regressions. However, firms cannot incorporate losses indefinitely according to the abandonment option assumption (e.g., Hayn, 1995), so most firms that experience losses also report profits in the history. I address this issue by including a firm-fixed effect in the regressions of return/returncomponents on earnings. The (untabulated) results are consistent with those in Table 3. In addition, I cumulate earnings and returns (return components) over 1, 3, or 5 years, and find that cumulated losses are positively associated with cumulated cash flow news and negatively associated with cumulated discount rate news (untabulated results).
} 
$12.0 \%$, respectively. In Hayn (1995), the ERC $\left(\beta_{0}\right)$ for loss firms (profit firms) is $0.01(2.62)$

and the $R^{2}{ }_{R}$ for loss firms (profit firms) is $0.0 \%(16.9 \%) .{ }^{13}$

${ }^{13}$ My ERC and $R^{2} R$ are lower than those in Hayn (1995), since I have a longer sample period. When I use the sample prior to 1991, the (untabulated) results are close to those in Hayn (1995). This is also consistent with the findings in Collins, Maydew, and Weiss (1997) that the association between stock price and earnings has declined over the past forty years. According to Collins et al. (1997), the declining ERC and $R^{2} R$ in my paper can be, at least partially, attributable to the increasing frequency of losses. 


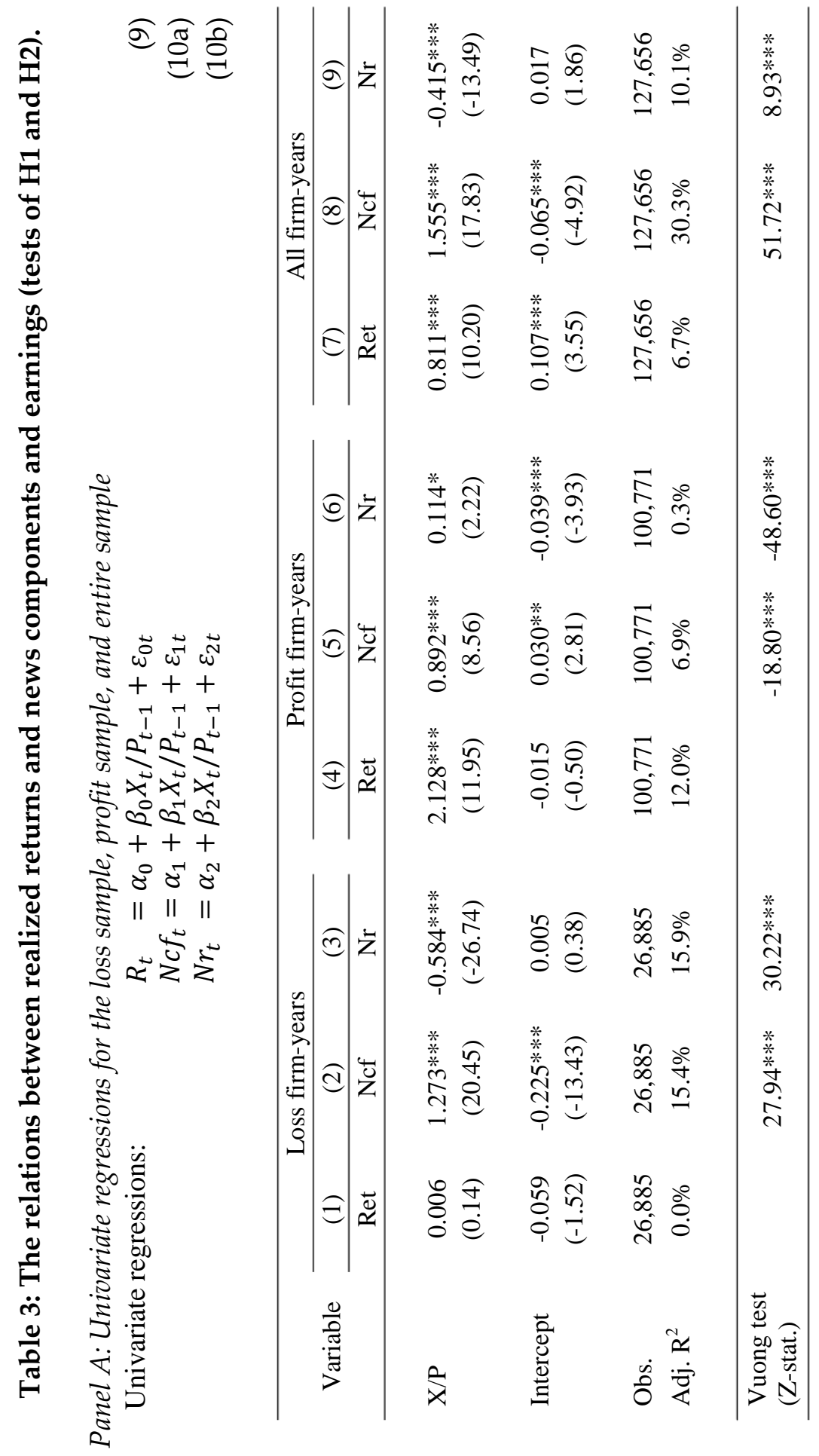




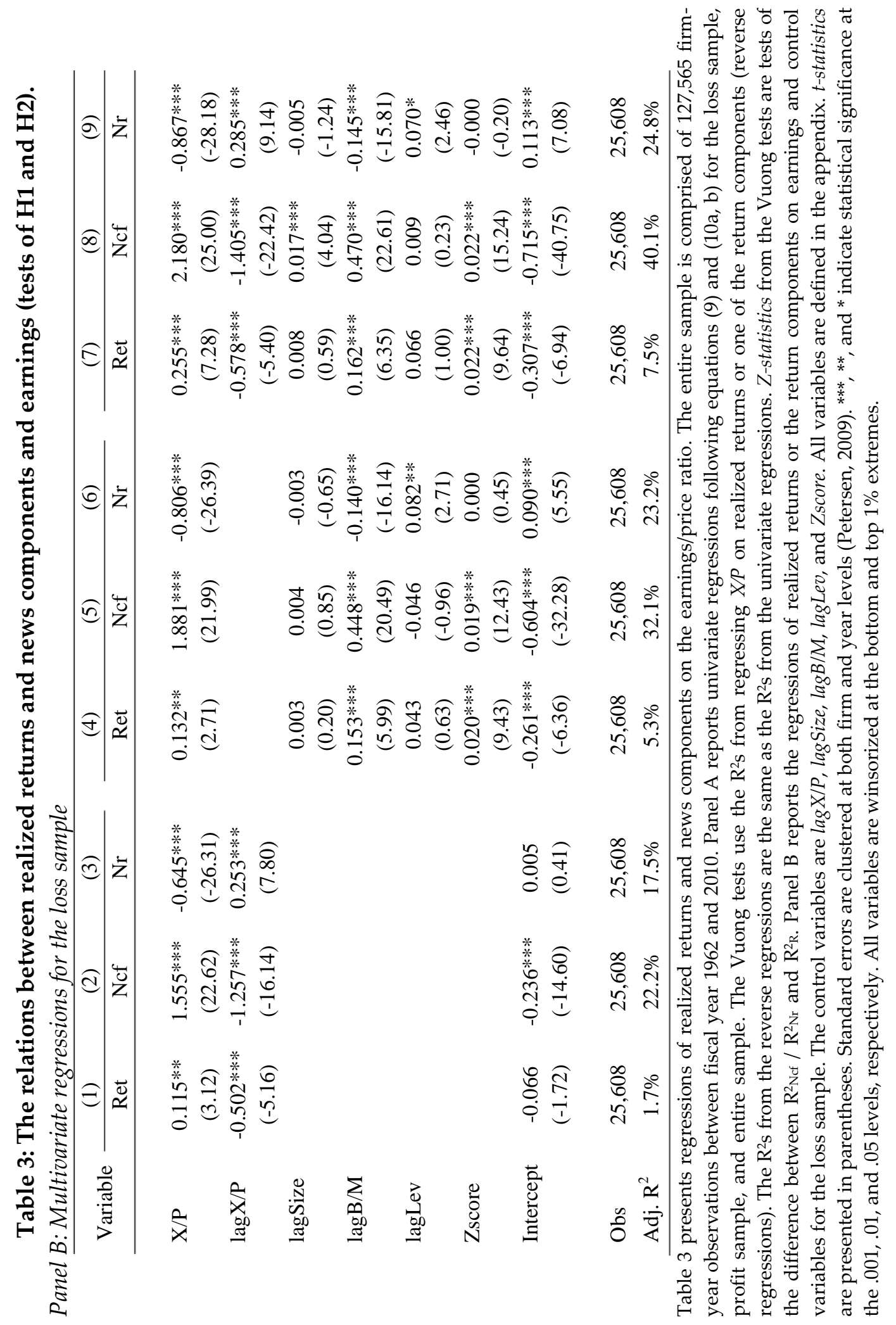


Results in Panel A of Table 3 show that, for the loss sample, cash flow news (Ncf) is positively related to earnings (which is itself negative, so the cash flow news is valuedecreasing) and discount rate news $(\mathrm{Nr})$ is negatively related to earnings, so the discount rate news is value-increasing (expected-return-decreasing). The coefficients on X/P (which is always negative) are $1.273\left(\beta_{1}, \mathrm{t}\right.$-stat. $\left.=20.45\right)$ and $-0.584\left(\beta_{2}\right.$, t-stat. $\left.=-26.74\right)$ in columns 2 and 3, respectively. This result is consistent with my first hypothesis. Under the view that $(i)$ the likelihood of abandonment is higher for loss firms than for profit firms and (ii) the abandonment option limits both downside value and risk, reporting a loss conveys negative news about future cash flows and positive (expected return decreasing) news about discount rates contemporaneously. These two types of news have offsetting effects on realized returns, so the return-earnings relation for loss firms is dampened, as illustrated by a comparison of adjusted $R^{2} S$ and slope coefficients of regressions in columns $1-3$. The adjusted $R^{2} \mathrm{~S}$ in column $1\left(R^{2} R\right)$, column $2\left(R^{2} \mathrm{Ncf}_{\mathrm{f}}\right)$, and column $3\left(R^{2} N_{r}\right)$ represent the portion of stock returns (Ret), cash flow news (Ncf), and discount rate news $(\mathrm{Nr})$ explained by losses, respectively. I use Vuong's Z-statistics (1989) to compare $R^{2}{ }_{N c f}$ or $R^{2} N r$ with $R^{2} R^{14}$ Columns 1-3 in Panel A show that $R^{2}{ }_{N c f}(15.4 \%)$ and $R^{2} N r(15.9 \%)$ are both significantly larger (at the .001 level or better) than $R^{2} R(0.0 \%)$,

\footnotetext{
${ }^{14}$ Vuong's (1968) Z-statistics compare the explanatory powers $\left(R^{2} s\right)$ of regressions that have the same dependent variable but different independent variables. I calculate the $R^{2}$ by regressing earnings on realized returns or each of the return components (reverse regression) for the Vuong test. For a univariate regression, the $\mathrm{R}^{2}$ of the reverse regression is the same as that of the original regression, so I can use the Vuong Zstatistics to compare $R^{2} \mathrm{~S}$ from reverse regressions of earnings on realized returns or each of the return components.
} 
indicating that losses are informative about each of the news components $(z$-stat. $=27.94$ and 30.22), although the overall return-earnings relation is weak. Also, the magnitude of $\beta_{0}(0.006, \mathrm{t}$-stat. $=0.14)$ is substantially lower than that of both $\beta_{1}(1.273, \mathrm{t}$-stat. $=20.45)$ and $\beta_{2}(-0.584$, t-stat. $=-26.74)$. Taken together, the results in Panel A of Table 3 support H1 and H2.

Panel A of Table 3 also provides results for the profit sample. For the profit sample, $\beta_{0}, \beta_{1}$, and $\beta_{2}$ are all reliably positive $\left(\beta_{0}=2.128\right.$, $\mathrm{t}$-stat. $=11.95 ; \beta_{1}=0.892$, $\mathrm{t}$-stat. $=$ 8.56; $\beta_{2}=0.114$, t-stat. $\left.=2.22\right)$, indicating that positive earnings provide favorable cash flow news and favorable discount rate news (value-increasing). Also, the $R^{2}{ }_{R}(12.0 \%)$ is significantly higher than both $R^{2}{ }_{N c f}(6.9 \%)$ and $R^{2}{ }_{N r}(0.3 \%)$ for profit firms (z-stat. $=-18.80$ and -48.60). These results imply that the profits are more associated with cash flow news than with discount rate news.

A comparison of results for the loss sample and profit sample in Panel A shows that the $R^{2}{ }_{N c f}$ and $R^{2}{ }_{N r}$ for the loss sample (15.4\% and $\left.15.9 \%\right)$ exceed those for the profit sample $(6.9 \%$ and $0.3 \%)$, while the overall $R^{2} R$ for the loss sample $(0.0 \%)$ is lower than that for the profit sample (12.0\%). This finding suggests that losses are more informative than profits about cash flow news and discount rate news when considered separately; the overall return-earnings association is weaker for the loss observations because the two types of news influence returns in the opposite directions. 
The last three columns in Panel A report the results of univariate regressions for the entire sample. The ERC $\left(\beta_{0}\right)$ for the entire sample lies between those for the loss and profit samples, and so does the $R^{2} R\left(\beta_{0}=0.811\right.$ and $\left.R^{2} R=6.7 \%\right)$. Since $X / P$ is positively associated with $N c f$ for both the loss and profit samples, the association between earnings and cash flow news is strengthened for the whole sample. Panel A shows that $\beta_{1}$ in column 8 is larger in magnitude than the analogous coefficients in column 2 and 5 $\left(\beta_{1}=1.273,0.892\right.$, and 1.555 in columns 2,5 , and 8 , respectively). The explanatory power of $X / P$ for $N c f\left(R^{2} N c f\right)$ increases, from $15.4 \%$ and $6.9 \%$, to $30.3 \%$. On the other hand, the associations between $X / P$ and $N r$ have opposite signs for the loss and profit samples, weakening the relation between earnings and discount rate news for the entire sample. As a result, $\beta_{2}$ in column $9\left(\beta_{2}=-0.415\right.$, $\mathrm{t}$-stat. $\left.=-13.49\right)$ is smaller in magnitude than that in column $1\left(\beta_{2}=-0.584\right.$, t-stat. $\left.=-26.74\right)$, and so does the $R^{2}{ }_{N r}\left(R^{2}{ }_{N r}=15.9 \%\right.$ in column 1 , and $R^{2}{ }_{N r}=10.1 \%$ in columns 9). Consistent with Hecht and Vuolteenaho (2006), earnings are negatively related to discount rate news for the sample as a whole. Taken together, the evidence in Panel A suggests that the offsetting relations between earnings and the news components exist in the loss observations, not the profit observations.

Panel B of Table 3 reports the regression results for the loss sample with controls for (one-year) lagged earnings-to-price ratio $(\operatorname{lag} X / P)$, lagged firm size $($ Size), lagged book-to-market ratio $(B / M)$, lagged leverage ratio (lagLev), and current Altman Z score (Zscore). As discussed previously, these variables represent expected earnings level, exit 
value and operation value at the beginning of the year, growth opportunity, capital structure, and probability of bankruptcy, respectively. I focus on the results in the last three columns, where the regressions contain all control variables. Controlling for lagged earnings $(\operatorname{lag} X / P)$, the regression coefficient on current earnings $(X / P)$ reflects the associations between the return components and the unexpected part of current earnings (earning surprise). The coefficients on $X / P$ in columns $2-3$ of Panel $B$ have larger magnitudes than their counterparts in Panel A, indicating that the news components are more associated with the unexpected part in losses than with losses per se. Consistent with $\mathrm{Li}$ (2011) and equation (15), the coefficient on lagB/M is reliably positive in column 7 (coeff. $=0.162$, t-stat. $=6.35)$, suggesting that loss firms with larger exit values have higher realized returns. The positive coefficient on Zscore implies that loss firms with lower probability of bankruptcy have more positive realized returns (coeff. $=0.022$, t-stat. $=9.64)$. In addition, the results in the eighth and ninth columns show that firms with larger size (Size), more exit value $(B / M)$, or lower probability of bankruptcy (Zscore) have more positive cash flow news, and those with lower book-tomarket ratio $(B / M)$ or higher leverage $(L e v)$ have more positive discount rate news. In sum, results in Table 3 are consistent with Hypotheses 1 and 2.

\subsubsection{Tests of Hypotheses 3 and 4}

The third and fourth hypotheses ( $\mathrm{H} 3$ and $\mathrm{H} 4)$ relate the informativeness of losses to the earnings attributes and other characteristics of loss firms. The third hypothesis 
(H3) predicts that losses firms that report more transitory losses or more nonrecurring charges will have smaller downward revisions to both the valuation numerator and denominator; the fourth hypothesis (H4) predicts that loss firms will have smaller downward revisions to both the valuation numerator and denominator, when they have more R\&D spending, more cash holdings, more external financing, more specialized assets, or fewer industry competitors. As discussed previously, the extent to which a reported loss revises investors' estimation of the valuation numerator and denominator depends on earnings attributes and firm characteristics (e.g., Joos and Plesko, 2005; Darrough and Ye, 2007; Li, 2011).

The first measure of earnings attributes, $L_{1}$, is the predicted probability of loss reversal (PLR) from the logistic regression model in Joos and Plesko (2005). This model distinguishes loss firms that are more likely to regain profitability from those that are more likely to remain in loss positions (Li, 2011). Hayn (1995) argues that losses signal that future earnings could be low enough to make the abandonment option attractive, so the expected persistence of current losses is a measure of the likelihood of abandonment. A higher predicted probability of loss reversal $\left(L_{1}: P L R\right)$ indicates lower likelihood of abandonment, reducing the informativeness of reported losses. (The appendix reports the details of the construction of the proxies for earnings attributes and firm characteristics.) 


$$
\begin{aligned}
& L R=\beta_{1} R O A+\beta_{2} \text { pastROA }+\beta_{3} \text { Size }+\beta_{4} \text { SGR }+\beta_{5} \text { FirstLoss }+ \\
& \beta_{6} \text { LossSeq }+\beta_{7} \text { Divdum }+\beta_{8} \text { Divstop }+\varepsilon,
\end{aligned}
$$

where $L R=($ loss reversal $)$ is an indicator variable equal to 1 if the firm becomes profitable in the subsequent year, and 0 otherwise; $R O A=$ return on assets; pastROA= average $R O A$ over year $t-5$ to $t-1$; Size $=$ natural logarithm of current market value of equity; $S G R=$ sales growth rate; FirstLoss $=$ an indicator variable equal to 1 if the firm was profitable in year $t-1$, and 0 otherwise; LossSeq $=$ an ordinal variable that counts the number of sequential losses over the past five years before the current loss (from year $t$ 5 to $t-1) ;$ Divdum $=$ an indicator variable equal to 1 if the firm is paying dividends, and 0 otherwise; Divstop $=$ an indicator variable equal to 1 if the firm stopped paying dividends in the current year, and 0 otherwise.

Following Joos and Plesko (2005), I estimate equation (16) annually using 5-year rolling windows (year $t-4$ to year $t$ ) and compute the predicted probability of loss reversal $(P L R)$ for the current year (year $t)$. Panel A1 of Table 4 reports the coefficient estimates of equation (16) using the Fama-MacBeth (1973) approach for fiscal years 1970 - 2010. Consistent with Joos and Plesko (2005), Panel A1 shows that losses are more likely to reverse for firms with higher profitability, larger size, shorter loss sequence, and more dividend payment.

The second measure of earnings attributes, $L_{2}$, is nonrecurring charges $\left(L_{2}\right.$ : SPIW). Following Darrough and Ye (2007), it is defined as the absolute value of negative 
special items, deflated by one-year lagged market value of equity. Darrough and Ye (2007) also use four measures $\left(L_{3}-L_{6}\right)$ of the sustainability of loss firms, including R\&D expenditures $\left(L_{3}: R D X\right)$, cash holdings $\left(L_{4}:\right.$ Cash), new stock issues ( $\left.L_{5}: S T K I S S\right)$, and new debt issues ( $L_{6}$ : DBTISS). The measures in Darrough and Ye (2007) $\left(L_{2}-L_{6}\right)$ are proxies for the sustainability of loss firms, and therefore inversely related to the informativeness of reported losses. All these measures $\left(L_{3}-L_{6}\right)$ are scaled by the market value of equity at the beginning of the year.

The other measures of firm characteristics $\left(L_{7}-L_{9}\right)$ are asset structure and the number of industry competitors. According to Berger et al. (1996), it is more difficult to dispose of specialized assets, so firms with more specialized assets have a lower likelihood of exercising the abandonment option. Following Berger et al. (1996), I calculate asset structure as the ratios of fixed assets to total assets $\left(L_{7}:\right.$ PPE/AT) and inventory to current assets $\left(L_{8}: I N V / A C T\right)$. As discussed previously, industries with more members are more likely to have markets for operating assets and higher competition, so losses reported by firms in such industries would increase the likelihood of abandonment. The last measure is defined as the natural logarithm of the number of firms in the same four-digit SIC industry $\left(L_{9}: \ln (\operatorname{Ind} \#)\right)$. The likelihood of abandonment decreases in the portion of specialized assets $\left(L_{7}\right.$ and $\left.L_{8}\right)$ and increases in the number of industry members $\left(L_{9}\right)$. 
Panel A2 of Table 4 reports descriptive statistics of the measures of earnings attributes $\left(L_{1}\right.$ and $\left.L_{2}\right)$ and firm characteristics $\left(L_{3}-L_{9}\right)$. The results show that losses have $37 \%$ predicted probability of reversing into profits in the following year, and more than half of reported losses contain nonrecurring charges. On average, 30\% of loss firms' total assets are comprised of fixed assets, and $28 \%$ of their current assets are inventories. Seventy-five percent of loss firms belong to 4-digit SIC industries with more than four other firms. To study the relations between these measures, I regress the predicted probability of loss reversal $\left(L_{1}: P L R\right)$ on the other eight variables, as PLR is the measure most relevant to the "abandonment option" (e.g., Joos and Plesko, 2005). The (untabulated) results show that PLR is positively associated with Cash, DBTISS, PPE/AT, and INVIACT, and negatively associated with SPIW, RDX, SKTISS, and $\log (\operatorname{Ind\# ).}$

Each of the variables $\left(L_{1}-L_{9}\right)$ is introduced into equations $(10 \mathrm{a}, \mathrm{b})$ as both a main effect and an interaction with $X / P$ (Eq. (12)). The results are reported in Panel B of Table 4. Tests of $\mathrm{H} 3$ and $\mathrm{H} 4$ focus on the coefficients on the interaction terms $\left(\gamma_{1}\right.$ and $\left.\gamma_{2}\right)$ in equations (12a, b). Larger values of $L_{i}(i=1-8)$ are associated with lower informativeness of losses, while a larger value of $L_{9}$ is associated with higher informativeness of losses. Thus, $\gamma_{1}<0$ and $\gamma_{2}>0$ for $X / P^{\prime}$ s interaction with $L_{i}(i=1-$ 8), while $\gamma_{1}>0$ and $\gamma_{2}<0$ for $X / P^{\prime}$ s interaction with $L_{9}$.

Panel B of Table 4 reports the effect of earnings attributes or firm characteristics on the relation between the news components and earnings for the loss firm-years. The 
coefficients on earnings' interactions with PLR and SPIW are both reliably negative in column 1 (coeff. $=-1.245$ and -1.363 , $\mathrm{t}$-stat. $=-3.99$ and -8.48 ), and both reliably positive in column 2 (coeff. $=0.532$ and 0.702 , t-stat. $=5.30$ and 8.09). Prior literature shows that loss firms with more transitory losses or more nonrecurring charges have lower likelihood of abandonment (e.g., Joos and Plesko, 2005; Darrough and Ye, 2007), so such loss firms would experience less adverse cash flow news and less favorable discount rate news than other loss firms. The coefficients on earnings' interactions with Cash and DBTISS are negative and significant in column 3 (coeff. $=-0.290$ and -0.125 , t-stat. $=-5.37$ and 3.30), and positive and significant in column 4 (coeff. $=0.110$ and 0.054 , t-stat. $=2.87$ and 2.81). Darrough and Ye (2007) argue that loss firms with more cash holdings or debt financing have higher sustainability, so losses reported by such firms are less informative about cash flows and risk. Furthermore, the coefficient on earnings' interaction with INV/ACT is $-0.612(\mathrm{t}$-stat. $=-3.79)$ in column 5 and $0.262(\mathrm{t}$-stat. $=4.59)$ in column 6. Since the likelihood of abandonment is inversely related to asset specialization (e.g., Berger et al., 1996), loss firms with more specialized asset structures have smaller downward revisions in both valuation numerator and denominator. Finally, the coefficients on earnings' interaction with $\log (\operatorname{Ind} \#)$ are reliably positive and negative in the fifth and sixth columns (coeff. $=0.125$ and -0.052 , t-stat. $=6.55$ and -6.62 ), respectively. Thus, the number of industry competitors affects the informativeness of losses in conveying cash flow news and discount rate news. 
The results in the last two columns are consistent with those in the first six columns, except for the coefficients on earnings' interactions with RDX and DBTISS. When all the measures of the earnings attributes and firm characteristics are included, the coefficients on earnings' interaction with $R D X$ become significant (coeff. $=-0.675$ and 0.541 , t-stat. $=-3.23$ and 5.43), and those on earnings' interaction with DBTISS become insignificant (coeff. $=-0.024$ and 0.020 , t-stat. $=-0.60$ and 1.03 ) in the last two columns. Taken together, the evidence in Panel B supports the third and fourth hypotheses (H3 and H4), showing that the informativeness of losses varies with earnings attributes and/or firm characteristics. That is, losses convey less adverse cash flow news and less favorable discount rate news for loss firms with more transitory losses, more nonrecurring charges, more cash holdings, more specialized asset structures, and fewer industry competitors 
Table 4: The effects of earnings attributes and firm characteristics on the relations between the news components and earnings (tests of $\mathrm{H} 3$ and $\mathrm{H} 4$ ).

Panel A: Summary statistics of the proxies for earnings attributes and firm characteristics

Panel A1. Logistic regression of loss reversal

\begin{tabular}{|c|c|c|c|c|c|c|c|c|}
\hline Variable & ROA & pastROA & Size & SGR & FirstLoss & LossSeq & Divdum & Divstop \\
\hline Predicted sign & + & + & + & $?$ & + & - & + & - \\
\hline Coeff. & 3.184 & 0.445 & 0.085 & 0.284 & -0.122 & -0.186 & 0.206 & -0.165 \\
\hline t-stat. & (9.34) & (1.05) & (2.61) & (3.13) & $(-1.02)$ & $(-2.96)$ & (3.52) & $(-1.50)$ \\
\hline \multicolumn{9}{|c|}{ Panel A2. Descriptive statistics } \\
\hline Variable & $N$ & Mean & SD & P5 & Q1 & Median & Q3 & P95 \\
\hline$L_{1}:$ PLR & 17,168 & 0.369 & 0.137 & 0.113 & 0.279 & 0.389 & 0.465 & 0.569 \\
\hline$L_{2}:$ SPIW & 17,168 & 0.064 & 0.116 & 0.000 & 0.000 & 0.005 & 0.075 & 0.331 \\
\hline$L_{3}: \operatorname{RDX}$ & 17,168 & 0.051 & 0.080 & 0.000 & 0.000 & 0.005 & 0.075 & 0.233 \\
\hline$L_{4}:$ Cash & 17,168 & 0.215 & 0.296 & 0.006 & 0.042 & 0.119 & 0.273 & 0.739 \\
\hline$L_{5}:$ DBTISS & 17,168 & 0.191 & 0.477 & 0.000 & 0.000 & 0.001 & 0.151 & 1.025 \\
\hline$L_{6}:$ STKISS & 17,168 & 0.031 & 0.097 & 0.000 & 0.000 & 0.002 & 0.010 & 0.189 \\
\hline$L_{7}: \mathrm{PPE} / \mathrm{AT}$ & 17,168 & 0.299 & 0.235 & 0.029 & 0.108 & 0.234 & 0.439 & 0.784 \\
\hline$L_{8}:$ INV/ACT & 17,168 & 0.280 & 0.227 & 0.000 & 0.060 & 0.265 & 0.459 & 0.668 \\
\hline$L_{9}: \log (\operatorname{Ind} \#)$ & 17,168 & 2.754 & 1.456 & 0.000 & 1.609 & 2.773 & 3.912 & 4.990 \\
\hline
\end{tabular}




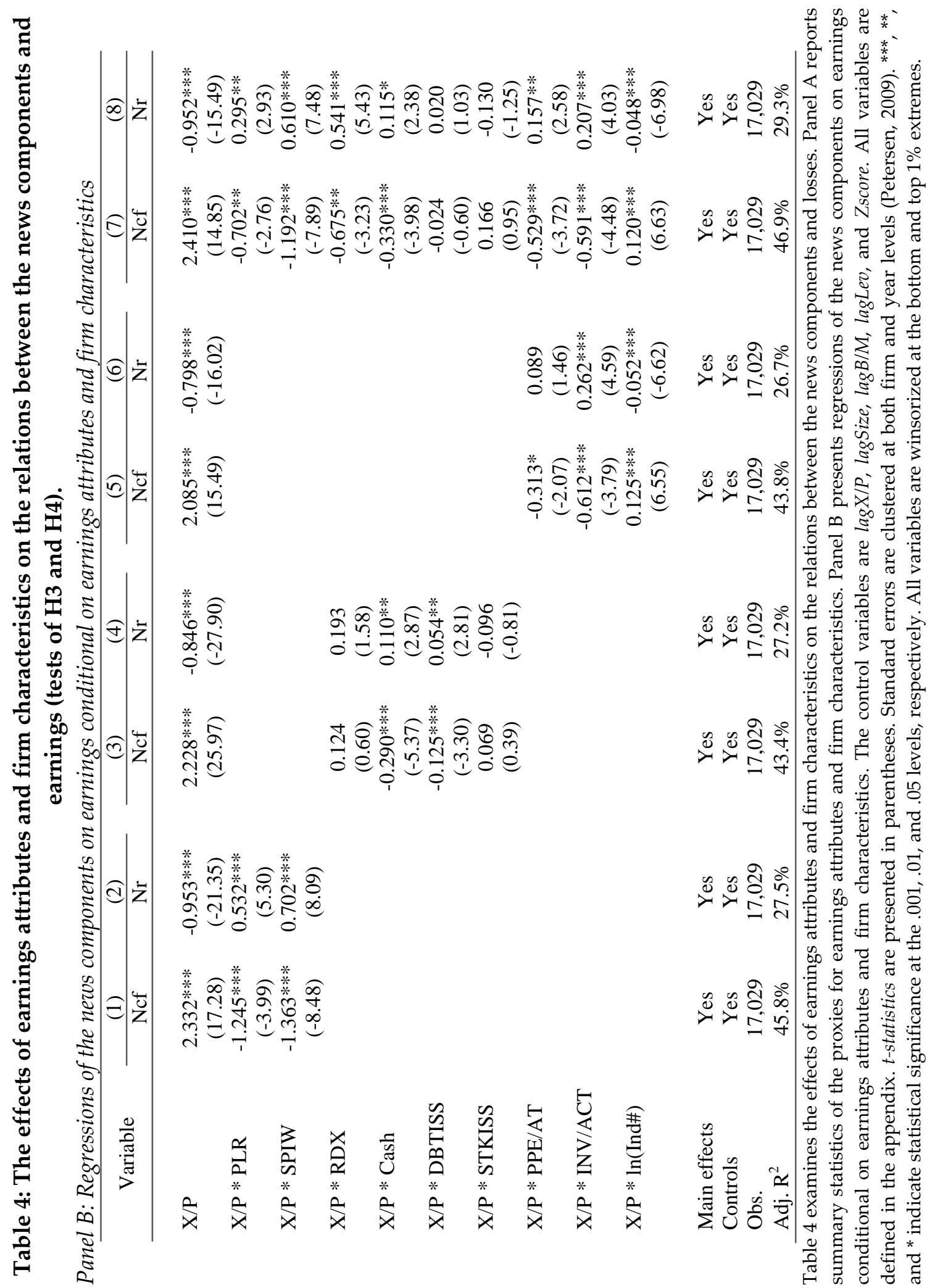




\subsubsection{Extensions}

I explore whether the return-earnings relation of losses is more dampened by discount rate news than by firm risk (expected return); whether losses act as a heuristic trigger of asset disposal; and whether certain earnings attributes and firm characteristics are related to loss firms' likelihood of abandonment. Lastly, I show how earnings quality of loss firms affects the informativeness of losses.

\subsubsection{Firm risk and the return-earnings relation of losses}

Prior literature shows that the earnings response coefficient (ERC) decreases with firm risk (e.g., Easton and Zmijewski, 1989), so Hayn (1995) examines whether the muted earnings response coefficient (ERC) associated with losses is attributable to the higher risk (expected return) of loss firms. Grouping loss and profit observations into portfolios according to their risk levels (proxied by bond ratings), she finds that (i) the ERC declines with the risk of loss observations; (ii) the ERC of losses is lower than that of profits within each risk portfolio. Thus, Hayn (1995) concludes that "the higher risk of the loss firms cannot, itself, explain the low informativeness of losses", which is measured by ERC. Based on Hayn's (1995) finding, I investigate whether the returnearnings relation of losses is more dampened by discount rate news than by firm risk (expected return). I employ two tests of the effect of firm risk (expected return) on the return-earnings relation of losses. The Vuolteenaho (2002) return decomposition method yields return components that are additive and comparable, so the coefficients on 
earnings from the component regressions (Eq. (10)) have the same properties. I regress expected return on earnings (Eq. (10c)) and compare the $\mathrm{R}^{2}$ and coefficient with those from the regressions of the news components on earnings (Eq. $(10 a, b))$ for the loss sample. Second, I test whether controlling for the return components changes the coefficient on $X / P$ in the regression of realized returns on losses.

The results of the first test are reported in Panel A of Table 5. $\log R$ is the natural logarithm of one plus the realized return and $E(\log R)$ equals $\log R$ minus the sum of the news components, i.e., $E(\log R)=\log R-N c f-N r .{ }^{15}$ As discussed above, the regression coefficients from the component regressions are additive $\left(\beta_{0}=\beta_{1}+\beta_{2}+\beta_{3}\right.$, see Eq. (11)) and their magnitudes are comparable. The coefficient on $X / P$ in column $1\left(\beta_{0}=0.092\right)$ equals the sum of those in columns $2-4\left(\beta_{1}=1.273, \beta_{2}=-0.584\right.$, and $\left.\beta_{3}=-0.596\right)$; similarly, the coefficient on $\mathrm{X} / \mathrm{P}$ in column $5\left(\beta_{0}=0.392\right)$ equals the sum of those in columns $6-8\left(\beta_{1}=2.180, \beta_{2}=-0.867\right.$, and $\left.\beta_{3}=-0.920\right) .{ }^{16}$ As predicted, $\beta_{3}$ in both columns 4 and 8 is reliably negative (at the .001 level), indicating that expected returns increase in the magnitude of losses. I use Vuong's Z-statistics (1989) to compare $R^{2} \log _{R}, R^{2}{ }_{\mathrm{Ncf}}$, or $R^{2} \mathrm{Nr}$ with $R^{2} E(\log R)$. The $\mathrm{R}^{2}$ in column $4\left(R^{2} E(\log R)=6.3 \%\right)$ is significantly larger than the $\mathrm{R}^{2}$ in column $1\left(R^{2} \log R=0.1 \%\right)$ and significantly smaller than those in columns 2 and $3\left(R^{2}{ }_{N c f}=\right.$

\footnotetext{
${ }^{15}$ The Vuolteenaho (2002) return decomposition method computes the news components using the natural logarithm of one plus the realized return $(\log R)$, rather than the realized return $(R e t)$ itself. In this subsection, I use $\log R$ to calculate expected return $(E(\log R))$ and measure stock return using $\log R$ that equals the sum of all the return components.

${ }^{16}$ The sum of the coefficients in columns $2-4$ equals 0.093 (not 0.092), and the sum of those in columns $6-8$ equals 0.393 (not 0.392 ), because of rounding.
} 
$15.4 \%$ and $R^{2}{ }_{N r}=15.9 \%$ ) (at the .001 level). The comparison between $R^{2} s$ implies that losses are more associated with the news components than with firm risk (expected return), so losses are more important in providing news than in reflecting firm risk. In particular, $R^{2}{ }_{\mathrm{N} r}$ is significantly larger than $R^{2} E\left(\log _{\mathrm{g}}\right)$ (at the .001 level), suggesting that the return-earnings relation of losses is more dampened by discount rate news than by firm risk (expected return). These results also confirm Hayn's (1995) argument that high firm risk per se cannot explain the muted return-earnings relation for losses. 


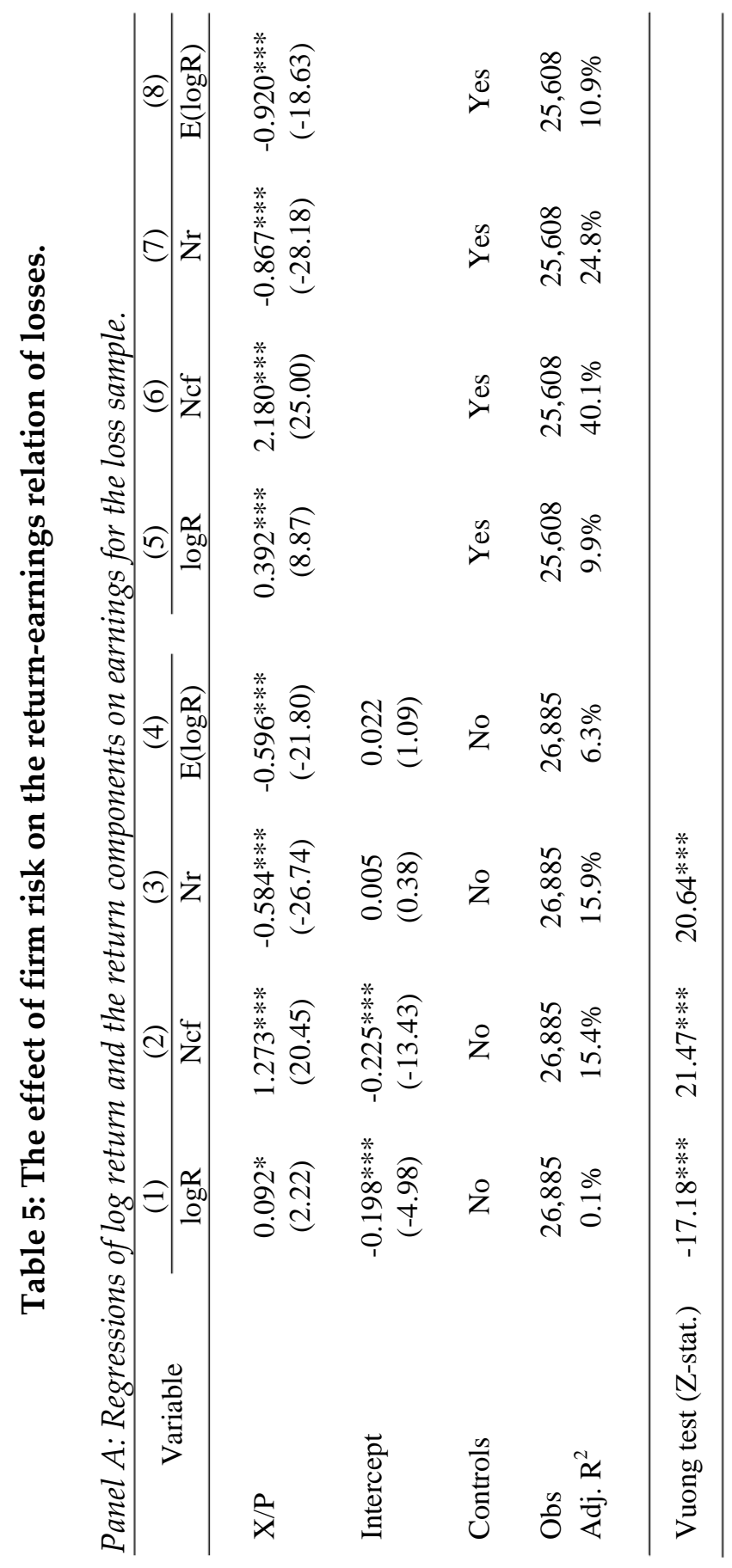


Table 5: The effect of firm risk on the return-earnings relation of losses.

Panel B: Regressions of log return on earnings and the return components for the loss sample

\begin{tabular}{lcccc}
\hline \multirow{2}{*}{ Variable } & $(1)$ & $(2)$ & $(3)$ & $(4)$ \\
\cline { 2 - 5 } $\mathrm{E}(\log \mathrm{R})$ & $0.497^{* * *}$ & $0.579^{* * *}$ & $0.467^{* * *}$ & $1.129^{* * *}$ \\
& $(21.18)$ & $(24.09)$ & $(23.90)$ & $(63.87)$ \\
$\mathrm{Ncf}$ & & & & $0.820^{* * *}$ \\
& & & & \\
$\mathrm{Nr}$ & & & $0.446^{* * *}$ & \\
& & & $(11.72)$ & \\
& & & & \\
$\mathrm{X} / \mathrm{P}$ & $0.389^{* * *}$ & $0.925^{* * *}$ & $1.209^{* * *}$ & $-0.356^{* * *}$ \\
& $(10.29)$ & $(20.16)$ & $(22.13)$ & $(-15.38)$ \\
& & & & \\
Controls & No & Yes & Yes & Yes \\
& & & & \\
Obs & 25,608 & 25,608 & 25,608 & 25,608 \\
Adj. $\mathrm{R}^{2}$ & $21.1 \%$ & $37.1 \%$ & $41.3 \%$ & $80.9 \%$ \\
\hline
\end{tabular}

Table 5 investigates the relation between firm risk (expected return) and the earnings response coefficient (ERC) for the loss sample. Panel A reports the regressions of realized returns, expected returns, or news components on the earnings/price ratio, following Hecht and Vuolteenaho (2006). The Vuong tests use the $R^{2} s$ from regressing $X / P$ on realized returns or one of the return components (reverse regressions). The $R^{2} s$ from reverse regressions are the same as the $R^{2} \mathrm{~s}$ from the univariate regressions. Z-statistics from the Vuong tests are tests of the difference between $R^{2} \log _{R} / R^{2}{ }_{N c f} / R^{2}{ }_{N r}$ and $R^{2} E(\log R)$. Panel $\mathrm{B}$ reports the results of regression of realized returns on the earnings/price ratio conditional on expected returns and the news components. The control variables are lagX/P, lagSize, lagB/M, lagLev, and Zscore. All variables are defined in the appendix. $t$-statistics are presented in parentheses. Standard errors are clustered at both firm and year levels (Petersen, 2009).***,**, and ${ }^{*}$ indicate statistical significance at the $.001, .01$, and .05 levels, respectively. All variables are winsorized at the bottom and top $1 \%$ extremes.

The results of the second test are shown in Panel B of Table 5. I use the expected return measure $(E(\log R)=\log R-N c f-N r)$ from the Vuolteenaho (2002) return decomposition to control for firm risk in the regression of realized returns on losses. The coefficient on $X / P$ is reliably positive in column 2 after controlling for firm risk and other control variables (coeff. $=0.925$, t-stat. $=20.16)$, indicating that losses have a negative effect on unexpected returns. In columns 3 and 4, I further control for one of the news 
components so that the coefficient on $X / P$ reflects the association of earnings with the other news component. In particular, the coefficient on $X / P$ is reliably negative after controlling for $N c f$ in column 4 (coeff. $=-0.356$, t-stat. $=-15.28$ ), while it is reliably positive after controlling for $\mathrm{Nr}$ (coeff. $=1.209$, t-stat. $=22.13$ ). These results provide further evidence to support the first hypothesis (H1).

The coefficient on $X / P$ in column 3 is larger than those in other columns. This phenomenon suggests that the ERC of losses is muted by both high firm risk and the favorable discount rate news, so it is important to separate the information about future cash flows from the information about risk in earnings when we consider the information content of losses. In sum, the results in Panel B confirm Hayn's (1995) argument that the high risk of loss firms alone (as reflected in the expected returns) cannot explain the muted return-earnings relation for losses.

\subsubsection{Losses, asset sales, and the news components}

Following prior literature, my paper is based on the assumption that shareholders will exercise the abandonment option rather than absorb losses indefinitely (e.g., Hayn, 1995; Joos and Plesko, 2007). Pinnuck and Lillis (2007) find that loss firms reduce the size and scope of their investments in labor, providing indirect evidence to support this assumption. I assess the validity of this assumption by studying the prevalence of asset sales in the year following a loss. 
Data on asset sales are obtained from the SDC Platinum mergers and acquisition (M\&A) database. This database categorizes each transaction as a merger, an acquisition, an asset acquisition, or an acquisition of certain assets. The sample of asset sales in this test consists of the transactions listed in the last two categories from 1985 to $2010 .{ }^{17} \mathrm{I}$ aggregate the value of all transactions in each firm-year. Panel A of Table 6 reports the sample composition of asset sales. There are 10,040 observations of asset sales in total.

I use two methods to test whether losses trigger asset sales in the subsequent year. First, I perform a logistic regression of an indicator variable of asset sales $(D A S)$ on the loss indicator (LOSS), where the dependent variable equals one if the firm sells assets in the following year, and zero otherwise, for the entire sample. Second, I regress DAS on earnings $(X / P)$ for the loss sample and profit sample separately. Thus, the loss indicator (LOSS) and earnings $(X / P)$ are the main variables of interest. Following Warusawitharana (2008), I use firm size (Size), stock return (Ret), book-to-market ratio $(B / M)$, leverage $(L e v)$, cash holdings (Cash), and sales growth rate (SGR) as control variables.

Panel B of Table 6 shows that the probability of asset sales in the following year (DAS) is positively associated with the loss indicator (LOSS) and negatively associated with the firm's earnings $(X / P)$. Specifically, the coefficient on LOSS is significantly

${ }_{17}$ According to Warusawitharana (2008), the SDC dataset provides comprehensive coverage on asset sales from 1985 onwards. 
positive in column1 (coeff. $=0.298, \mathrm{t}$-stat. $=8.31$ ), and the coefficients on $X / P$ are significantly negative in columns 1 and 2 (coeff. $=-0.592$ and -1.039 , t-stat. $=-5.43$ and 8.99). The marginal effect of the loss indicator (LOSS) on the likelihood of asset sales $(D A S)$ is $0.574\left(=\frac{1}{[1+\exp (-0.298)]}\right)$. Ceteris paribus, a firm's likelihood of abandonment increases by $57.4 \%$ after reporting a loss. Regressing $D A S$ on earnings $(X / P)$ for the loss and profit samples separately, I find that the coefficient on $X / P$ is reliably negative in column 3 (coeff. $=-0.649$, t-stat. $=-7.23)$ and insignificant in column 4 (coeff. $=-0.365$, $\mathrm{t}$ stat. $=-0.72$. This result implies that earnings are associated with likelihood of abandonment for loss firms, but not profit firms.

Tests of $\mathrm{H} 3$ and $\mathrm{H} 4$ show that certain earnings attributes and firm characteristics affect the informativeness of losses by assuming that they are related to the likelihood of abandonment. Panel $\mathrm{C}$ of Table 6 examines the validity of this assumption. I introduce each measure of earnings attributes or firm characteristics from Section 5.2.2 into the logistic regression of the asset sale indicator $(D A S)$ on earnings $(X / P)$ as both a main effect and an interaction with $X / P$. Control variables are the same as those in Panel $B$. When all the measures of earnings attributes and firm characteristics are included, the signs on the earnings' interactions with those measures are consistent with predictions, except for the interaction with Cash. The coefficients on earnings' interactions with SPIW and PPE/AT are both positive and significant at the .01 level (coeff. $=2.484$ and $1.289, \mathrm{t}-$ stat. $=3.76$ and 2.63 ) in column 4 , indicating that loss firms with more nonrecurring 
charges and/or more specialized asset structure have lower likelihood of abandonment than other loss firms.

In conclusion, Table 6 provides support for the two key assumptions of my analysis, namely that, (i) reported losses move shareholders closer to the threshold of exercising the abandonment option; and that (ii) certain earnings attributes and firm characteristics affect loss firms' likelihood of abandonment.

Table 6: Losses and asset sales.

Panel A: Sample selection

\begin{tabular}{lrrr}
\hline \multicolumn{1}{c}{ Sample development } & Freq. & & Percent \\
\hline No asset sales & 76,177 & & $88.35 \%$ \\
Asset sales (SDC) & 10,040 & & $11.65 \%$ \\
$\quad$ Value disclosed & & 5,431 & \\
$\quad$ Value not disclosed & & 4,609 & \\
Total & 86,217 & & $100.00 \%$ \\
\hline
\end{tabular}


Table 6. Losses and asset sales.

Panel B: Logistic regressions of the asset sale indicator on the loss indicator and earnings variable for the entire sample, loss sample, and profit sample

\begin{tabular}{|c|c|c|c|c|}
\hline \multirow{2}{*}{ Variable } & \multicolumn{2}{|c|}{ All firm-years } & \multirow{2}{*}{$\begin{array}{c}\text { Loss firm-years } \\
(3)\end{array}$} & \multirow{2}{*}{$\begin{array}{c}\text { Profit firm-years } \\
(4)\end{array}$} \\
\hline & (1) & (2) & & \\
\hline LOSS & $\begin{array}{c}0.298^{* * *} \\
(8.31)\end{array}$ & & & \\
\hline $\mathrm{X} / \mathrm{P}$ & $\begin{array}{c}-0.592 * * * \\
(-5.43)\end{array}$ & $\begin{array}{c}-1.039 * * * \\
(-8.99)\end{array}$ & $\begin{array}{c}-0.649 * * * \\
(-7.23)\end{array}$ & $\begin{array}{l}-0.365 \\
(-0.72)\end{array}$ \\
\hline Size & $\begin{array}{c}0.350 * * * \\
(21.51)\end{array}$ & $\begin{array}{c}0.341 * * * \\
(21.27)\end{array}$ & $\begin{array}{c}0.304 * * * \\
(14.87)\end{array}$ & $\begin{array}{c}0.371 * * * \\
(21.26)\end{array}$ \\
\hline Ret & $\begin{array}{l}-0.190^{*} \\
(-2.44)\end{array}$ & $\begin{array}{c}-0.208 * * \\
(-2.72)\end{array}$ & $\begin{array}{c}-0.253 * * * \\
(-4.14)\end{array}$ & $\begin{array}{l}-0.155 \\
(-1.69)\end{array}$ \\
\hline $\mathrm{B} / \mathrm{M}$ & $\begin{array}{c}0.297 * * * \\
(8.54)\end{array}$ & $\begin{array}{c}0.298^{* * * *} \\
(8.47)\end{array}$ & $\begin{array}{c}0.221 * * * \\
(6.74)\end{array}$ & $\begin{array}{c}0.345^{* * * *} \\
(6.34)\end{array}$ \\
\hline Lev & $\begin{array}{c}1.561 * * * \\
(16.11)\end{array}$ & $\begin{array}{c}1.581 * * * \\
(16.16)\end{array}$ & $\begin{array}{c}1.353 * * * \\
(9.04)\end{array}$ & $\begin{array}{c}1.652 * * * \\
(16.31)\end{array}$ \\
\hline Cash & $\begin{array}{c}-0.385^{* * *} \\
(-3.47)\end{array}$ & $\begin{array}{c}-0.348 * * \\
(-3.21)\end{array}$ & $\begin{array}{c}-0.605^{* * *} \\
(-4.64)\end{array}$ & $\begin{array}{l}-0.248 \\
(-1.94)\end{array}$ \\
\hline SGR & $\begin{array}{c}-0.166^{* * * *} \\
(-3.30)\end{array}$ & $\begin{array}{c}-0.173 * * * \\
(-3.37)\end{array}$ & $\begin{array}{c}-0.168 * * * \\
(-3.86)\end{array}$ & $\begin{array}{l}-0.155^{*} \\
(-2.10)\end{array}$ \\
\hline Intercept & $\begin{array}{c}-4.654 * * * \\
(-41.77)\end{array}$ & $\begin{array}{c}-4.531 * * * \\
(-42.16)\end{array}$ & $\begin{array}{c}-3.972 * * * \\
(-32.87)\end{array}$ & $\begin{array}{c}-4.895 * * * \\
(-38.97)\end{array}$ \\
\hline Obs. & 85,389 & 85,389 & 22,236 & 63,153 \\
\hline Pseudo $\mathrm{R}^{2}$ & $9.2 \%$ & $9.1 \%$ & $7.1 \%$ & $10.0 \%$ \\
\hline
\end{tabular}


Table 6. Losses and asset sales.

Panel C: Logistic regressions of the asset sale indicator on earnings and its interaction with earnings attributes and firm characteristics.

\begin{tabular}{|c|c|c|c|c|c|}
\hline \multirow{2}{*}{ Variable } & \multirow{2}{*}{$\begin{array}{l}\text { Predicted } \\
\text { sign }\end{array}$} & \multicolumn{4}{|c|}{ Loss firm-years } \\
\hline & & $(1)$ & (2) & (3) & (4) \\
\hline $\mathrm{X} / \mathrm{P}$ & - & $\begin{array}{c}-1.714 * * * \\
(-5.61)\end{array}$ & $\begin{array}{c}-0.572 * * \\
(-3.06)\end{array}$ & $\begin{array}{c}-1.488 * * * \\
(-3.40)\end{array}$ & $\begin{array}{c}-1.872 * * \\
(-3.28)\end{array}$ \\
\hline $\mathrm{X} / \mathrm{P} * \mathrm{PLR}$ & + & $\begin{array}{l}1.359 \\
(1.50)\end{array}$ & & & $\begin{array}{l}0.668 \\
(0.64)\end{array}$ \\
\hline $\mathrm{X} / \mathrm{P} * \mathrm{SPIW}$ & + & $\begin{array}{c}2.540 * * * \\
(3.93)\end{array}$ & & & $\begin{array}{c}2.484 * * * \\
(3.76)\end{array}$ \\
\hline $\mathrm{X} / \mathrm{P} * \mathrm{RDX}$ & + & & $\begin{array}{l}-0.074 \\
(-0.06)\end{array}$ & & $\begin{array}{l}1.634 \\
(1.16)\end{array}$ \\
\hline $\mathrm{X} / \mathrm{P} *$ Cash & + & & $\begin{array}{c}-0.713 * * \\
(-3.11)\end{array}$ & & $\begin{array}{l}-0.458 \\
(-1.81)\end{array}$ \\
\hline $\mathrm{X} / \mathrm{P} * \mathrm{DBTISS}$ & + & & $\begin{array}{l}0.122 \\
(0.65)\end{array}$ & & $\begin{array}{l}0.064 \\
(0.38)\end{array}$ \\
\hline $\mathrm{X} / \mathrm{P} * \mathrm{STKISS}$ & + & & $\begin{array}{l}1.515 \\
(1.24)\end{array}$ & & $\begin{array}{l}1.597 \\
(1.21)\end{array}$ \\
\hline $\mathrm{X} / \mathrm{P} * \mathrm{PPE} / \mathrm{AT}$ & + & & & $\begin{array}{c}1.280 * * \\
(2.84)\end{array}$ & $\begin{array}{c}1.289 * * \\
(2.63)\end{array}$ \\
\hline $\mathrm{X} / \mathrm{P} * \mathrm{INV} / \mathrm{ACT}$ & + & & & $\begin{array}{l}0.831 \\
(1.41)\end{array}$ & $\begin{array}{l}0.460 \\
(0.76)\end{array}$ \\
\hline $\mathrm{X} / \mathrm{P} * \ln (\mathrm{Ind} \#)$ & - & & & $\begin{array}{l}-0.130 \\
(-1.50)\end{array}$ & $\begin{array}{l}-0.116 \\
(-1.27)\end{array}$ \\
\hline Main effects & & Yes & Yes & Yes & Yes \\
\hline Controls & & Yes & Yes & Yes & Yes \\
\hline Obs. & & 14,648 & 14,648 & 14,648 & 14,648 \\
\hline Pseudo $\mathrm{R}^{2}$ & & $7.9 \%$ & $7.3 \%$ & $7.9 \%$ & $8.2 \%$ \\
\hline
\end{tabular}

Table 6 documents the prevalence of asset disposal after reporting losses, following Warusawitharana (2008). The dependent variable is an indicator of asset sales (DAS) in the following year. Data on asset sales are obtained from the SDC Platinum database from 1985 to 2010. Panel A analyzes the sample selection process. Panel B reports logistic regressions of of $D A S$ on the loss indicator, earnings, and control variables. Panel $\mathrm{C}$ reports logistic regressions of $D A S$ on earnings and its interactions with the measures of earnings attributes and firm characteristics. The control variables are Size, Ret, B/M, Lev, Cash, and SGR. All variables are defined in the appendix. t-statistics are presented in parentheses. Standard errors are clustered at both firm and year levels (Petersen, 2009). ${ }^{* *},{ }^{* *}$, and ${ }^{*}$ indicate statistical significance at the .001, .01, and .05 levels, respectively. All variables are winsorized at the bottom and top $1 \%$ extremes. 


\subsubsection{Earnings quality and the informativeness of losses}

Earnings quality affects the likelihood of exercising the abandonment option for two reasons. First, investors of firms with bad earnings quality will perceive more uncertainty about future operating cash flows than those with good earnings quality, because earnings quality represents the information precision of earnings that reflect the results of continuously applying the firm's current technology (Burgstahler and Dichev, 1997). Bad earnings quality will reduce the operation value by increasing the discount rate associated with future operating cash flows (e.g., Francis, LaFond, Olsson, and Schipper, 2004, 2005). Thus, loss firms with bad earnings quality would have higher likelihood of exercising the abandonment option than those with good earnings quality. Second, earnings reflect bad news more quickly than good news when the accounting system is conservative (e.g., Basu, 1997). As a measure of earnings quality, accounting conservatism (asymmetric timeliness) is positively related to the frequency of losses (e.g., Givoly and Hayn, 2000; Klein and Marquardt, 2006). Holding performance constant, firms using conservative accounting report lower earnings than those using aggressive accounting. Thus, losses reported by firms using conservative accounting should increase the likelihood of abandonment less than those using aggressive accounting. In sum, losses reported by firms with poor earnings quality will have higher likelihood of exercising the abandonment option than those with good earnings quality. 
Thus, I predict that loss firms with poor earnings quality will have more adverse cash flow news and more favorable discount rate news than other loss firms.

To test this prediction, I construct two measures of earnings quality, i.e., accruals quality (e.g., Francis et al., 2004, 2005) and conservatism (e.g., Khan and Watts, 2009). Accruals quality is measured by the extent to which working capital accruals map into operating cash flow realizations. The unexplained portion of the variation in working capital accruals is an inverse measure of earnings quality. Conservatism captures the idea that accounting requires a higher verification threshold for good news than bad news, resulting in asymmetric timeliness with respect to recognition of gains versus losses. The incremental timeliness of losses over gains is a proxy for conservatism.

Following Francis et al. (2005), I use the modified Dechow and Dichev (2002) approach to estimate the accruals quality $(A Q)$. Specifically, I estimate Eq. (17) for each of the Fama and French 49 industry groups with at least 20 firms in year $t$. Annual crosssectional estimation of Eq. (17) yields firm-year specific residuals, which form the basis for the accruals quality measure: $A Q_{j, t}=\sigma\left(v_{j}\right)_{t}$ is the standard deviations of firm $j^{\prime} \mathrm{s}$ residuals $\left(v_{j, t}\right)$, calculated over years $t-4$ through $t$. Larger (smaller) standard deviations of residuals $\left(A Q_{j, t}\right)$ indicate poorer (better) earnings quality.

$$
\begin{aligned}
& \operatorname{CACC}_{j, t}=\varphi_{0, j}+\varphi_{1, j} C F O_{j, t-1}+\varphi_{2, j} C F O_{j, t}+\varphi_{3, j} C F O_{j, t+1}+ \\
& \varphi_{4, j} \Delta \operatorname{Rev}_{j, t}+\varphi_{5, j} P P E_{j, t}+v_{j, t}
\end{aligned}
$$


where $C A C C_{j, t}=\Delta C A_{j, t}-\Delta C L_{j, t}-\Delta C a s h_{j, t}+\Delta S T D E B T_{j, t}=$ total current accruals in year $t, C F O_{j, t}=I B_{j, t}-T A C C_{j, t}=$ firm $j^{\prime}$ s cash flow from operations in year $t, I B_{j, t}=$ firm $j^{\prime} \mathrm{s}$ net income before extraordinary items in year $t, T A C C_{j, t}=\Delta C A_{j, t}-\Delta C L_{j, t}-\Delta C a s h_{j, t}+$ $\triangle S T D E B T_{j, t}-D P_{j, t}=$ firn $j^{\prime}$ s total accruals in year $t, \Delta C A_{j, t}=$ firm $j^{\prime} s$ change in current asset $(A C T)$ between year $t-1$ and year $t, \Delta C L_{j, t}=$ firm $j$ 's change in current liabilities $(L C T)$ between year $t-1$ and year $t, \Delta \operatorname{Cash}_{j, t}=$ firm $j^{\prime}$ s change in cash $(C H E)$ between year $t-1$ and year $t, \triangle S T D E B T_{j, t}=$ firm $j^{\prime}$ s change in debt in current liabilities $(D L C)$ between year $t-1$ and year $t, D P_{j, t}=$ firm $j^{\prime}$ s depreciation and amortization expenses $(D P)$ between year $t-1$ and year $t, \Delta R e v_{j, t}=$ firm $j^{\prime}$ s change in total revenues $(R E V T)$ between year $t-1$ and year $t, P P E_{j, t}=$ firm $j^{\prime}$ s gross value of PP\&E (PPEGT) between year $t-1$ and year $t$. All variables are scaled by lagged total assets $(A T)$ and winsorized at the $1 \%$ and $99 \%$ extreme values. Prior to 1988 (the effective year of SFAS No. 95), I use the indirect approach to calculate the accruals and cash flow from operations. After $1988, \mathrm{CFO}_{j, t}$ is obtained from the cash flow statement, $T A C C_{j, t}=I B_{j, t}-C F O_{j, t}$, and $C A C C_{j, t}=I B_{j, t}-$ $C F O_{j, t}-D P_{j, t}=T A C C_{j, t}-I B_{j, t}$

Following Khan and Watts (2009), I use the modified Basu (1997) approach to estimate conservatism. Specifically, I estimate annual cross-sectional regressions of Eq. (18), so the estimates of $\mu_{i, t}$ and $\lambda_{i, t}(i=1-4)$ are constant across firms but vary over time. I specify the incremental timeliness of bad news as a linear function of firm characteristics each year: $\operatorname{Cscore}_{j, t}=\lambda_{1, t}+\lambda_{2, t} \operatorname{Size}_{j, t}+\lambda_{3, t} M / B_{j, t}+\lambda_{4, t} \operatorname{Lev}_{j, t}$. Therefore, 
Cscore varies with cross-sectional variation in the firm-year characteristics (Size, $M / B$, and $L e v)$, and over time through intertemporal variation in $\lambda_{i, t}(i=1-4)$ and the firmyear characteristics. To conform this variable to the ordering of AQ, I use the negative of the Cscore measure, negCscore $=-$ Cscore, so that larger (smaller) values of negCscore correspond to less (more) conservative accounting and poorer (better) earnings quality.

$$
\begin{aligned}
& X_{j, t} / P_{j, t-1}=\beta_{1, t}+\beta_{2, t} D_{j, t}+R_{j, t}\left(\mu_{1, t}+\mu_{2, t} \operatorname{Size}_{j, t}+\mu_{3, t} M / B_{j, t}+\right. \\
& \left.\mu_{4, t} \operatorname{Lev}_{j, t}\right)+D_{j, t} * R_{j, t}\left(\lambda_{1, t}+\lambda_{2, t} \operatorname{Size}_{j, t}+\lambda_{3, t} M / B_{j, t}+\lambda_{4, t} \operatorname{Lev}_{j, t}\right)+ \\
& \left(\delta_{1, t} \operatorname{Size}_{j, t}+\delta_{2, t} M / B_{j, t}+\delta_{3, t} \operatorname{Lev}_{j, t}+\delta_{4, t} D_{j, t} * \operatorname{Size}_{j, t}+\delta_{5, t} D_{j, t} *\right. \\
& \left.M / B_{j, t}+\delta_{6, t} D_{j, t} * L e v_{j, t}\right)+e_{j, t}
\end{aligned}
$$

where $X_{j, t} / P_{j, t-1}=$ firm $j$ 's income before extraordinary items $(I B)$ in year $t$ scaled by its market value of equity at the end of year $t-1, R_{j, t}=$ firm $j$ 's realized returns in year $t$, $D_{j, t}=1$ when $R_{j, t}<0$ and $D_{j, t}=0$ otherwise, Size $_{j, t}=$ natural logarithm of firm $j^{\prime} \mathrm{s}$ market value of equity $\left(P R C C_{-} F \times C S H O\right)$ in year $t, M / B_{j, t}=$ firm $j$ 's market-to-book ratio in year $t$, and $L e v_{j, t}=$ firm $j^{\prime}$ s leverage ratio in year $t$, defined as long-term and short-term debt $(D L T T+D L C)$ deflated by total assets $(A T)$.

Similar to the tests of $\mathrm{H} 3$ and $\mathrm{H} 4$, I introduce each of the earnings quality proxies in Eq. $(10 a, b)$ as both a main effect and an interaction with $X / P$. Consistent with my prediction, Table 7 shows that earnings quality is related to the informativeness of losses. The coefficients on the interaction between $X / P$ and $A Q$ are significantly positive in column 1 (coeff. = 1.607, t-stat. = 3.08) and significantly negative in column 2 (coeff. = - 
0.547 , $\mathrm{t}$-stat. $=-2.65)$. Similarly, the coefficients on the interaction between $X / P$ and negCscore are reliably positive and negative in the third and four columns (coeff. $=0.920$ and -0.318 , t-stat. $=2.82$ and -1.92$)$. This result is consistent with the coefficients on the interaction between $\mathrm{X} / \mathrm{P}$ and $S P I W$ in Table 4, using nonrecurring charges (SPIW) as an alternative proxy for accounting conservatism (e.g., Givoly and Hayn, 2000; Klein and Marquardt, 2006). When I consider both $A Q$ and negCscore in the last two columns, the coefficients on $X / P^{\prime}$ s interaction with negCscore become less significant and those on $X / P^{\prime}$ s interaction with $A Q$ become more significant. In sum, the results in Table 7 support my prediction that losses reported by firms with poor earnings quality convey more adverse cash flow news and more favorable discount rate news than other loss firms.

Table 7: The effects of earnings quality on the informativeness of losses.

\begin{tabular}{|c|c|c|c|c|c|c|}
\hline \multirow{2}{*}{ Variable } & (1) & (2) & (3) & (4) & (5) & (6) \\
\hline & $\mathrm{Ncf}$ & $\mathrm{Nr}$ & $\mathrm{Ncf}$ & $\mathrm{Nr}$ & $\mathrm{Ncf}$ & $\mathrm{Nr}$ \\
\hline $\mathrm{X} / \mathrm{P}$ & $\begin{array}{c}1.906 * * * \\
(21.00)\end{array}$ & $\begin{array}{c}-0.750 * * * \\
(-21.10)\end{array}$ & $\begin{array}{c}2.449 * * * \\
(13.42)\end{array}$ & $\begin{array}{c}-0.996 * * * \\
(-12.12)\end{array}$ & $\begin{array}{c}2.049 * * * \\
(10.61)\end{array}$ & $\begin{array}{c}-0.806 * * * \\
(-8.84)\end{array}$ \\
\hline $\mathrm{X} / \mathrm{P} * \mathrm{AQ}$ & $\begin{array}{c}1.607 * * \\
(3.08)\end{array}$ & $\begin{array}{c}-0.547 * * \\
(-2.65)\end{array}$ & & & $\begin{array}{c}2.196 * * * \\
(4.21)\end{array}$ & $\begin{array}{c}-0.820 * * \\
(-3.00)\end{array}$ \\
\hline AQ & $\begin{array}{c}-0.225^{*} \\
(-2.18)\end{array}$ & $\begin{array}{l}0.109 \\
(1.72)\end{array}$ & & & $\begin{array}{l}-0.131 \\
(-1.21)\end{array}$ & $\begin{array}{c}0.150^{*} \\
(2.09)\end{array}$ \\
\hline $\mathrm{X} / \mathrm{P} *$ negCscore & & & $\begin{array}{c}0.920 * * \\
(2.82)\end{array}$ & $\begin{array}{l}-0.318 \\
(-1.92)\end{array}$ & $\begin{array}{l}0.740^{*} \\
(2.24)\end{array}$ & $\begin{array}{l}-0.192 \\
(-1.12)\end{array}$ \\
\hline negCscore & & & $\begin{array}{c}0.255^{* *} \\
(3.19)\end{array}$ & $\begin{array}{c}0.370 * * \\
(3.09)\end{array}$ & $\begin{array}{c}0.207 * * \\
(2.98)\end{array}$ & $\begin{array}{c}0.359^{* *} \\
(2.71)\end{array}$ \\
\hline Controls & Yes & Yes & Yes & Yes & Yes & Yes \\
\hline $\begin{array}{l}\text { Obs. } \\
\text { Adi. R2 }\end{array}$ & $\begin{array}{l}15,958 \\
41,4 \%\end{array}$ & $\begin{array}{l}15,958 \\
25,6 \%\end{array}$ & $\begin{array}{l}20,851 \\
40,1 \%\end{array}$ & $\begin{array}{l}20,851 \\
28,0 \%\end{array}$ & $\begin{array}{l}12,968 \\
41,9 \%\end{array}$ & $\begin{array}{l}12,968 \\
28,5 \%\end{array}$ \\
\hline
\end{tabular}


Table 7 presents regressions of the news components on earnings conditional on earnings quality for the loss sample. The measures of earnings quality are calculated following Francis et al. $(2004,2005)$ and Khan and Watts (2009). The control variables are lagX/P, lagSize, lagB/M, lagLev, and Zscore. All variables are defined in the appendix. $t$-statistics are presented in parentheses. Standard errors are clustered at both firm and year levels (Petersen, 2009). ${ }^{* *},{ }^{* *}$, and * indicate statistical significance at the .001, .01, and .05 levels, respectively. All variables are winsorized at the bottom and top $1 \%$ extremes.

\subsection{Robustness Checks}

\subsubsection{Alternative explanations for the muted return-earnings relation for losses}

As discussed previously, I find that, on average, losses provide adverse cash flow news and favorable discount rate news, dampening the return-earnings relation for losses. Darrough and Ye (2007) claim that some loss firms are not financially or operationally distressed and have good future prospects, so they may experience favorable cash flow news. If favorable cash flow news is coupled with adverse discount rate news, the news components would have the same type of offsetting effect on the return-earnings relation as adverse cash flow news coupled with favorable discount rate news. In this test, I examine this explanation for the muted return-earnings relation for losses.

Prior literature documents that losses are persistent (e.g., Joos and Plesko, 2005; Li, 2011), and future cash flows are inversely related to the persistent of losses. On average, losses are more likely to revise the valuation numerator downward than upward. My (untabulated) results show that 33\% of the loss observations reverse into profits in the following year (year $t+1$ ) and $77 \%$ of the loss sample have one or more 
losses reported in the past five years (year $t-5$ to $t$-1). Intuitively, persistent losses revise investors' expectations of future cash flows downward, so a large portion of the loss observations provide adverse cash flow news to investors. In this situation, the returnearnings relation would be weakened only if the adverse cash flow news is coupled with favorable discount rate news; otherwise, losses would be positively related to realized returns.

To support this argument, I divide loss observations into four subsamples based on the signs of the news components and examine the associations between the news components and losses in each of the subsamples. Panel A of Table 8 reports the number of observations for each of the four subsamples. Over $80 \%$ of the loss observations have negative cash flow news $(21,687 / 26,885=80.7 \%)$, and $63 \%$ have positive discount rate news $(13,666 / 21,687=63.0 \%)$. The $\chi^{2}$ test $\left(\chi^{2}=466.07\right)$ shows that the sign of cash flow news is related to that of discount rate news for loss observations. Panel B of Table 8 documents the regressions of the news components on earnings for the four subsamples of loss observations. For the two subsamples with negative cash flow news, $X / P$ is positively related to $N c f($ coeff. $=0.943$ and 0.579 , t-stat. $=15.64$ and 11.42$)$ and negatively related to $N r$ (coeff. $=-0.378$ and -0.101 , t-stat. $=-21.08$ and -6.44 ). Consistent with the results in Table 3, these results imply that most loss observations convey adverse cash flow news and favorable discount rate news to investors. For the subsample with positive $N c f$ and postive $N r, X / P$ is negatively associated with both news components, 
although its explanatory power is higher for $N c f$ than for $N r(4.7 \%>0.3 \%)$. For the subsample with positive $N c f$ and negative $N r, X / P$ does not explain the news components. In sum, the results in Table 8 reject the alternative explanation for the muted return-earnings relations for losses. ${ }^{18}$

Table 8: Subsamples of loss firm-years according to the signs of the news components.

Panel A. $2 \times 2$ analysis for the loss firm-years according to the signs of the news components

\begin{tabular}{lrrr}
\hline $2 \times 2$ analysis & $\mathrm{Nr} \geq 0$ & $\mathrm{Nr}<0$ & Total \\
\hline $\mathrm{Ncf} \geq 0$ & 2,426 & 2,772 & 5,198 \\
$\mathrm{Ncf}<0$ & 13,666 & 8,021 & 21,687 \\
Total & 16,092 & 10,793 & 26,885 \\
Pearson $\chi^{2}=466.07$ & & \\
\hline
\end{tabular}

${ }^{18} \mathrm{My}$ main results in this paper are robust to exclusion of the loss observations with positive cash flow news. 


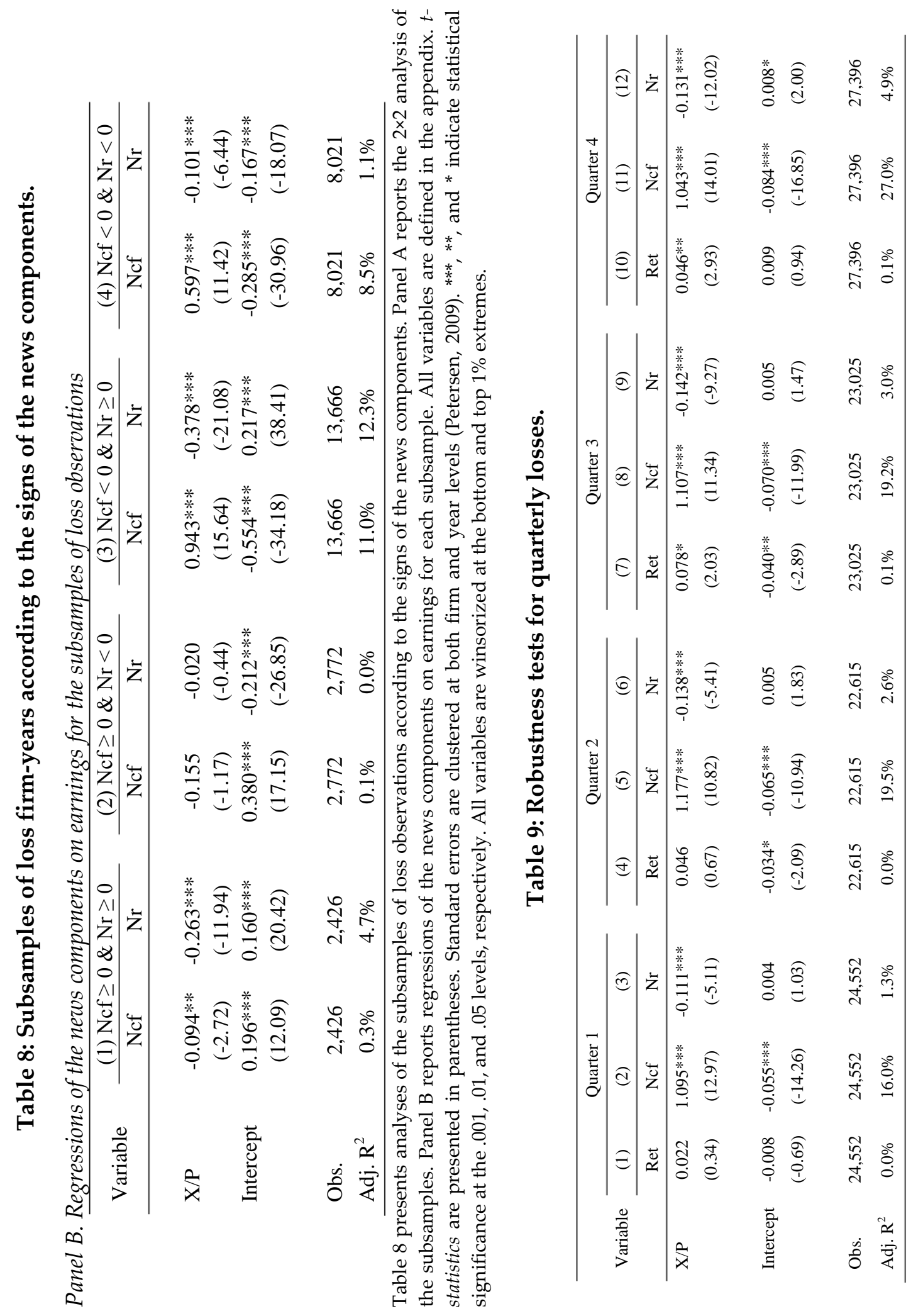


Table 9 presents regressions of quarterly returns and quarterly the news components on quarterly losses. All variables are defined in the appendix. $t$-statistics are presented in parentheses. Standard errors are clustered at both firm and year levels (Petersen, 2009). ${ }^{* * *},{ }^{* *}$, and ${ }^{*}$ indicate statistical significance at the $.001, .01$, and .05 levels, respectively. All variables are winsorized at the bottom and top $1 \%$ extremes.

\subsubsection{Analysis of quarterly losses}

I examine whether the relation between losses and the news components exists for quarterly loss observations. Li (2011) suggests that quarterly losses are persistent, and investors do not fully anticipate the persistence of quarterly losses. Thus, it is possible that investors underestimate the persistence of quarterly losses and do not adjust the likelihood of exercising the abandonment option accordingly. In this case, quarterly losses would not be significantly correlated with the news components embedded in quarterly realized returns. I probe this question by studying the relations between the news components and losses in fiscal quarters.

I measure earnings as income before extraordinary items for fiscal quarter $t(I B Q)$ deflated by the market value of equity at the end of fiscal quarter $t-1(P R C C Q \times C S H O Q)$. Quarterly losses are defined as firm-quarters with negative earnings $(I B Q<0)$. Stock returns (RET) are assigned to each firm's fiscal year-quarter so as to match the time period of its reported financial data. To ensure the return period captures the market response to the earnings in quarter $t$ (not $t-1)$, I calculate the quarterly return over the 3month period ending at the month of the earnings announcement (press release) for fiscal quarter $t$. The news components in quarterly realized returns are calculated using the Vuolteenaho (2002) return decomposition method. 
Table 9 reports the regressions of quarterly returns or the return components on quarterly earnings for the loss sample. Similar to annual losses, quarterly losses are weakly associated with (quarterly) realized returns. The return-earnings relation is weak for all the quarters. Although the ERCs in the third and fourth quarters are positive and significant at the .05 level (columns 7 and 10), their magnitudes are small compared with the coefficients on $X / P$ in columns $8,9,11$, and 12. Similar to annual losses, quarterly losses are positively related to cash flow news and negatively related to discount rate news. In addition, $R^{2}{ }_{N c f}$ and $R^{2}{ }_{N r}$ for losses in the fourth fiscal quarter (26.96\% and $\left.4.91 \%\right)$ are higher than other quarters. Comparison of the $\mathrm{R}^{2} \mathrm{~s}$ suggests that annual losses convey more cash flow news and discount rate news than quarterly losses. Table 9 shows that investors adjust their estimation of loss firms' likelihood of abandonment according to the information in quarterly losses.

\subsubsection{Alternative proxies for the news components}

I assess the sensitivity of my results to the news components calculated following Easton and Monahan (2005). Their method measures cash flow news and discount rate news using the revision in analyst earnings forecasts and the change in implied cost of capital; details are in Appendix C. Similar to the way I calculated the news components per Vuolteenaho (2002), favorable/adverse cash flow news (discount rate news) using the Easton and Monahan (2005) method means positive/negative change in future cash flows (discount rate/expected return). 
The main advantage of the Easton and Monahan (2005) method is that it uses analyst forecasts that incorporate cash flows expected from non-going-concern events (Berger et al., 1996, page 264), while the Vuolteenaho (2002) method uses GAAP earnings that measure going-concern earnings. However, the Easton and Monahan (2005) method uses implied cost of capital measures based on valuation methods that do not consider the abandonment option; the Vuolteenaho (2002) method is derived from the definition of book-to-market ratio and the clean surplus relation. Also, the news components based on the Vuolteenaho (2002) method comes from the same return decomposition framework. Thus, the magnitudes of the news components are additive and comparable, while the news components based on the Easton and Monahan (2005) method are not. Because loss firms have smaller firm size and less analyst following, the Easton and Monahan (2005) method that requires analyst forecast data for at least 2 years reduces the size of the loss sample by about $90 \%$.

Panel A of Table 10 documents descriptive statistics of implied cost of capital measures and the news components per Easton and Monahan (2005) for the loss sample. I use four methods to estimate the implied cost of capital $\left(E R_{J}\right.$, where $J$ denotes the method used to estimate the implied cost of capital measure), including Gebhardt, Lee, and Swaminathan (2001) (GLS), Claus and Thomas (2001) (CT), Easton (2004) (MPEG), and Botosan and Plumlee (2002) (VL). Cash flow news $\left(C N_{E M}\right)$ and discount rate news $\left(R N_{J}\right.$, where $J=G L S, C T, M P E G$, or $\left.V L\right)$ are estimated using the Easton and Monahan 
(2005) method. $C N_{E M}$ uses analyst forecast revisions, and $R N_{J}$ measures the change in implied cost of capital $J$ (where $J=G L S, C T, M P E G$, or $V L$ ).

Results in Panel A indicate that firms have lower earnings forecasts and lower implied cost of capital after reporting losses. Consistent with the results in Table 2, the means and medians of the cash flow news $\left(C N_{E M}\right)$ are both significantly negative, and those of the discount rate news ( $R N_{G L S}, R N_{C T}, R N_{M P E G}$, and $\left.R N_{V L}\right)$ are significantly positive. Panel B of Table 10 shows that losses are positively associated with cash flow news $\left(C N_{E M}\right)$ and negatively associated with discount rate news $\left(R N_{J}\right.$, where $J=G L S, C T$, MPEG, or $V L$ ), consistent with the results in Table 3. Panel B also shows that expected return (ERGLS, ERCT, ERMPEG, and $\left.E R_{V L}\right)$ and earnings $(X P)$ are negatively correlated, consistent with the results in Table 5.

Table 10: Results using alternative proxies for the return components.

Panel A: Descriptive statistics of the return components using the Easton and Monahan (2005) approach

\begin{tabular}{lcccccccc}
\hline Variable & $\mathrm{N}$ & Mean & $\begin{array}{c}\text { Std. } \\
\text { Dev. }\end{array}$ & $\mathrm{P} 5$ & $\mathrm{Q} 1$ & Median & $\mathrm{Q} 3$ & \multirow{2}{*}{$\mathrm{P} 95$} \\
\hline $\mathrm{CN}_{\mathrm{EM}}$ & 12,930 & $\mathbf{- 0 . 2 8 3}$ & 0.429 & -1.207 & -0.385 & $\mathbf{- 0 . 1 7 5}$ & -0.049 & 0.139 \\
& & & & & & & & \\
$\mathrm{RN}_{\mathrm{GLS}}$ & 954 & $\mathbf{0 . 3 4 3}$ & 1.618 & -2.469 & -0.192 & $\mathbf{0 . 0 9 8}$ & 0.692 & 4.388 \\
$\mathrm{RN}_{\mathrm{CT}}$ & 4,148 & $\mathbf{0 . 7 8 0}$ & 4.971 & -7.185 & -0.911 & $\mathbf{0 . 0 8 0}$ & 2.013 & 12.245 \\
$\mathrm{RN}_{\mathrm{MPEG}}$ & 1,033 & $\mathbf{0 . 8 8 9}$ & 3.629 & -5.257 & -0.386 & $\mathbf{0 . 3 3 4}$ & 2.082 & 9.030 \\
$\mathrm{RN}_{\mathrm{VL}}$ & 1,746 & $\mathbf{1 . 2 3 8}$ & 6.398 & -9.731 & -1.210 & $\mathbf{0 . 4 0 8}$ & 3.142 & 15.697 \\
& & & & & & & & \\
$\mathrm{ER}_{\mathrm{GLS}}$ & 1,180 & $\mathbf{0 . 0 9 5}$ & 0.091 & 0.014 & 0.052 & $\mathbf{0 . 0 7 7}$ & 0.109 & 0.226 \\
$\mathrm{ER}_{\mathrm{CT}}$ & 5,490 & $\mathbf{0 . 1 5 5}$ & 0.163 & 0.018 & 0.070 & $\mathbf{0 . 1 0 4}$ & 0.168 & 0.496 \\
$\mathrm{ER}_{\mathrm{MPEG}}$ & 1,271 & $\mathbf{0 . 1 8 1}$ & 0.116 & 0.063 & 0.112 & $\mathbf{0 . 1 6 1}$ & 0.221 & 0.366 \\
$\mathrm{ER}_{\mathrm{VL}}$ & 3,497 & $\mathbf{0 . 2 1 3}$ & 0.133 & 0.020 & 0.125 & $\mathbf{0 . 2 0 0}$ & 0.290 & 0.445 \\
\hline
\end{tabular}




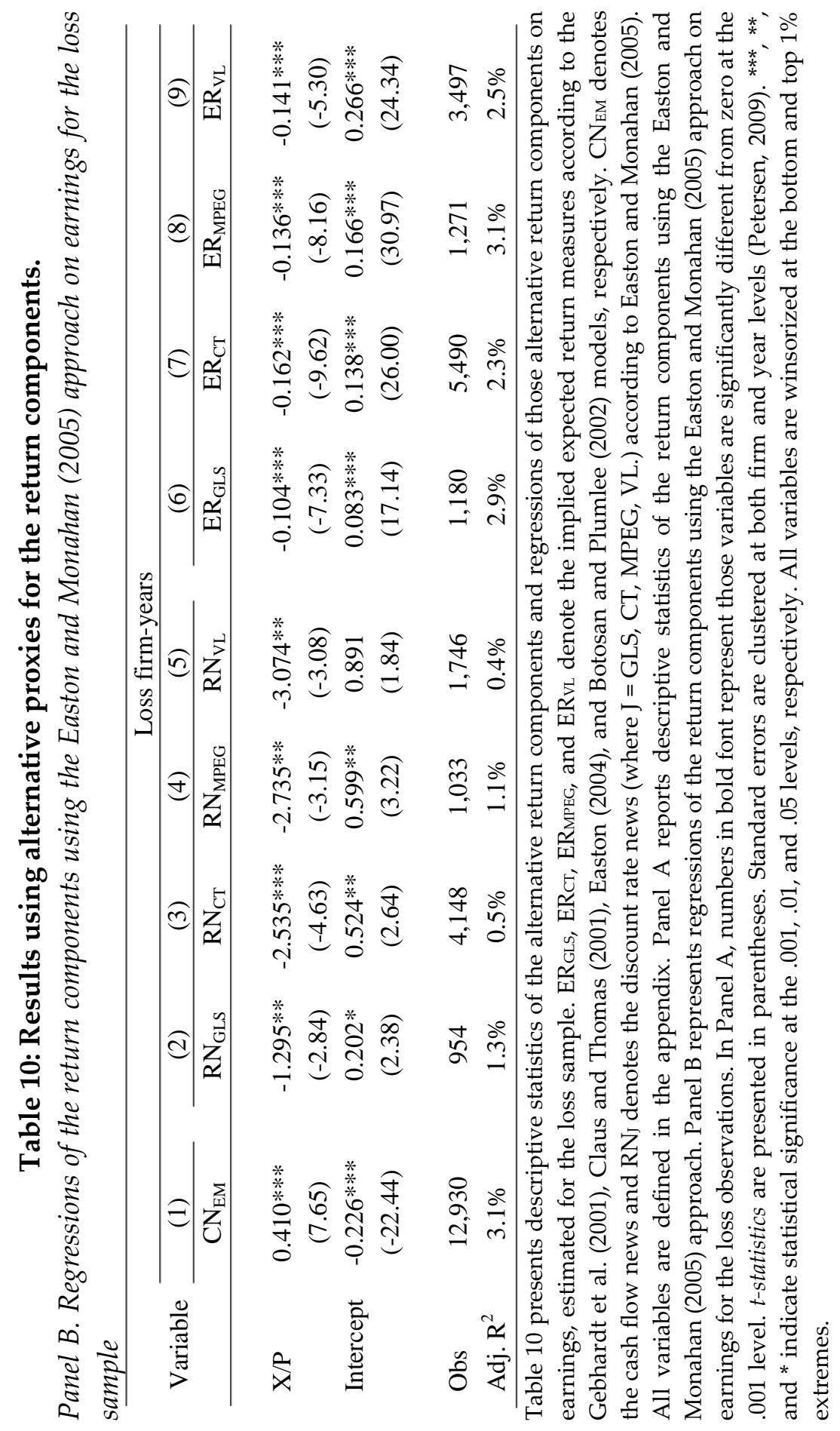




\section{Summary and Conclusions}

This paper investigates the valuation relevance of accounting losses as conveying news about future payoffs (cash flow news) and news about risk (discount rate news). Accounting losses are informative because of their relation to the abandonment option. If shareholders decide to abandon the firm (or some portion thereof) in exchange for receiving the exit value of the disposed resources, the uncertainty about the cash flows from these resources is resolved. Theory suggests that exit value is the lower bound of firm value, so firms characterized by higher likelihood of abandonment are expected to have lower firm value and lower risk, as reflected in a lower discount rate. Previous research shows that accounting losses move investors closer to exercising the abandonment option (e.g., Hayn, 1995). Under this view, losses provide adverse news about cash flows (the valuation numerator) and favorable news about discount rates (the valuation denominator). Since the effects of the two types of news are mutually offsetting-the cash flow news decreases firm value and the discount rate news increases firm value - the relation between earnings and returns is weaker for loss firms than for firms reporting accounting profits. Empirical tests of this prediction support the view that losses are indeed informative, once their effects on cash flows and discount rates are analyzed separately.

These results shed light on the way the earnings performance (profit or loss) is used by investors to price shares. While previous research has drawn the inference that 
losses are not very informative (compared to positive earnings), results in this paper indicate that losses are, in fact, explicitly informative about both the valuation numerator (cash flows) and the valuation denominator (discount rates). 


\section{Appendix A. Proofs of the propositions in the valuation model}

Proof. [Calculation of $E\left(P_{2}\right)$ and $\left.E(R)\right]$

According to Eq. (7) and Eq. (6), $E\left(P_{2}\right)$ and $E(R)$ can be viewed as the valuation numerator and valuation denominator in stock returns and stock price, respectively. I show how $E\left(P_{2}\right)$ and $E(R)$ react to earnings $(e)$ in this appendix.

The moment generating function of firm value (i.e., $P_{2}$ ) at the end of the period is:

$$
\begin{aligned}
& M_{k}(t)= \\
& \int_{-\infty}^{\frac{a}{c}} \exp (t a) \frac{1}{\sqrt{2 \pi} \sigma} \exp \left[-\frac{1}{2}\left(\frac{v-\mu}{\sigma}\right)^{2}\right] d v+\int_{a / c}^{\infty} \exp (t c v) \frac{1}{\sqrt{2 \pi} \sigma} \exp \left[-\frac{1}{2}\left(\frac{v-\mu}{\sigma}\right)^{2}\right] d v= \\
& \exp (t a) \Phi(x)+\exp \left(c \mu t+\frac{1}{2} c^{2} \sigma^{2} t^{2}\right)[1-\Phi(x-c \sigma t)]
\end{aligned}
$$

where $\Phi(\cdot)$ is the standard normal cumulative distribution function and $x=-\frac{c \mu-a}{c \sigma}=$ $\left[(a / c-\bar{\theta}) h_{\theta}+(a / c-e) h_{\varepsilon}\right] /\left(h_{\theta}+h_{\varepsilon}\right)^{3 / 2}$. In this expression, $x$ measures the gap between operation value and exit value.

I calculate the mean and variance of $P_{2}$ by taking the first and second order derivatives of $M_{k}(t)$ with respect to $t$.

This implies that the first moment of $P_{2}$ is given by

$$
\begin{aligned}
E\left(P_{2}\right)=a \Phi(x) & +c \mu[1-\Phi(x)]+c \sigma \phi(x) \\
& =a \Phi(x)+c[\mu+\sigma \lambda(x)][1-\Phi(x)] \\
& =a \Phi(x)+c[a / c-\sigma x+\sigma \lambda(x)][1-\Phi(x)]
\end{aligned}
$$

Similarly, the second moment is: 


$$
E\left(P_{1}^{2}\right)=a^{2} \Phi(x)+c^{2}\left(\mu^{2}+\sigma^{2}\right)[1-\Phi(x)]+c^{2} \sigma(\mu+a / c) \phi(x)
$$

The variance of $P_{2}$ equals $E\left(P_{2}^{2}\right)$ minus $E\left(P_{2}\right)^{2}$ :

$$
\begin{aligned}
\operatorname{Var}\left(P_{2}\right)=E\left(P_{2}^{2}\right) & -E\left(P_{2}\right)^{2} \\
= & c^{2} \sigma^{2}\left\{\left[1+x \phi(x)+x^{2} \Phi(x)\right][1-\Phi(x)]-\phi(x)[\phi(x)+x \Phi(x)]\right\} \\
= & c^{2} \sigma^{2}[1-\Phi(x)]\{1+[x-\lambda(x)][\phi(x)+x \Phi(x)]\} \\
= & c^{2} \sigma^{2}\left\{[1-\Phi(x)]+x[\phi(x)+x \Phi(x)]-[\phi(x)+x \Phi(x)]^{2}\right\}
\end{aligned}
$$

The functional form of the expected return (the discount rate) becomes:

$$
\begin{aligned}
& E(R)=\gamma \operatorname{Var}\left(P_{2}\right)=\gamma c^{2} \sigma^{2}[1-\Phi(x)]\{1+[x-\lambda(x)][\phi(x)+ \\
& x \Phi(x)]\}
\end{aligned}
$$

where $\Phi(\cdot)(\phi(\cdot))$ is the cumulative distribution function (probability distribution function) of the standard normal, $x=-\frac{c \mu-a}{c \sigma}=\left[(a / c-\bar{\theta}) h_{\theta}+(a / c-e) h_{\varepsilon}\right] /\left(h_{\theta}+\right.$ $\left.h_{\varepsilon}\right)^{3 / 2}$, and $\lambda(x)=\phi(x) /[1-\Phi(x)]$ is the inverse Mills ratio. In Eq. (A2), $x$ measures the gap between operation value and exit value.

Based on Eq. (A1) and (A2), the firm's market value at date 2 is:

$$
\begin{aligned}
& P_{2}=\frac{\Phi(x)}{E(R)} \times a+\frac{1-\Phi(x)}{E(R)} \times c[\mu+\sigma \lambda(x)]=\beta_{1} \times a+\beta_{2} \times c[\mu+ \\
& \sigma \lambda(x)]
\end{aligned}
$$

where $\beta_{1}=\frac{\Phi(x)}{E(R)^{\prime}}, \beta_{2}=\frac{1-\Phi(x)}{E(R)}$, and $\lambda(x)=\phi(x) /[1-\Phi(x)]$.

Equation (A3) shows that market value of the firm is a weighted-average of operation value ( $\tilde{v}$ truncated at $x$ ) and exit value $(a)$, and the relative weights on the two 
components reflect the likelihood of abandonment $\left(\beta_{2} / \beta_{1}=1 / \Phi(x)-1\right)^{1}$. This observation is consistent with the findings of Barth et al. (1998) and Collins et al. (1999). As the likelihood of abandonment $(\Phi(x))$ increases, the relative weight on the exit value $\left(\beta_{1} / \beta_{2}\right)$ also increases.

The likelihood of abandonment $(\Phi(x))$ is increasing in $x(x=-(c \mu-a) / c \sigma)$, which reflects the gap between accounting earnings $(e)$ and exit value $(a / c)$. This gap $(x)$ is decreasing in observed accounting earnings $\left(\partial x / \partial e=-h \varepsilon /(h \theta+h \varepsilon)^{3 / 2}<0\right)$. Based on the chain rule, the likelihood of abandonment is a decreasing function of accounting earnings $((\partial \Phi(x) / \partial e=\partial \Phi(x) / \partial x \times \partial x / \partial e<0)$.

\section{Proof of Prop. 1}

$E\left(P_{2}\right)$ represents the valuation numerator and $E(R)$, the valuation denominator in stock returns, respectively. I focus on the first order derivatives of $E\left(P_{2}\right)$ and $E(R)$ with respect to $e$ (earnings) for this proof.

The first order derivative of equation (A1) with respect to $x$ :

$$
\begin{gathered}
\partial E\left(P_{2}\right) / \partial x=\partial[a \Phi(x)+(a-c \sigma x)(1-\Phi(x))+c \sigma \phi(x)] / \partial x \\
=a \phi(x)-c \sigma[1-\Phi(x)]-(a-c \sigma x) \phi(x) \\
-\operatorname{cox} \phi(x)=-c \sigma[1-\Phi(x)]<0
\end{gathered}
$$

${ }^{1}$ Since investors will abandon the firm if the cash flows are sufficiently low, the firm's cash flow distribution can be viewed as a truncated normal distribution. When capitalized cash flows $(c \tilde{v})$ fall below the exit value (a), investors will exercise the abandonment option. Thus, the cash flow distribution is left-truncated at $a / c$. 
We know that $\partial x / \partial e=-h \varepsilon /(h \theta+h \varepsilon)^{3 / 2}<0$. Based on the chain rule,

$$
\frac{\partial E\left(P_{2}\right)}{\partial e}=\frac{\partial E\left(P_{2}\right)}{\partial x} \times \frac{\partial x}{\partial e}>0
$$

Thus, investors' expected payoff $\left(E\left(P_{2}\right)\right)$ is increasing in the observed accounting earnings $(e)$.

The first order derivative of equation (A2) with respect to $x$ :

$$
\begin{gathered}
\partial E(R) / \partial x=\gamma c^{2} \sigma^{2}\left[2 x \Phi(x)+x^{2} \phi(x)-2 x \Phi^{2}(x)-2 x^{2} \phi(x) \Phi(x)-\right. \\
\phi(x)+2 x \phi^{2}(x)+\phi(x)-x^{2} \phi(x)-2 \phi(x) \Phi(x)+2 x^{2} \phi(x) \Phi(x)- \\
\left.2 x \phi^{2}(x)\right]=2 \gamma c^{2} \sigma^{2} \Phi(x)[1-\Phi(x)][x-\lambda(x)]<0,
\end{gathered}
$$

where $\lambda(x)=\phi(x) /[1-\phi(x)] .^{2}$

Similarly, based on the chain rule,

$$
\frac{\partial E(R)}{\partial e}=\frac{\partial E(R)}{\partial x} \times \frac{\partial x}{\partial e}>0
$$

Thus, the expected return $(E(R))$ is also increasing in the observed accounting earnings $(e)$.

In sum, losses are positively associated with both the valuation numerator and the valuation denominator. Because losses increase the likelihood of abandonment $\left(\frac{\partial x}{\partial e}<0\right.$ and $\left.\frac{\partial \Phi(x)}{\partial e}<0\right)$ that is negatively related to both the valuation numerator and

2 Truncated normal distribution has the following property: if $y \sim N(0,1)$, then $E(y \mid y>x)=\phi(x) /(1-$ $\Phi(x))=\lambda(x)>x$. 
denominator $\left(\frac{\partial E\left(P_{2}\right)}{\partial x}<0\right.$ and $\left.\frac{\partial E(R)}{\partial x}<0\right)$, losses revise the valuation numerator and denominator downward simultaneously $\left(\frac{\partial E\left(P_{2}\right)}{\partial e}>0\right.$ and $\left.\frac{\partial E(R)}{\partial e}>0\right)$.

\section{Proof of Prop. 2}

See the proof of Prop. 1. $E\left(P_{2}\right)$ and $E(R)$ are both increasing in $e$. When $e$ declines, $E\left(P_{2}\right)$ and $E(R)$ decrease at the same time, so they offset each other in forming stock returns (Eq. (7)). 


\section{Appendix B. Estimation of the VAR model}

Following Campbell (1991) and Vuolteenaho (2002), I estimate cash flow news and discount rate news using a log-linear vector autoregressive (VAR) model. In general, VAR estimation is facilitated by assuming that the dynamics of the data are well described by a stationary multivariate time-series model. Specifically, define $z_{i, t}$ to be a vector of firm-specific state variables that follows the vector autoregressive process:

$$
z_{i, t}=\Gamma z_{i, t}+\eta_{i, t}
$$

Consistent with the literature, the VAR coefficient matrix $\Gamma$ is assumed constant over time and firms. The error term vectors $\eta_{i, t}$ are zero-mean vectors of shocks and are assumed to have a variance-covariance matrix $\Omega$ and to be independent of all variables known at $t-1$.

I estimate a parsimonious VAR where the state variables are log stock returns, $\log$ book return on equity, and log book-to-market ratio (Vuolteenaho, 2002). The VAR model can be described as a system of (mean-adjusted) equations:

$$
\begin{aligned}
& r_{t}=\alpha_{1} r_{t-1}+\alpha_{2} \text { roe }_{t-1}+\alpha_{3} b m_{3}+\eta_{1 t} \\
& \text { roe }_{t}=\beta_{1} r_{t-1}+\beta_{2} \text { roe }_{t-1}+\beta_{3} b m_{3}+\eta_{2 t} \\
& b m_{t}=\gamma_{1} r_{t-1}+\gamma_{2} \text { roe }_{t-1}+\gamma_{3} b m_{3}+\eta_{3 t}
\end{aligned}
$$

where $r_{t}=\log$ stock return (cum dividend) in excess of the risk-free rate in period $t$; roe $_{t}=\log \left(1+X_{t} / B V_{t-1}\right)=\log$ book return on equity in period $t ; B V_{t-1}=$ book value of 
equity at time $t ; X_{t}=$ earnings in period $t$; and $b m_{t}=\log$ book-to-market ratio at time $t$. I estimate the VAR regressions by industry using weighted least squares. ${ }^{3}$

Return Decomposition Estimation. As shown by Campbell (1991), the return decomposition can be implemented empirically by combining the residuals from the VAR estimation with the unexpected current return equation (Eq. (A7)). Formally, let $e^{\prime}{ }_{k}=(0, \ldots, 1, \ldots, 0)$ denote a row vector with 1 as the $k^{\prime}$ th element and 0 elsewhere. As shown by Campbell and Shiller (1988a, b) and Vuolteenaho (2002), cash flow news and discount rate news can be computed as:

$$
\begin{aligned}
& N c f_{t}=\left(e_{1}+\lambda_{1}\right)^{\prime} \eta_{t} \\
& N r_{t}=-\lambda_{1}^{\prime} \eta_{t}
\end{aligned}
$$

where ' denotes the transpose operator, and $\lambda_{k}^{\prime}=e_{k}^{\prime} \rho \Gamma(1-\rho \Gamma)^{-1}$. The term $(1-\rho \Gamma)^{-1}$ is the matrix equivalent of the present value of a sum.

Some studies estimate discount rate news first and measure cash flow news as the residual. Chen and Zhao (2009) argue that this approach is limited because if discount rate news is not accurately measured, cash flow news (as the residual) inherits the potentially large misspecification error of the discount rate news. They suggest modeling cash flow news and discount rate news directly. I adopt their method.

\footnotetext{
${ }^{3}$ I use the Fama-French 49-industry classifications (Fama and French, 1997). All financial firms and utilities are excluded (SIC 6000-6999 and 4900-4999), leaving 45 industries.
} 
I set $\rho=0.967$ as in Vuolteenaho (2002). I also use different $\rho$ values for five price-to-dividend ratio portfolios as in Easton and Monahan (2005). Consistent with prior literature, the value of $\rho$ appears to have little impact on my results for the values between 0.92 and 1.00 . 


\section{Appendix C. Variable definitions}

\section{(1) Stock return and the return components}

Realized return Compound the realized return (RET) over the 12-month period ending at the (Ret) month of the annual earnings announcement. If the stock is delisted in the period, the CRSP delisting return is included in the realized return. If the delisting return is missing for poor performance related delisting (delisting codes 500 and 505-588), I use the replacement values suggested by Shumway and Warther (1999). Specifically, if the stock is traded on NYSE or AMEX prior to delisting, I replace the missing delisting return with $-30 \%$; if the stock is traded on NASDAQ prior to delisting, I replace the missing value with $55 \%$. I require delisting firms to have at least 9-month returns during the 12month return window.

Cash flow news News about future cash flows according to the VAR model in Vuolteenaho $(\mathrm{Ncf})$ (2002). A higher value represents better future cash flows.

Discount rate News about discount rate (risk) according to the VAR model in Vuolteenaho news $(N r)$ (2002). A higher value represents lower risk.

$\log$ return $(\log R) \quad$ Logarithm of one plus the realized return $=\log (1+$ Ret $)$.

Expected log Log return minus the sum of cash flow news and discount rate news $\operatorname{return}(E(\log R)) \quad=\log R-N c f-N r$.

\section{(2) Earnings and earnings attributes}

Earnings-to-price Income before extraordinary items $(I B)$ in year $t$ deflated by market value of ratio $(X / P)$ equity at the end of year $t-1=I B \downarrow /\left(P R C C_{-} F_{t-1} \times C S H O t-1\right)$ (Hayn, 1995). One-year lagged earnings-to-price ratio is labeled as $\operatorname{lag} X / P$.

Loss indicator

An indicator variable that equals one when the observation has a negative earnings number (Compustat: $I B<0$ ), and zero otherwise.

Return on assets Income before extraordinary items in year $t$ deflated by total assets at the end $(R O A)$ of year $t-1=I B \vee A T_{t-1}$.

Return on equity Income before extraordinary items in year $t$ deflated by book value of equity (ROE) at the end of year $t-1=I B_{V}\left(C E Q_{t-1}+T X D I T C_{t-1}\right)$. 
Predicted probability of loss reversal $(P L R)$

Nonrecurring charges (SPIW)
The predicted probability of loss reversal (PLR) is the fitted value of the following regression, estimated using 5-year rolling windows (Joos and Plesko, 2005).

$L R=\beta_{1}$ ROA $+\beta_{2}$ pastROA $+\beta_{3}$ Size $+\beta_{4}$ SGR $+\beta_{5}$ FirstLoss $+\beta_{6}$ LossSeq + $\beta_{7}$ Divdum $+\beta_{8}$ Divstop $+\varepsilon$,

where $L R=$ (loss reversal) an indicator variable equal to 1 if the firm becomes profitable in the subsequent year, and 0 otherwise; $R O A=$ return on assets; pastROA = average $R O A$ over the past five years (from year $t-5$ to $t-1$ ); Size = natural logarithm of current market value of equity; $S G R=$ sales growth rate; FirstLoss $=$ an indicator variable equal to 1 if the current year's loss is the first in a sequence, and 0 otherwise; $\operatorname{LossSeq}=$ an ordinal variable that counts the number of sequential losses over the past five years before the current loss (from year $t-5$ to $t-1$ ); Divdum $=$ an indicator variable equal to 1 if the firm is paying dividends, and 0 otherwise; Divstop $=$ an indicator variable equal to 1 if the firm stopped paying dividends in the current year, and 0 otherwise.

Special items in year $t=$ absolute value of the negative part of SPIt deflated by one-year lagged market value of equity $=\left|S P I_{t}\right| /\left(P R C C_{-} F_{t-1} \times C S H O t-1\right)$ if $S P I_{t}$ $<0$, and zero otherwise (Darrough and Ye, 2007).

\section{(3) Firm characteristics}

Market beta

(Beta)

Firm size (Size)

Book-to-market ratio $(B / M)$

Leverage ratio (Lev)

Altman (1968) Z score (Zscore)
Estimated beta from the CAPM model with a minimum of 24 monthly returns in the past 5 years. One-year lagged beta is labeled as lagBeta.

Natural logarithm of the market value of equity at the end of year $t=$ $\ln \left(\mathrm{PRCC}_{-} F_{t} \times \mathrm{CSHO}_{t}\right)$. One-year lagged firm size is labeled as lagSize.

Book value of equity over market value of equity at the end of year $t=\left(C E Q_{t}\right.$ + TXDITC $) /\left(\right.$ PRCC_ $\left._{-} \times \mathrm{CSHO}_{t}\right)$. One-year lagged book-to-market ratio is labeled as $\operatorname{lag} B / M$.

Total debt over total assets in year $t=\left(D L T T_{t}+D L C_{t}\right) / A T_{t}$. One-year lagged leverage ratio is labeled as lagLev.

Before 1980, Zscore $=1.2$ (working capital/total assets) +1.4 (retained earnings/total assets) +3.3 (earnings before extraordinary items and discontinued operations/total assets) +0.6 (market value of equity/total liabilities) +1.0 (sales/total assets); after 1980, Zscore $=10.4$ (working capital/total assets) +1.0 (retained earnings/total assets $)+10.6$ (earnings before extraordinary items and discontinued operations/total assets) +0.3 (market value of equity/total liabilities) - 0.17 (sales/total assets), according to Begley, 
Ming, and Watts (1996). One-year lagged Altman Z score is labeled as lagZscore.

Sales growth rate Sales growth rate in year $t=\left(S A L E_{\downarrow} S A L E_{t-1}\right)-1$.

$(S G R)$

$R \& D$

Research and development expenditures in year $t$ deflated by one-year

expenditures

$(R D X)$

lagged market value of equity $=X R D_{t} /\left(P R C C_{-} F_{t-1} \times C S H O_{t-1}\right)$ (Darrough and Ye, 2007).

Cash holding Cash and cash equivalents in year $t$ deflated by one-year lagged market value (Cash) of equity $=C H E_{t} /\left(\right.$ PRCC_ $\left._{t-1} \times C S H O_{t-1}\right)($ Darrough and Ye, 2007).

New debt issues (DBTISS)

New debt issues in year $t$ (Compustat: DLTIS) deflated by one-year lagged market value of equity $=D L T I S_{t} /\left(\right.$ PRCC_ $\left._{t} F_{-1} \times C S H O_{t-1}\right)($ Darrough and Ye, 2007).

New stock issues

New stock issues in year $t$ (Compustat: SSTK) deflated by one-year lagged (STKISS) market value of equity $=S S T K_{t} /\left(P R C C_{-} F_{t-1} \times C S H O_{t-1}\right)($ Darrough and $\mathrm{Ye}$, 2007).

Fixed assets to Fixed assets over total assets in year $t=P P E N T_{t} A T_{t}$ (Berger et al., 1996).

total assets

$(P P E / T A)$

Inventory to

Inventory over total current assets in year $t=I N V T_{t} A C T_{t}$ (Berger et al., 1996).

current assets

$(I N V / C A)$

Log industry

Natural logarithm of the number of firms in the 4-digit SIC industry in year $t$. firm number

$(\ln (\operatorname{Ind} \#))$

\section{(4) Asset sale indicator}

Asset sale

indicator $(D A S)$
An indicator variable that equals 1 if a firm or its subsidiary sold assets in year $t+1$, and 0 otherwise. The data for asset sales are obtained from the SDC platinum database from 1985 to 2010 (Warusawitharana, 2008). 


\section{(5) Earnings quality measures}

Accruals quality $\quad A Q_{j, t}=\sigma\left(v_{j}\right)_{t}$ is the standard deviation of firm $j^{\prime}$ s residuals $\left(v_{j, t}\right)$, calculated $(A Q)$

Asymmetric timeliness (negCscore) over years $t$-4 to $t$ (e.g., Francis et al.,2004, 2005).

$v_{j, t}$ is calculated by estimating the following model for each Fama-French 49 industry with at least 20 observations in year $t$.

$\operatorname{CACC}_{j, t}=\varphi_{0, j}+\varphi_{1, j} C F O_{j, t-1}+\varphi_{2, j} C F O_{j, t}+\varphi_{3, j} C F O_{j, t+1}+\varphi_{4, j} \Delta \operatorname{Rev}_{j, t}+$ $\varphi_{5, j} P P E_{j, t}+v_{j, t}$

where $C A C C_{j, t}=\Delta C A_{j, t}-\triangle C L_{j, t}-\triangle C a s h_{j, t}+\triangle S T D E B T_{j, t}=$ total current accruals in year $t, C F O_{j, t}=I B_{j, t}-T A C C_{j, t}=$ firm j's cash flow from operations in year $t, I B_{j, t}=$ firm $j$ 's net income before extraordinary items in year $t$, $T A C C_{j, t}=\Delta C A_{j, t}-\triangle C L_{j, t}-\triangle C a s h_{j, t}+\triangle S T D E B T_{j, t}-D P_{j, t}=$ firm $j^{\prime}$ s total accruals in year $t, \Delta C A_{j, t}=$ firm $j^{\prime}$ s change in current assets $(A C T)$ between year $t-1$ and year $t, \Delta C L_{j, t}=$ firm $j^{\prime}$ s change in current liabilities $(L C T)$ between year $t-1$ and year $t, \Delta \operatorname{Cash}_{j, t}=$ firm $j$ 's change in cash $(\mathrm{CHE})$ between year $t-1$ and year $t, \triangle S T D E B T_{j, t}=$ firm $j$ 's change in debt included in current liabilities $(D L C)$ between year $t-1$ and year $t, D P_{j, t}=$ firm $j$ 's depreciation and amortization expense $(D P)$ in year $t, \Delta R e v_{j, t}=$ firm $j^{\prime}$ s change in total revenues $(R E V T)$ between year $t-1$ and year $t, P P E_{j, t}=$ firm $j^{\prime}$ s gross value of PP\&E (PPEGT) between year $t-1$ and year $t$. All variables are scaled by lagged total assets $(A T)$ and winsorized at the $1 \%$ and $99 \%$ extreme values. Prior to 1988 (the effective year of SFAS No. 95), I use the indirect approach rather the cash flow statement to calculate the accruals and cash flow from operations. After 1988, $C F O_{j, t}$ is obtained from the cash flow statement, $T A C C_{j, t}=I B_{j, t}-$ $C F O_{j, t}$, and $C A C C_{j, t}=I B_{j, t}-C F O_{j, t}-D P_{j, t}=T A C C_{j, t}-I B_{j, t}$.

Following Khan and Watts (2009), the incremental timeliness of bad news is calculated as: negCscore j,t $_{1}=-\left(\hat{\lambda}_{1, t}+\hat{\lambda}_{2, t}\right.$ Size $\left._{j, t}+\hat{\lambda}_{3, t} M / B_{j, t}+\hat{\lambda}_{4, t} \operatorname{Lev}_{j, t}\right)$.

The regression coefficients are calculated by estimating the following model for each year.

$X_{j, t} / P_{j, t-1}=\beta_{1, t}+\beta_{2, t} D_{j, t}+R_{j, t}\left(\mu_{1, t}+\mu_{2, t} \operatorname{Size}_{j, t}+\mu_{3, t} M / B_{j, t}+\mu_{4, t} \operatorname{Lev}_{j, t}\right)+$ $D_{j, t} * R_{j, t}\left(\lambda_{1, t}+\lambda_{2, t}\right.$ Size $_{j, t}+\lambda_{3, t} M / B_{j, t}+\lambda_{4, t}$ Lev $\left._{j, t}\right)+\left(\delta_{1, t}\right.$ Size $_{j, t}+\delta_{2, t} M / B_{j, t}+$ $\left.\delta_{3, t} \operatorname{Lev}_{j, t}+\delta_{4, t} D_{j, t} * \operatorname{Size}_{j, t}+\delta_{5, t} D_{j, t} * M / B_{j, t}+\delta_{6, t} D_{j, t} * L e v_{j, t}\right)+e_{j, t}$, where $X_{j, t} / P_{j, t-1}=$ firm $j$ 's income before extraordinary items (IB) in year $t$ scaled by its market value of equity at the end of year $t-1, R_{j, t}=$ firm $j^{\prime}$ 's realized returns in year $t, D_{j, t}=1$ when $R_{j, t}<0$ and $D_{j, t}=0$ otherwise, Size $_{j, t}=$ natural logarithm of firm $j^{\prime}$ 's market value of equity (PRCC_F $\times$ CSHO) in year $t, M / B_{j, t}=$ firm $j^{\prime}$ s market-to-book ratio in year $t$, and $L e v_{j, t}=$ firm $j$ 's leverage ratio in year $t$, defined as long-term and short-term debt $(D L T T+D L C)$ deflated by total assets $(A T)$. 


\title{
(6) Alternative measures of the return components (Easton and Monahan, 2005)
}

\author{
Cash flow news $=\left(\right.$ roe $_{i t}-$ froe $\left._{i t, t}\right)+\left(\right.$ froe $_{i t+1, t+1}-$ froe $\left._{i t, t+1}\right)+\frac{\rho}{1-\rho \times \omega_{t}} \times\left(\right.$ froe $_{i t+1, t+2}-$ \\ $(C N E M)$ \\ froe $\left._{i t, t+2}\right)$, where roe $_{i t}=\ln \left(1+R O E_{i t}\right), R O E_{i t}=I B i \downarrow / B V_{i t-1}$, froe $_{i j, k}=\ln \left(1+R O E_{i j, k}\right)$. \\ $R O E_{i j, k}$ denotes the forecast of return on equity for fiscal year $k$ and is based \\ on the consensus $\mathrm{I} / \mathrm{B} / \mathrm{E} / \mathrm{S}$ forecast made after the earnings announcement of \\ year $j$. The approaches used to estimate $\rho$ and $\omega$ are based on Easton and \\ Monahan (2005).
}

Discount rate $\quad=-\frac{\rho}{1-\rho}\left(E R_{J, i t+1}-E R_{J, i t}\right)$, where ER is the implied cost of capital measure, $J$ news $\left(R N_{J}\right)$ : denotes the method used to estimate the implied cost of capital measure. The approach used to estimate $\rho$ is based on Easton and Monahan (2005).

Implied cost of Implied cost of capital measures. $J$ denotes the method used to estimate the capital $\left(E R_{J}\right)$ : implied cost of capital measure, including Gebhardt et al., (2001) (GLS), Claus and Thomas (2001) (CT), Easton (2004) (MPEG), and Botosan and Plumlee (2002) (VL). 


\section{References}

Abel, A.B., Dixit, A.K., Eberly, J.C., Pindyck, R.S., 1996. Options, the value of capital, and investment. The Quarterly Journal of Economics 111, 753-777.

Altman, E.I., 1968. Financial ratios, discriminant analysis and the prediction of corporate bankruptcy. The Journal of Finance 23, 589-609.

Amihud, Y., Lev, B., 1981. Risk reduction as a managerial motive for conglomerate mergers. The Bell Journal of Economics 12, 605-617.

Ball, R., Kothari, S.P., Watts, R.L., 1993. Economic determinants of the relation between earnings changes and stock returns. The Accounting Review 68, 622-638.

Barth, M.E., Beaver, W.H., Landsman, W.R., 1998. Relative valuation roles of equity book value and net income as a function of financial health. Journal of Accounting and Economics 25, 1-34.

Basu, S., 1997. The conservatism principle and the asymmetric timeliness of earnings1. Journal of Accounting and Economics 24, 3-37.

Begley, J., Ming, J., Watts, S., 1996. Bankruptcy classification errors in the 1980s: An empirical analysis of Altman's and Ohlson's models. Review of Accounting Studies 1, 267284.

Berger, P.G., Ofek, E., Swary, I., 1996. Investor valuation of the abandonment option. Journal of Financial Economics 42, 257-287.

Bonini, C.P., 1977. Capital investment under uncertainty with abandonment options. The Journal of Financial and Quantitative Analysis 12, 39-54.

Botosan, C.A., Plumlee, M.A., 2002. A re-examination of disclosure level and the expected cost of equity capital. Journal of Accounting Research 40, 21-40.

Burgstahler, D.C., Dichev, I.D., 1997. Earnings, adaptation and equity value. The Accounting Review 72, 187-215.

Callen, J.L., Segal, D., 2004. Do accruals drive firm-level stock returns? A Variance Decomposition Analysis. Journal of Accounting Research 42, 527-560. 
Campbell, J., Shiller, R., 1988a. The dividend-price ratio and expectations of future dividends and discount factors. Review of Financial Studies 1, 195-228.

Campbell, J.Y., 1991. A variance decomposition for stock returns. The Economic Journal 101, 157-179.

Campbell, J.Y., Shiller, R.J., 1988b. Stock prices, earnings, and expected dividends. The Journal of Finance 43, 661-676.

Chen, L., Zhao, X., 2009. Return decomposition. Review of Financial Studies 22, 5213-5249.

Cheung, J.K., 1990. The valuation significance of exit values: A contingent-claim analysis. Contemporary Accounting Research 6, 724-737.

Claus, J., Thomas, J., 2001. Equity premia as low as three percent? Evidence from analysts' earnings forecasts for domestic and international stock markets. The Journal of Finance 56, 1629-1666.

Collins, D.W., Maydew, E.L., Weiss, I.S., 1997. Changes in the value-relevance of earnings and book values over the past forty years. Journal of Accounting and Economics 24, 39-67.

Collins, D.W., Morton, P., Xie, H., 1999. Equity valuation and negative earnings: The Role of Book Value of Equity. The Accounting Review 74, 29-61.

Darrough, M., Ye, J., 2007. Valuation of loss firms in a knowledge-based economy. Review of Accounting Studies 12, 61-93.

Dechow, P.M., Dichev, I.D., 2002. The quality of accruals and earnings: The role of accrual estimation errors. The Accounting Review 77, 35-59.

Dichev, I.D., 1998. Is the risk of bankruptcy a systematic risk? The Journal of Finance 53, 1131-1147.

Easton, P.D., 2004. PE Ratios, PEG ratios, and estimating the implied expected rate of return on equity capital. The Accounting Review 79, 73-95.

Easton, P.D., Harris, T.S., 1991. Earnings as an explanatory variable for returns. Journal of Accounting Research 29, 19-36. 
Easton, P.D., Monahan, S.J., 2005. An evaluation of accounting-based measures of expected returns. The Accounting Review 80, 501-538.

Easton, P.D., Zmijewski, M.E., 1989. Cross-sectional variation in the stock market response to accounting earnings announcements. Journal of Accounting and Economics 11, 117-141.

Fama, E.F., French, K.R., 1992. The cross-Section of expected stock returns. The Journal of Finance 47, 427-465.

Fama, E.F., French, K.R., 1997. Industry costs of equity. Journal of Financial Economics 43, 153-193.

Fama, E.F., MacBeth, J.D., 1973. Risk, return, and equilibrium: Empirical tests. Journal of Political Economy 81, 607-636.

Francis, J., LaFond, R., Olsson, P., Schipper, K., 2005. The market pricing of accruals quality. Journal of Accounting and Economics 39, 295-327.

Francis, J., LaFond, R., Olsson, P.M., Schipper, K., 2004. Costs of equity and earnings attributes. The Accounting Review 79, 967-1010.

Galai, D., Masulis, R.W., 1976. The option pricing model and the risk factor of stock. Journal of Financial Economics 3, 53-81.

Gebhardt, W.R., Lee, C.M.C., Swaminathan, B., 2001. Toward an implied cost of capital. Journal of Accounting Research 39, 135-176.

Ghosh, C., Owers, J.E., Rogers, R.C., 1991. The financial characteristics associated with voluntary liquidations. Journal of Business Finance $\mathcal{E}$ Accounting 18, 773-789.

Givoly, D., Hayn, C., 2000. The changing time-series properties of earnings, cash flows and accruals: Has financial reporting become more conservative? Journal of Accounting and Economics 29, 287-320.

Hayn, C., 1995. The information content of losses. Journal of Accounting and Economics 20, 125-153.

Hecht, P., Vuolteenaho, T., 2006. Explaining returns with cash-flow proxies. Review of Financial Studies 19, 159-194. 
Hite, G.L., Owers, J.E., Rogers, R.C., 1987. The market for interfirm asset sales: Partial sell-offs and total liquidations. Journal of Financial Economics 18, 229-252.

Jain, P.C., 1985. The effect of voluntary sell-off announcements on shareholder wealth. The Journal of Finance 40, 209-224.

John, K., Lang, L.H.P., Netter, J., 1992. The voluntary restructuring of large firms in response to performance decline. The Journal of Finance 47, 891-917.

Joos, P., Plesko, G.A., 2005. Valuing loss firms. The Accounting Review 80, 847-870.

Khan, M., Watts, R.L., 2009. Estimation and empirical properties of a firm-year measure of accounting conservatism. Journal of Accounting and Economics 48, 132-150.

Kim, E.H., Schatzberg, J.D., 1987. Voluntary corporate liquidations. Journal of Financial Economics 19, 311-328.

Klein, A., Marquardt, C.A., 2006. Fundamentals of accounting losses. The Accounting Review 81, 179-206.

Lang, L., Poulsen, A., Stulz, R., 1995. Asset sales, firm performance, and the agency costs of managerial discretion. Journal of Financial Economics 37, 3-37.

Lev, B., 1989. On the usefulness of earnings and earnings research: Lessons and directions from two decades of empirical research. Journal of Accounting Research 27, 153192.

Li, K., 2011. How well do investors understand loss persistence? Review of Accounting Studies 16, 630-667.

MacKay, P., 2003. Real flexibility and financial structure: An empirical analysis. Review of Financial Studies 16, 1131-1165.

Patatoukas, P.N., Yan, H., 2010. The impact of earnings surprises on stock returns: Theory and evidence. SSRN eLibrary.

Petersen, M.A., 2009. Estimating standard errors in finance panel data sets: Comparing approaches. Review of Financial Studies 22, 435-480. 
Pinnuck, M., Lillis, A.M., 2007. Profits versus losses: Does reporting an accounting loss act as a heuristic trigger to exercise the abandonment option and divest employees? The Accounting Review 82, 1031-1053.

Plummer, C.E., Tse, S.Y., 1999. The effect of limited liability on the informativeness of earnings: Evidence from the stock and bond Markets. Contemporary Accounting Research $16,541-574$.

Riedl, E.J., Serafeim, G., 2011. Information risk and fair values: An examination of equity betas. Journal of Accounting Research 49, 1083-1122.

Robichek, A.A., Horne, J.C.V., 1967. Abandonment value and capital budgeting. The Journal of Finance 22, 577-589.

Sadka, G., 2007. Understanding stock price volatility: The role of earnings. Journal of Accounting Research 45, 199-228.

Schary, M.A., 1991. The probability of exit. The RAND Journal of Economics 22, 339-353.

Shumway, T., Warther, V.A., 1999. The delisting bias in CRSP's Nasdaq data and its implications for the size effect. The Journal of Finance 54, 2361-2379.

Subramanyam, K.R., Wild, J.J., 1996. Going-concern status, earnings persistence, and informativeness of earnings. Contemporary Accounting Research 13, 251-273.

Vuolteenaho, T., 2002. What drives firm-level stock returns? The Journal of Finance 57, 233-264.

Vuong, Q.H., 1989. Likelihood ratio tests for model selection and non-nested hypotheses. Econometrica 57, 307-333.

Warusawitharana, M., 2008. Corporate asset purchases and sales: Theory and evidence. Journal of Financial Economics 87, 471-497.

Watts, R.L., 2003. Conservatism in accounting part II: Evidence and research opportunities. Accounting Horizons 17, 287-301. 


\section{Biography}

Bin Li was born in Zhejiang Province, China, on November 1 ${ }^{\text {st }}, 1982$. He received his Bachelor of Finance and Master of Accounting degrees from Renmin University of China and Tsinghua University in 2005 and 2007, respectively. He obtained his Ph.D. in Accounting from Duke University in 2012. 